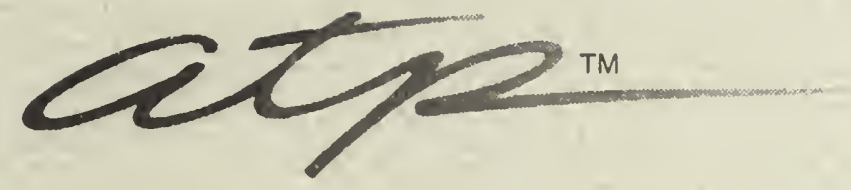

\title{
ADVANCED TECHNOLOGY PROGRAM
}

\section{Development, Commercialization, and Diffusion of Enabling Technologies}

\author{
Progress Report for Projects Funded 1993-1995
}

\author{
Jeanne W. Powell
}

U.S. DEPARTMENT OF COMMERCE Technology Administration

National Institute of Standards and Technology

Advanced Technology Program 

ADVANCED TECHNOLOGY PROGRAM

\section{Development, Commercialization, and Diffusion of Enabling Technologies}

\section{Progress Report for Projects Funded 1993-1995}

Jeanne W. Powell

U.S. DEPARTMENT OF COMMERCE Technology Administration

National Institute of Standards and

Technology

Advanced Technology Program

December 1997

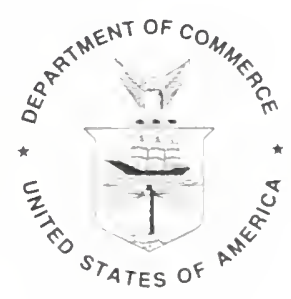

U.S. DEPARTMENT OF COMMERCE William M. Daley, Secretary

TECHNOLOGY ADMINISTRATION

Gary R. Bachula, Acting Under Secretary for Technology

NATIONAL INSTITUTE OF STANDARDS AND TECHNOLOGY

Raymond G. Kammer, Director 


\begin{abstract}
The Advanced Technology Program (ATP), administered by the National Institute of Standards and Technology, partners with U.S. industry to develop high risk and enabling technologies, with significant potential for stimulating U.S. economic growth. Industry submits proposals containing a research plan for the work to be performed, an explanation of how the nation broadly will benefit from the new technical capability, a business plan for future commercialization of goods and services that may derive from the technology, plans for diffusing the technology beyond the innovators, and a project budget indicating the proposed cost-share arrangement. In a highly competitive process, a peer review panel, involving a mix of technical experts and business and economic experts, selects projects for funding. Once the projects are selected, the ATP staff monitors them and evaluates progress and impacts. An important component of ATP's economic evaluation plan for tracking project progress and outcomes is the administration of an electronic survey on a regular basis to all project participants funded since 1993 to determine progress of projects compared with business plans and projected economic benefit goals outlined in their proposals. The resulting Business Reporting System (BRS) database is intended for use for ATP project management, as well as for evaluation research. This report summarizes BRS data covering periods through December 31, 1996, filed by 480 companies in 210 ATP projects, funded in 19 competitions during FY 1993-1995. The report provides an overview of pathways to achieving targeted commercial and broader economic goals; a status report of completed R\&D; an analysis of commercialization and technology diffusion activities; and analyses of other effects of ATP funding, such as stimulation of R\&D collaborations, and increased private sector investment in high risk and enabling $\mathrm{R} \& \mathrm{D}$.
\end{abstract}

\title{
Keywords
}

Advanced Technology Program; Business Reporting System; economic evaluation; R\&D; technology development and deployment

\section{Acknowledgements}

This report was made possible through the cooperation of hundreds of ATP-funded organizations who are providing information through ATP's Business Reporting System in support of program evaluation and project monitoring efforts. Stephen F. Weber, Building and Fire Research Laboratory, developed the BRS software, which has proved critical to timely and efficient data analysis. Many individuals in the ATP contributed to the report: Jon King and Karen Lellock assisted with data preparation and analysis; Joann Brooks, graphics artist, prepared the diverse illustrations; and Rosalie Ruegg provided insightful and detailed reviews of several drafts of the report. The author also wishes to acknowledge the many other reviewers within ATP and NIST for their helpful comments and suggestions. In particular, thanks are due to Connie Chang, Maryellen Kelley, Stephen Weber, Robert Hebner, and David King for their suggestions and advice in finalizing the report. 


\section{EXECUTIVE SUMMARY}

This report provides a statistical overview of progress reported by hundreds of companies and other organizations funded by the ATP during the period from 1993 through 1995. The report annotates the statistics with comments from project participants. The information is based entirely on Business Reporting System (BRS) reports to the ATP filed by 480 individual organizations through December 31,1996 . While not all the companies and projects are progressing at the same rate, or have achieved the same level of progress, the statistical analysis presented here provides an overview of the degree of progress towards research and commercialization goals of a large group of ATP award recipients. It provides a snapshot at a point in time; plans for commercialization and technology diffusion are being further detailed and implemented by the companies continuously.

Progress reports from individual firms, and aggregate summary statistics of progress for the group of projects provide evidence of (a) opportunities for economic spillovers and broad national economic benefit; (b) acceleration of the R\&D process and reduction in time-to-market in highly competitive markets; (c) stimulation of collaboration and collaboration effects; (d) increased private sector investment in high risk technology development; and (e) progress towards ultimate commercialization of ATP-funded technologies through new products, processes, and services.

Opportunities for economic spillovers and national economic benefit:

- Participants in 210 projects have identified more than 1,000 different applications (or uses) of the technologies under development, providing evidence that the technologies funded by ATP are highly enabling. New applications are being identified continuously.

- Companies have provided commercialization plans for nearly 800 applications spanning the spectrum of industries, providing evidence that they are seriously pursuing commercialization of the technologies developed in their ATP projects.

- Most of the technologies under development offer substantial performance and productivity improvements over existing capabilities.

- Most of the technologies under development feed into the early stages of the production chain, creating a greater opportunity for intermediate producers and downstream customers in multiple application areas to benefit from market spillovers.

- Patent and copyright activities planned and underway offer potential for dissemination of knowledge through patent disclosure and for additional commercialization opportunities by others through licensing arrangements. Licensing to others is a primary or secondary strategy for commercializing 43 percent of the planned applications. More than 100 new patents have been filed, and 11 have been issued.

- Conference activity and publication of papers have been particularly vigorous in some projects. Overall, an average of approximately two conference papers were presented and 0.6 professional journal articles published per project during the period covered. These disseminated results of ATP-funded projects become available to scientists and engineers employed in other firms or universities. 
Acceleration of the $R \& D$ process and reduction of time-to-market in highly competitive markets:

- Eighty-six percent of organizations indicate they are already ahead in their R\&D cycle as a result of ATP funding; of these, 39 percent believe they would not have started the project at all without ATP funding; the remainder typically would have proceeded at a significantly slower rate without ATP funding.

- Acceleration by two years or more is anticipated for 62 percent of planned commercial applications.

- Speed-to-market is considered "critical" or "important" for 98 percent of the commercial applications. The window of opportunity for successful entry into the marketplace is perceived by the companies as two years or less after the ATP funding period for 75 percent of currently identified applications.

\section{Stimulation of Collaborations and Collaboration Effects:}

- For the projects that have completed at least one year, 78 percent of the organizations reporting indicated that collaboration was helping to achieve the ATP project goals. For these:

- Eighty-five percent indicated that the ATP was responsible to a moderate or great extent for their collaborations.

- With respect to the benefits of collaboration, the number one effect, reported by 99 percent of the organizations, was that it helped stimulate creative thinking.

- Other important effects reported included helping them save time, helping them obtain R\&D expertise and identify customer needs, and encouraging them to undertake future collaborations.

- As might be expected, collaboration can cause higher project management costs, but in fact only about half reported that they incurred significant or moderate project coordination costs as a result of collaborating.

- Other costs of collaborating were reported by a minority of companies: significant delays in beginning the R\&D due to collaboration were reported by 20 percent, and six percent anticipated time delays in market entry as a result of collaboration difficulties.

- Overall, benefits of collaborating are reported by a far larger percentage of the group than costs, suggesting that collaboration is having a largely positive influence in technology development. (Seventy-eight percent indicate collaboration helped the project. Of this group, nearly all indicate significant or moderate benefits from one or more collaboration effects, compared with 50 percent who indicated moderate or significant increase in project coordination and management costs.)

- In addition to R\&D collaboration, ATP-funded companies are planning and pursuing alliances to commercialize their technologies, with small companies particularly focused on this strategy. Seventy-six strategic alliances have been formed, and 15 license agreements have been signed for the purpose of commercializing technologies developed in ATP projects. 
Increased investment in high risk technology development:

- Seventy percent of organizations report that their ATP-funded project encompasses a broader scope and/or higher level of technical risk as a result of the ATP. Fifty-seven percent report that ATP funding has increased their interest in performing long-term research. (These effects are in addition to the accelerated pace mentioned earlier.)

- Industry has increased its investment in the ATP-funded technology development areas, beyond what would have occurred in the absence of the ATP awards, by an estimated $\$ 200$ million; i.e., across the group of projects, companies have expanded the scale of their R\&D efforts in the ATP-funded areas by the amount of ATP funding received plus an additional $\$ 200$ million. This represents an estimated 59 percent increase in industry funding over what industry would have invested without the ATP awards.

- An additional $\$ 150$ million of new funding from other sources has been attracted to support the ATP-funded technology development or the commercialization of products embodying ATPfunded technology.

- Expectations that large improvements in performance or large reductions in production costs will result from the ATP-funded projects are evidence that industry is pursuing "discontinuous" or "breakthrough" innovations, and suggestive of relatively risky R\&D. For 29 percent of applications, performance improvements of 100-500 percent or more are anticipated. Cost reductions of 25 percent or more are anticipated for 28 percent of applications.

- Another indication of the "breakthrough" nature of an innovation is that it enables "new-to-theworld" products or services. Thirty-five percent of applications are considered by the project participants to be "new-to-the-world" solutions to a market need or problem with the potential to create totally new markets. Many companies plan to utilize their ATP-funded technology in a mix of "new-to-the-world" products and cost reduction and performance improvements in other products, processes, or services.

Progress towards commercialization of ATP-funded technologies:

- Progress is being made towards developing new capabilities and achieving cost savings through new and improved processes.

- Forty percent of the companies, representing 52 percent of the projects, report they are now able to make a new or improved product, even though the product may not yet be ready for the marketplace.

- Twenty-eight percent of companies, representing 39 percent of the projects, report they have adopted process improvements resulting from their ATP technology.

- Companies are engaging in commercialization planning activities, at their own expense, needed to enter the marketplace in a timely manner, once the technology is ready. (ATP funds R\&D only.)

- Companies in 77 percent of the projects have completed product/process definition for at least one application; companies in 56 percent of the projects have completed concept testing 
for at least one application of their technology; and concept testing has been conducted for one-third of all applications being planned by the ATP-funded companies.

- Companies in 71 percent of the projects have conducted other market analysis activities; for example, sales forecasting or related product development or testing.

- Companies in 25 percent of the projects have moved to new quarters to expand production capacity; companies in 19 percent of projects have purchased or leased new plant and equipment to expand production capacity.

- Forty-one percent of projects have completed a production prototype for at least one application, and 35 percent of projects have completed pilot production or a commercial demonstration.

- Actual production of products is already underway for 12 percent of the projects, and four percent of the planned commercial applications.

- About 10 percent of companies, representing 15 percent of projects, indicate they have earned early revenues, amounting to more than $\$ 20$ million, for example, from sales of samples and prototypes. The first licensing revenues have been realized.

- The large revenue flows lie in the future. Revenue is expected for only about one-fourth of applications ("spin-offs") before the end of ATP funding and not until four or more years after the ATP funding ends for nearly 10 percent of applications and 10 percent of projects. Revenue is expected for most within four years after the ATP funding ends.

Taken as a whole, the results of this report confirm the results of earlier studies and increase the robustness of statistical evidence that the ATP is making solid progress towards achieving its mission of economic growth through technological advancement. With the BRS in place, the ATP is positioned to capture developments and report on the evolution of ATP-funded technologies towards commercialization and the generation of national economic benefits. 


\section{TABLE OF CONTENTS}

Abstract ........................... ii

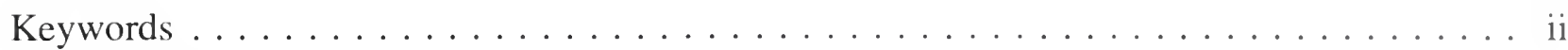

Acknowledgements ........................ ii

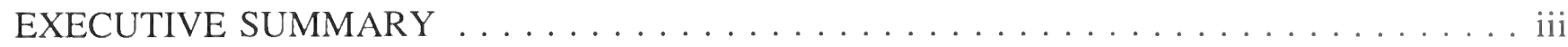

1. THE ATP'S BUSINESS REPORTING SYSTEM: A TOOL FOR ECONOMIC

EVALUATION . . . . . . . . . . . . . . . . . . . . . . . . 1

Overview of the Advanced Technology Program (ATP) . . . . . . . . . . . 1

Overview of the Business Reporting System . . . . . . . . . . . . . . . . 1

About This Report .................................. 3

2. PATHS TO NATIONAL ECONOMIC BENEFITS . . . . . . . . . . . . . . . 7

Development of Enabling Technologies . . . . . . . . . . . . . . . . 7

Identification of Business Opportunities . . . . . . . . . . . . . . . . . 7

Business Goals . . . . . . . . . . . . . . . . . . . . . . . 10

Identification of Commercialization Strategies $\ldots \ldots \ldots \ldots \ldots$

3. R\&D STATUS REPORT . . . . . . . . . . . . . . . . . . . . . . 15

Level of Progress in Completing R\&D Phase . . . . . . . . . . . . . . . 15

Effect of ATP Funding on R\&D Progress . . . . . . . . . . . . . . . 16

When Can Revenue Be Expected $\ldots \ldots \ldots \ldots \ldots \ldots \ldots \ldots \ldots \ldots$

4. STIMULATION OF COLLABORATION AND RELATED EFFECTS . . . . . . . . . . 19

Stimulation of R\&D Collaboration . . . . . . . . . . . . . . . . . . 19

Collaboration Effects . . . . . . . . . . . . . . . . . . . . . . . 20

Anecdotal Comments ............................. 21

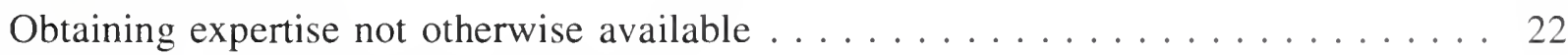

Obtaining assistance from universities ...................... 23

Learning more about potential markets and customer needs and accelerating entry into the marketplace ............................ 24

Formation of stronger supplier-customer relationships $\ldots \ldots \ldots \ldots \ldots$

Strengthening credibility within the organization and with other organizations . . . 26

Elaboration of the "benefits and costs" of collaboration . . . . . . . . . . . 26

Formation of Strategic Alliances Outside the ATP Project for Commercialization of ATP-

funded Technologies ....................... 27

5. IMPACT ON INDUSTRY R\&D . . . . . . . . . . . . . . . . . . . . . . . . . 29

Stimulation of Private Sector Investment and Leveraging of Other Investment . . . . . 29

Increased Credibility . . . . . . . . . . . . . . . . 30

6. EARLY COMMERCIALIZATION ACTIVITIES .................. 33

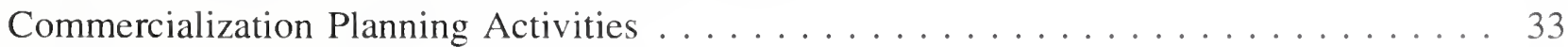

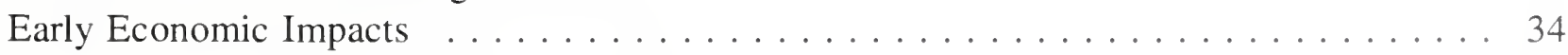

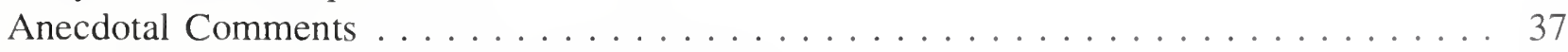

Ability to make new and/or better products . . . . . . . . . . . 37 
Prototyping and customer testing . . . . . . . . . . . . . . . . 37

Implementation of new or improved production processes $\ldots \ldots \ldots \ldots \ldots 38$

Installation of demonstration units . . . . . . . . . . . . . . . 39

7. INTELLECTUAL PROPERTY PROTECTION AND DIFFUSION OF TECHNOLOGY . 40

Protection and Disclosure of Intellectual Property . . . . . . . . . . . . . . . . 40

Dissemination of Non-Proprietary Information $\ldots \ldots \ldots \ldots \ldots \ldots . \ldots . \ldots 4$

8. RELATIONSHIP TO PRIOR WORK AND CONCLUSIONS . . . . . . . . . . . . 43

Relationship to Prior Work . . . . . . . . . . . . . . . . . . . . 43

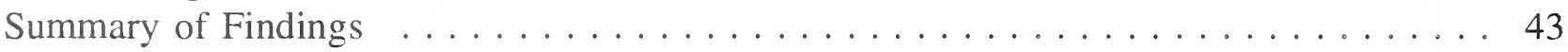

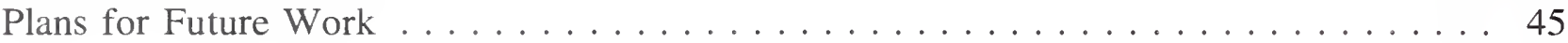

REFERENCES ................................. 46

APPENDICES .................................. 47

\section{LIST OF TABLES}

Table 1. BRS Participation and Timing Relative To All ATP Awards and Participants ... 3

Table 2. Examples of Effect of ATP Funding on Company Goals for the Technology . . . . 11

Table 3. Strategic Alliances and Licensing Agreements for Commercialization . . . . . . . . 28

Table 4. Dissemination of Non-proprietary Information from ATP-funded Projects . . . . . . . 41

\section{LIST OF FIGURES}

Figure 1. Distribution of Types of Participation and Types of Organizations in the

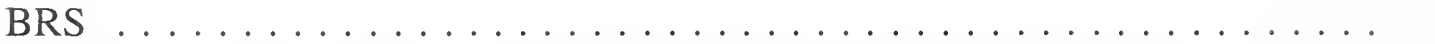

Figure 2. Distribution for Organizations in the BRS That Had Completed One or Two Years of ATP Funding . . . . . . . . . . . . . . . . . . . 5 5

Figure 3. Technologies Under Development . . . . . . . . . . . . . . . . . 6

Figure 4. Plans for Diverse Applications of ATP-funded Technologies . . . . . . . . . 8

Figure 5. How ATP-funded Technologies Are Expected Eventually To Be

Commercially Deployed

Figure 6. Stages of Production In Which the ATP-funded Technologies Are

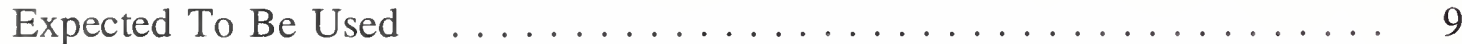

Figure 7. Quantitative Business Goals . . . . . . . . . . . . . . . . . . . 10

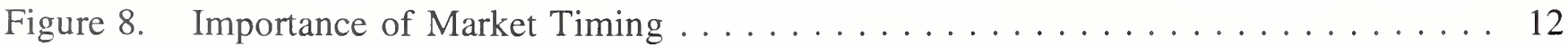

Figure 9. Strategies for Commercializing ATP-funded Technologies . . . . . . . . . 13

Figure 10. Strategic Alliances Planned ......................... 14

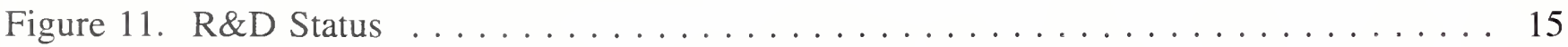

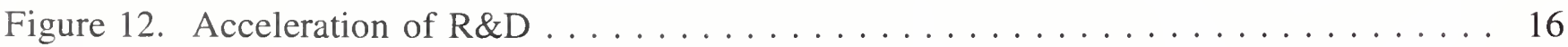

Figure 13. When Can We Expect To See Revenues from ATP-funded Technologies? . . . . . 17

Figure 14. Stimulation of Collaborations . . . . . . . . . . . . . . . . . . . . . . . 19 
Figure 15. Effects Most Enabled by Collaboration . . . . . . . . . . . . . . . . . . 20

Figure 16. Other Effects Enabled by Collaboration . . . . . . . . . . . . . . . . . 21

Figure 17. Costs Attributed to Collaboration . . . . . . . . . . . . . . . . . 22

Figure 18. Stimulation of Industry R\&D Investment . . . . . . . . . . . . . . . . . . 29

Figure 19. Change in the Nature of Industry $R \& D \ldots \ldots \ldots \ldots \ldots \ldots$

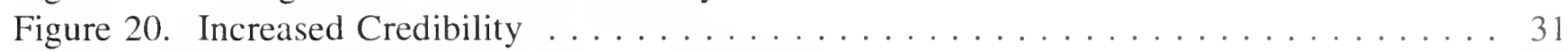

Figure 21. Increased Credibility -- Small Businesses ................ 31

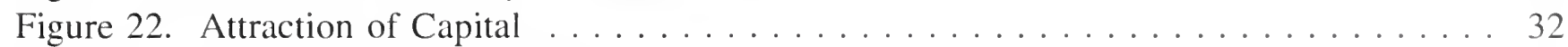

Figure 23. Market Analysis Progress . . . . . . . . . . . . . . . . . . 33

Figure 24. Acquisition of New Facilities and Equipment . . . . . . . . . . . . . . 34

Figure 25. Progress Towards Commercial Production . . . . . . . . . . . . . . . . 35

Figure 26. Progress Towards Early Products and Processes . . . . . . . . . . . . . . 36

Figure 27. Intellectual Property Strategies Planned . . . . . . . . . . . . . . 41

Appendix A. Plans for Diverse Applications of ATP-funded Technologies--

Information/Computer Systems . . . . . . . . . . . . . . . . 47

Appendix B. Plans for Diverse Applications of ATP-funded Technologies--

Manufacturing (Discrete) $\ldots \ldots \ldots \ldots \ldots \ldots$............... 48

Appendix C. Plans for Diverse Applications of ATP-funded Technologies--

Biotechnology . . . . . . . . . . . . . . . . . . . . . . . . 49

Appendix D. Plans for Diverse Applications of ATP-funded Technologies--

Electronics ........................... 50

Appendix E. Plans for Diverse Applications of ATP-funded Technologies--

Chemicals \& Chemical Processing ................. 51

Appendix F. Plans for Diverse Applications of ATP-funded Technologies--Energy

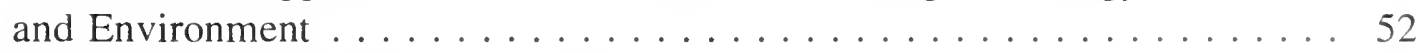

Appendix G. SIC Codes included in "Other" Category . . . . . . . . . . . . . . . 55 


\section{THE ATP'S BUSINESS REPORTING SYSTEM: A TOOL FOR ECONOMIC EVALUATION}

\section{Overview of the Advanced Technology Program (ATP)}

The Advanced Technology Program (ATP), administered by the U.S. Commerce Department's National Institute of Standards and Technology (NIST), partners with U.S. industry to fund the development of high risk and enabling technologies, with significant potential for stimulating U.S. economic growth. Industry submits proposals containing a research plan for the work to be performed, an explanation of how the nation broadly will benefit from the new technical capability, a business plan for future commercialization of at least some of the goods and services that may derive from the technology, plans for diffusing the technology beyond the innovators, and a project budget indicating the proposed cost-share arrangement. Through a highly competitive peer review process, involving a mix of technical experts from government laboratories, and business and economic experts from the private sector and government, projects with both high technical and business/economic merit are selected for funding. The ATP costs shares with industry the R\&D costs of the award-winning projects; the companies are fully responsible for business planning and product development costs.

The ATP provides funding for both single-company projects and joint ventures. Eligible joint ventures consist of a minimum of two for-profit companies participating in the R\&D and contributing cost share, and may contain additional companies, universities, or research organizations. Only U.S.owned companies or U.S. subsidiaries of foreign-owned companies are eligible to receive awards and the latter only if they meet certain tests. Single company proposers can receive funding of up to $\$ 2$ million in direct costs over three years and must cover their own indirect costs. (Beginning in 1998, large single-company proposers -- Fortune 500 or equivalent -- must cover at least 60 percent of total project costs.) Joint ventures may propose a project of any size for up to five years of funding but must cover more than 50 percent of total project costs.

Since its first congressional appropriation in 1990, the Advanced Technology Program has funded 352 projects, with over 840 participating organizations across a mix of 233 single company projects and 119 joint venture projects. Project awards amount to $\$ 1.151 \mathrm{~B}$, with industry committing an additional $\$ 1.172 \mathrm{~B}$ cost share.

\section{Overview of the Business Reporting System}

Program evaluation has been a central component of ATP operations from the beginning. In the early years of the program, the ATP relied on third-party surveys of projects to determine their progress. In early 1994, the ATP implemented the Business Reporting System (BRS), a comprehensive data collection tool for tracking, on a routine and regular basis, progress of projects against business plans and projected economic benefits outlined in the project proposals and updated over the course of the projects. The survey system, electronically administered, has been implemented for projects selected in the 1993 competition and since, from their inception. To ensure maximum confidentiality of information and detail concerning the multiple commercialization activities of joint venture members, data is collected at the individual participant level (from individual companies, universities, and notfor-profit organizations) within a project. 
The survey information collected through the BRS comprises part of the integrated ATP database framework. It is intended for use for ATP project management, as well as by researchers for performing evaluation research. Over time, the data is expected to support comprehensive analyses of the behavior of firms conducting R\&D and developing new technologies, of the business progress, and economic benefits.

The Business Reporting System consists of five major parts:

- A Baseline Report. At the beginning of the project, in the Baseline Report, companies identify potential areas of application of the technology being developed with ATP funding. They identify quantitative business goals, including cost or performance targets; key attributes of the technology needed to achieve these goals; planned strategies for commercialization; e.g., in-house production, licensing, and strategic alliances. They outline their strategies for protecting intellectual property; and identify their plans for disseminating non-proprietary information.

- Anniversary Reports. Annually, in the Anniversary Report, companies expand upon the baseline information to cover progress towards implementing commercialization strategies. They report on early economic impacts of the project, as well as collaboration experiences, attraction of new funding, new intellectual property created, and dissemination of information through conferences, publications, and other mechanisms. They also provide a summary of company financial data.

- Close-out Report. At the project conclusion, in the Close-out Report, companies update Anniversary Report information and identify remaining technical and business barriers to commercialization of the technology, define specific business goals for the following five-year period, and indicate expected future effects of the ATP project outside that organization.

- Post-project Reports. Following the end of ATP funding, companies report three times--once every two years--concerning actual progress in commercializing the technology and related impacts inside and outside the organization.

- Quarterly Reports. At the end of each quarter, other than the initial and anniversary quarters, companies report one or more significant business developments related to the ATP projects.

Companies funded in FY 1993 and later are required to submit these reports under the terms and conditions of their ATP awards. Under ATP's agreements with project participants, all information reported through the BRS is considered proprietary and confidential. Information is released and published only in aggregate, summary statistical form, or in quotes without attribution, unless companies explicitly agree to disclosure or the same information is available from company press releases.

The BRS supports three objectives:

A. To track business progress against company plans for achieving

-Commercialization

-Broad-based economic impacts

B. To develop short-term statistical indicators of results

C. To build a database to support long-term evaluation of ATP economic impact. 


\section{About This Report}

The report provides a snapshot of plans and progress of projects funded in competitions held from 1993 through 1995, and of the pathways to achieving impact. It provides a status report of R\&D completed; an analysis of commercialization activities; and analyses of other effects of ATP funding, such as stimulation of effective R\&D collaborations, increased private sector investment in high risk and enabling R\&D, creation of intellectual property, and dissemination of non-proprietary knowledge. Although significantly different from the earlier surveys in terms of the method of data collection, the size of the sample, and the specific projects covered, the current study, based on BRS data, has significant parallels to the earlier surveys in terms of issues covered and results.

The report draws on the BRS to measure progress of 210 projects and 480 separately reporting organizations funded during FY 1993-1995. The information is based on business reports filed through December 31, 1996. Table 1 illustrates the BRS participation (shaded areas) by year of award and relative to the total number of projects and participants funded. The 210 projects covered include all ATP awards made during the 1993-1995 period, with the exception of nine projects since cancelled. The projects funded in FY 1996 and 1997 are not included because they had not yet begun reporting at the time the data were analyzed. The 60 projects funded between 1990 and 1992 are not included because they were funded prior to implementation of the BRS.

\section{Table 1. BRS Participation and Timing Relative To All ATP Awards and Participants}

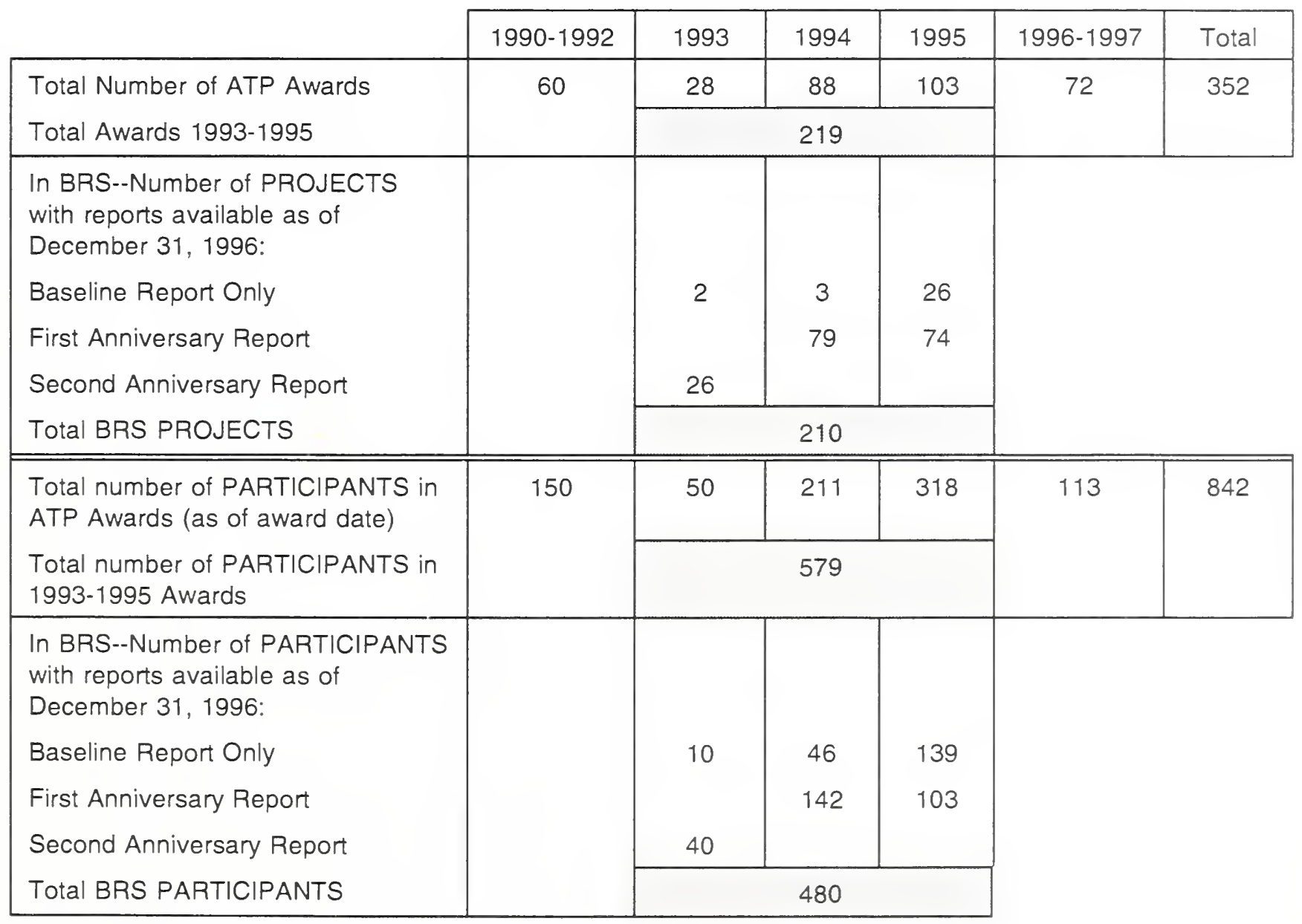


The difference between the 480 participants covered in the BRS data and the total of 579 participants in the FY 1993-1995 awards, reflects several factors: 1) cancellation of nine projects; 2) changes in joint venture membership over the course of the awards; 3) limitation of BRS reporting to major participants for a few very large joint ventures and exclusion of non-profit organizations with a purely administrative function; and 4) some late reports.

Figure 1 illustrates the distribution of types of organizations and types of ATP projects (singlecompany or joint venture) included in the data. It includes all those organizations that had provided at least an initial Baseline Report by December 31, 1996, even if some had not yet reported actual progress.

\section{Figure 1. Distribution of Types of Participation and Types of Organizations in the BRS}

Types of Project Participation

(480 Organizations)

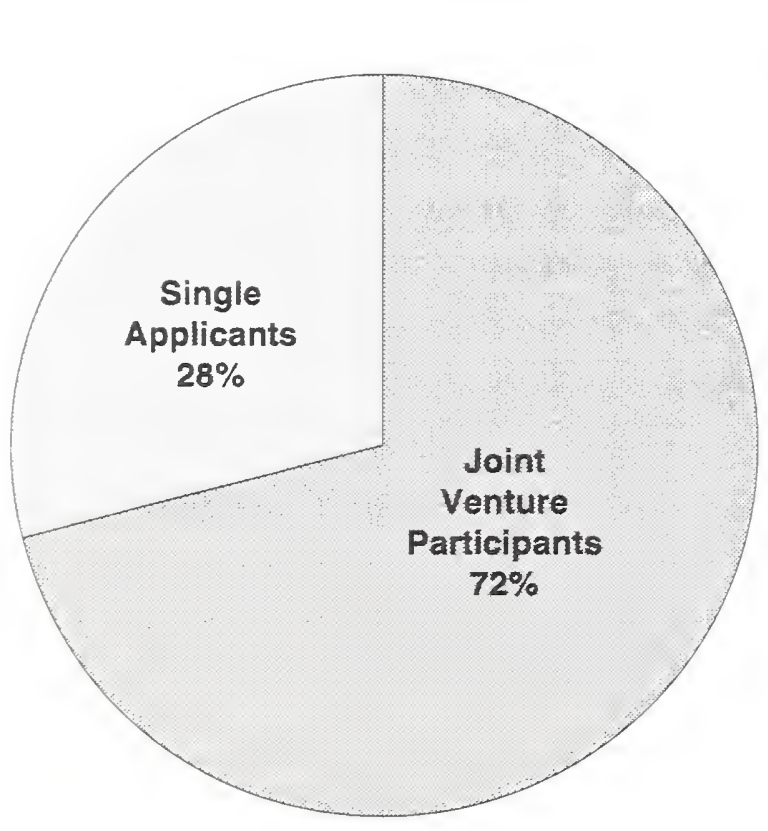

Notes: "Fewer than 500 employees.

** Fortune 500 or equivalent as of Fortune 500 listing published April 1997.
Types of Organizations

(480 Organizations)

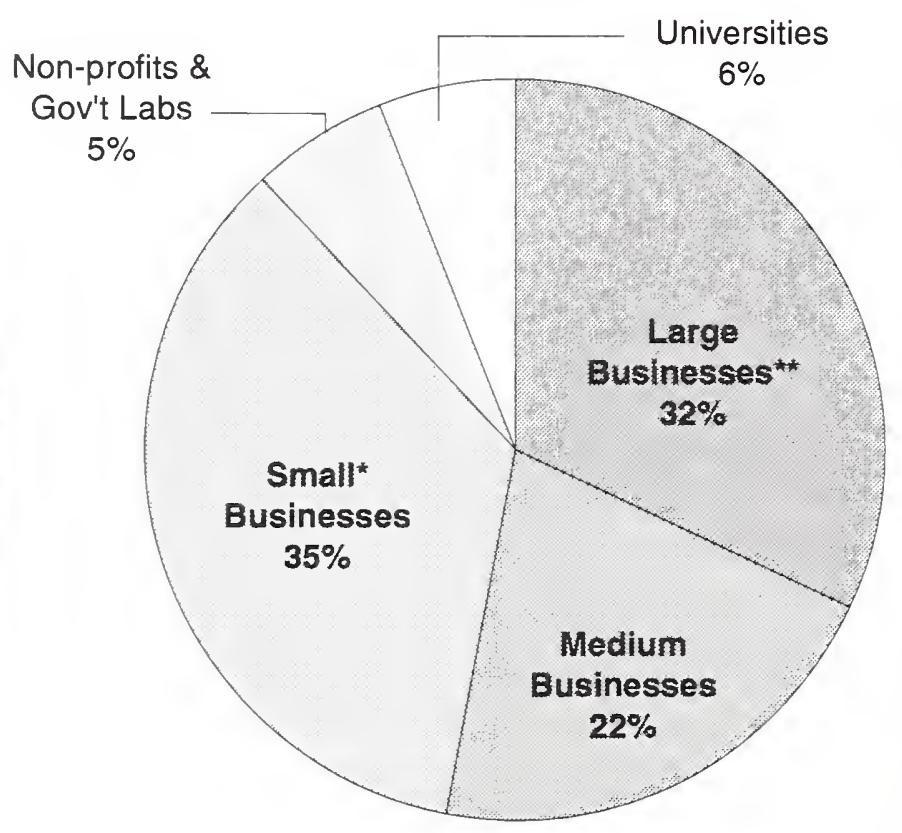

Source: Business Progress Reports from 480 organizations in 210 ATP projects funded 1993-1995.

The subgroup of organizations reporting actual commercialization progress and other effects of ATP funding after one-to-two years of funding represent those shown in Table 1 as having filed First or Second Anniversary Reports. They are described further in Figure 2. Of the entire group of 285 participants in 179 projects providing Anniversary Reports after one-to-two years of ATP funding, 268 participants in 176 projects reported some degree of commercialization progress. The remaining organizations are largely universities and non-profits who do not plan to commercialize their ATPfunded technologies but have reported on other effects of ATP funding. This early attention to 
commercialization is consistent with the ATP's model that requires companies to set commercial goals up front, and to integrate plans for their R\&D goals and for their business/economic goals from the outset.

\section{Figure 2. Distribution for Organizations in the BRS That Had Completed One or Two Years of ATP Funding}

Types of Project Participation 285 Organizations

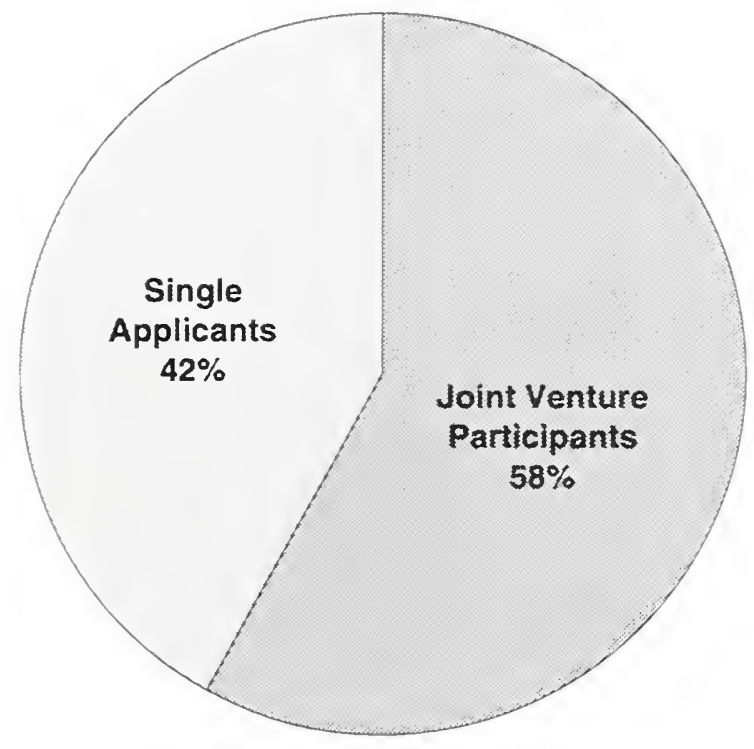

Notes: "Fewer than 500 employees.

* Fortune 500 or equivalent as of Fortune 500 listing published April 1997.
Types of Organizations 285 Organizations

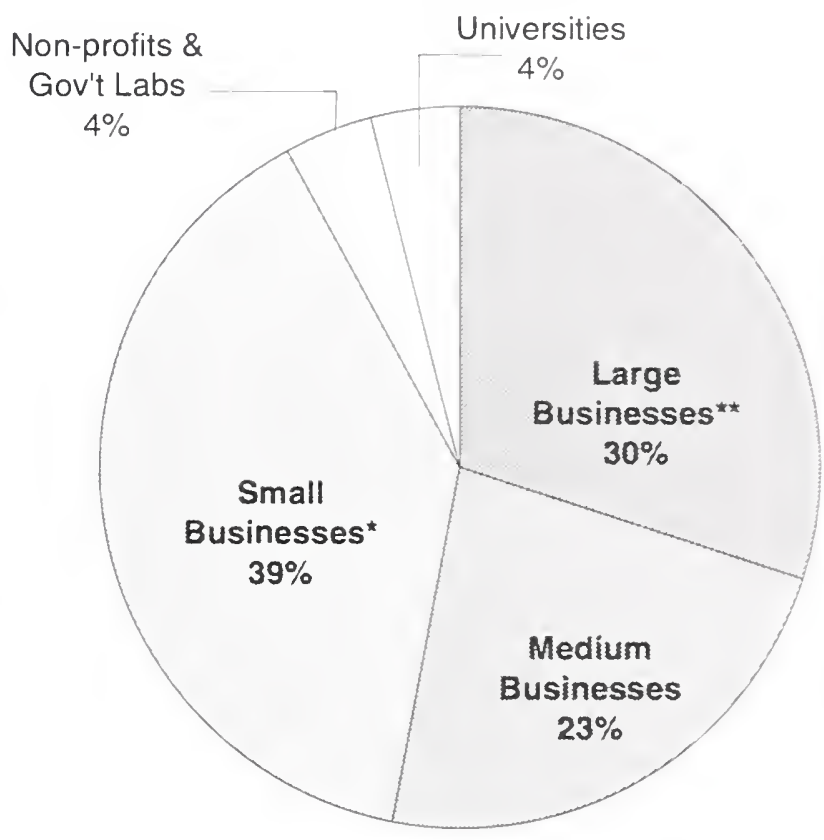

Source: Business Progress Reports from 285 organizations in 179 projects funded 1993-1995 -after one or two years of ATP funding. 
Figure 3. Technologies Under Development

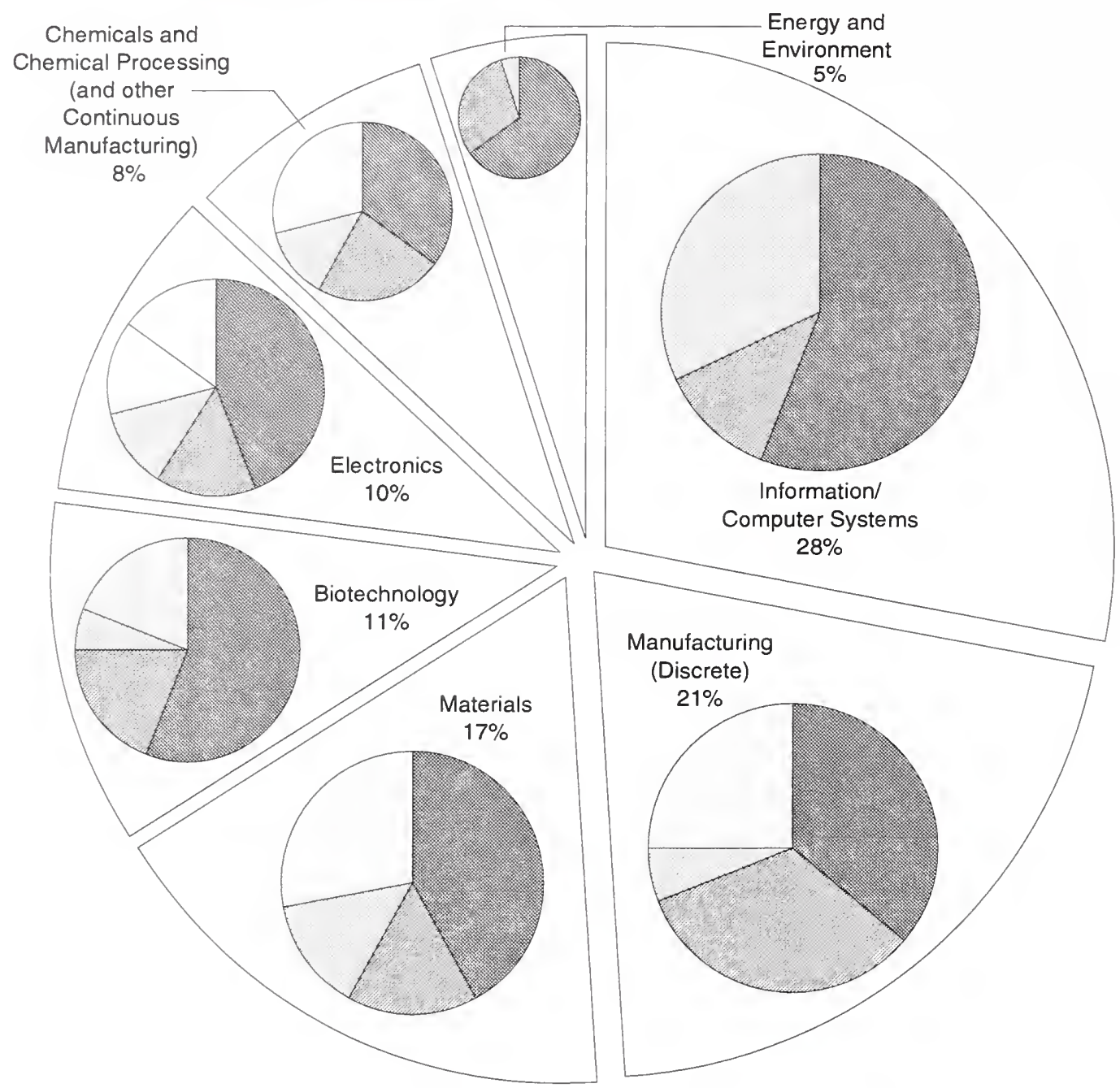

Source: Business Progress Reports from 404 organizations in 208 projects funded 1993-1995

LEGEND for Breakdown of Technology Areas

Information/Computer Systems

Computer Software, $56 \%$

Computer Hardware, $12 \%$

Other/Not Specified, $32 \%$

Biotechnology

Human Diagnostic Biotechnology, 56\%

Human Therapeutics, 19\%

Biomolecular and Biomimetic Materials, 6\%

Other/Not Specified, $19 \%$
Manufacturing (Discrete)

Automobile Manufacturing, $36 \%$

Machine Tools, 33\%

Intelligent Manufacturing, 6\%

Other/Not Specified, 25\%

\section{Electronics}

Displays, $44 \%$

Electronic Instrumentation/Sensors and Control Systems, 15\%

Optics and Photonics, 12\%

Semiconductors and Microelectronic

Fabrication Technology, $14 \%$

Other/Not Specified, 15\%
Materials

Composites, $42 \%$

Coatings, $16 \%$

Metals and Alloys, 14\%

Other/Not Specified, $\mathbf{2 8} \%$

\section{Energy and Environment}

[xix. Energy Distribution/ Conservation, $65 \%$

Energy Resources/

Generation, 30\%

Other/Not specified, $5 \%$

Chemicals and Chemical Processing (and other Continuous Manufacturing)

Catalysis/Biocatalysis, 35\%

Separation Technology, $\mathbf{2 3} \%$

Process Control, 13\%

Other/Not Specified, $29 \%$ 


\section{PATHS TO NATIONAL ECONOMIC BENEFITS}

Of the 480 organizations in 210 projects providing business reports, 375 companies in 208 projects have reported plans for commercializing one or more applications of the ATP-funded technologies. Not surprisingly, most universities, non-profits, and government laboratories have not provided plans for commercialization, but they have reported plans for dissemination of non-proprietary information concerning technology developed with ATP funds. These plans of businesses for commercialization and of non-profits for knowledge dissemination are important because they point out two different kinds of pathways by which the technologies will have future economic impact.

\section{Development of Enabling Technologies}

The ATP funds technology development projects, on a cost-sharing basis with industry, through both General Competitions, open to all technology areas, and Focused Competitions, targeted to specified technologies and specified goals. Many projects and entire Focused Programs, consisting of sets of related projects, involve an interdisciplinary mix of science and technology fields. The ATP uses its own 5-digit, hierarchical technology classification system to identify technology areas under development by different organizations and projects. Individual companies self select primary and secondary codes which best describe their areas of R\&D.

Figure 3 (opposite page) summarizes the technologies according to their first and second level code assignments. More than one-fourth of the technology development projects directly involve Information Technology/Computer Systems, either hardware or software. Discrete manufacturing and materials comprise major parts of the remainder. These three areas of concentration reflect the fact that seven of the 12 ATP Focused Program areas funded in FY 1993-1995 involve substantial information technology and/or materials processing and manufacturing technology. (This distribution differs somewhat from other Technology Area charts published by the ATP because the distribution shown in Figure 3 (a) reflects only the projects funded in FY 1993-1995; (b) reflects R\&D activity at the organization level; whereas, organizations in a given joint venture project do not necessarily work in the same technology area; and (c) is based purely on the number of organizations working in a given technology area, not on the relative amount of funding to the technology area.)

Further analysis of projects funded in these broad technology areas begins to capture the interdisciplinary nature of the work. For example, the second-tier analysis in Figure 3 shows that six percent of the work in Manufacturing (Discrete) involves "intelligent" manufacturing; 12 percent of the work in Information/Computer Systems is hardware. A third-tier analysis (not presented) would show that computer hardware has a strong electronics component. Digital data storage is one example. This next level of analysis also would reveal the overlapping of projects across disciplines and the difficulty of classifying them. For instance, some computer systems components and related manufacturing technologies are assigned to the Electronics category; e.g., Displays and Semiconductors and Microelectronic Fabrication technology.

\section{Identification of Business Opportunities}

Nearly 400 project participants have identified more than 1,000 applications of the technologies under development and provided detailed and current commercialization plans for nearly 800 applications spanning the spectrum of SIC industries. Figure 4 illustrates the diverse application areas of the enabling technologies funded in the Materials area. A detailed examination of individual reports 


\section{Figure 4. Plans for Diverse Applications of ATP-funded Technologies}

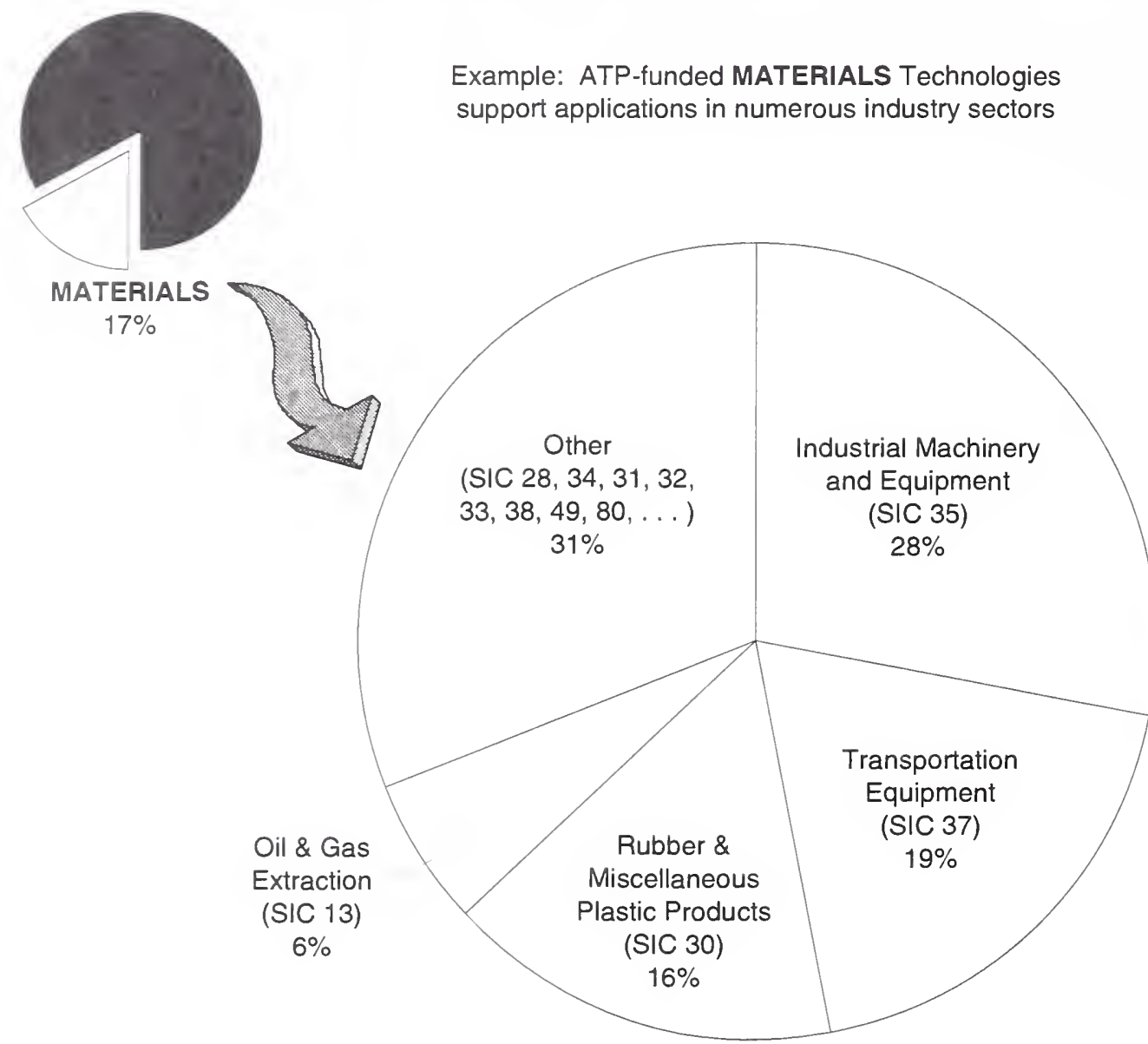

Note: "Other" SIC catagories are defined in Appendix G.

Source: Business Progress Reports for 778 applications beinq pursued by 375 companies in 207 ATP projects funded $1993-1995$.

reveals more explicitly the diverse linkages. For example, company reports for one project involving metal and alloy technology reveals planned applications in electrical power generation (SIC 49), chemical processing (SIC 28), and pulp and paper machinery and bearings (SIC 35). A singlecompany project involving coatings reports applications in seals (SIC 30), industrial machinery for printing rolls, pump components, bearings, and power transmission and computer displays (SIC 35), and sensors (SIC 38). Illustrations of linkages between other technology areas under development and their diverse application areas appear in the Appendices.

Commercialization will occur through eventual embodiment of the ATP-funded technology in a product, service, manufacturing process, or possibly some combination of these. Figure 5 summarizes the percentages that are expected to occur in each form. This figure suggests that most commercial deployment of ATP technologies will occur through manufactured products, with the focus on new, as compared with improved, products, processes or services. Responses to a follow-up question further indicate that for 35 percent of the applications, companies envision their application to be a "new-to-the world" solution to a market need or problem. Such applications represent opportunities to create totally new markets. Individual companies and projects are planning to use their new technical capabilities to achieve a mix of "new-to-the-world" solutions and cost reductions and performance improvements in products, processes, or services. 
Figure 5. How ATP-funded Technologies Are Expected Eventually To Be Deployed
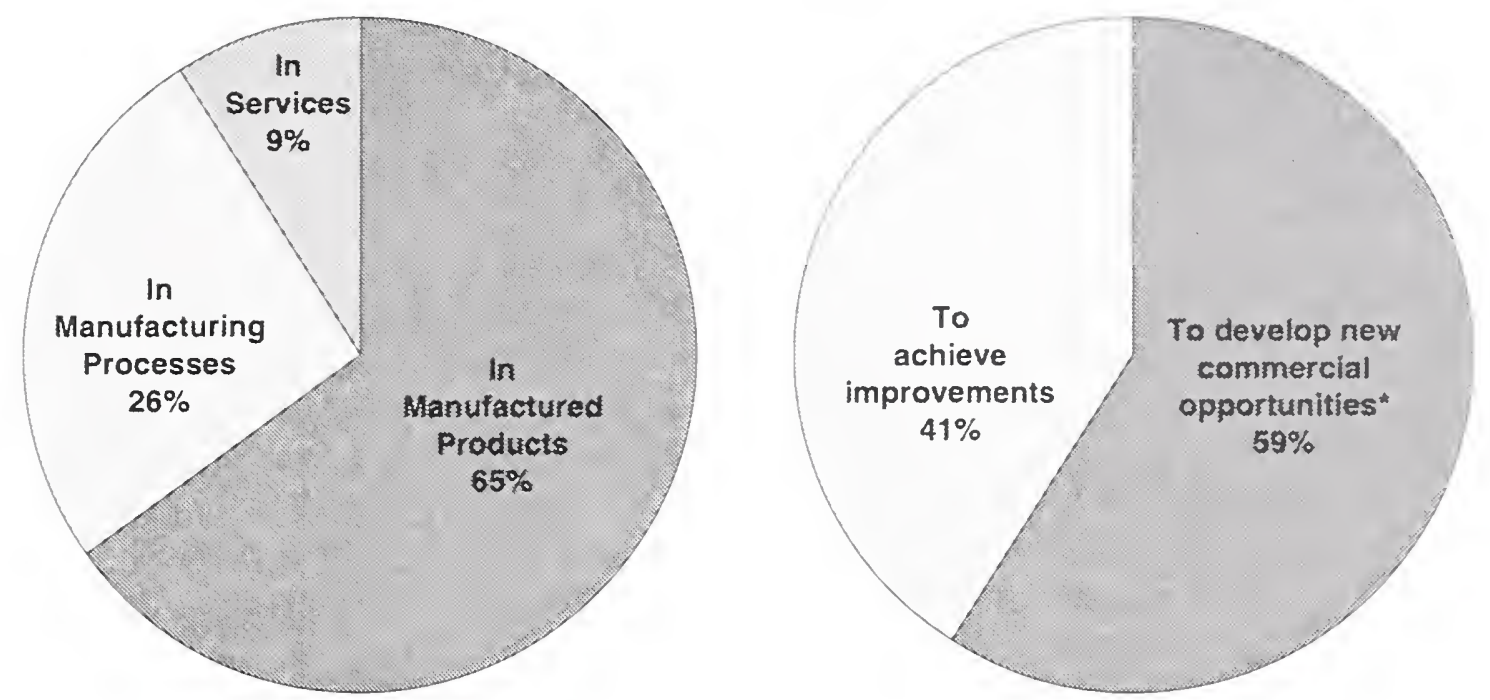

Note: "In response to a follow-up question (not depicted), project participants indicated that $35 \%$ of applications represent "New-to-the-world" solutions to a market need or problem.

Source: Business Progress Reports for 778 applications being pursued by 375 companies in 207 ATP projects funded $1993-1995$

As shown in Figure 6, many companies envision that products and processes embodying the ATPfunded technology will be used in multiple stages of production extending from Raw Materials Production to End User. Sixty-three percent of the technology applications involve relatively earlystage Components Manufacturing.

\section{Figure 6. Stages of Production In Which the ATP-funded Technologies Are Expected To Be Used}

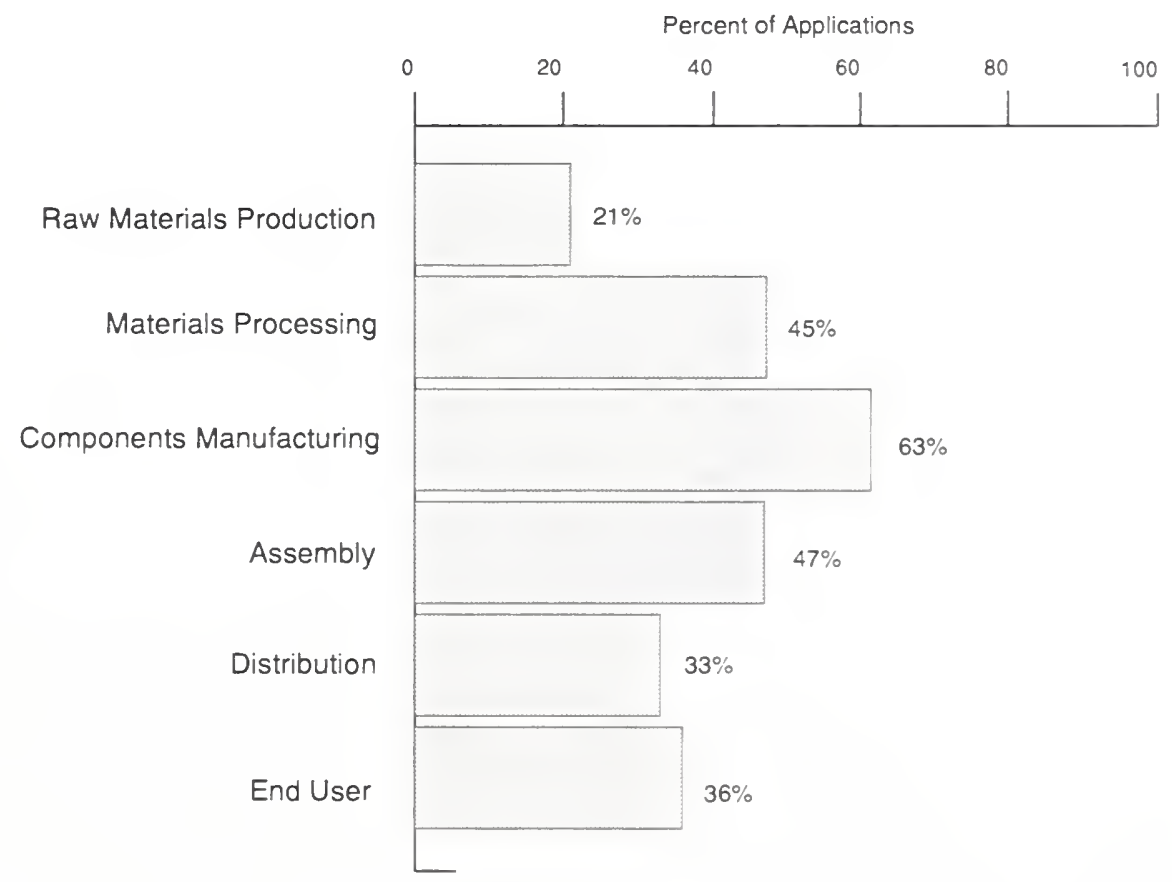

Note: Most companies plan to address more than one stage of production; many plan to address more than two.

Source: Business Progress Reports for 778 applications being pursued by 375 companies in 207 ATP projects funded 1993-1995 
The entry of the ATP technology into an early stage of the production cycle, in combination with the diversity of applications expected to result from individual projects and technologies, increases the opportunity for downstream customers/users to experience market spillovers (consumer surplus). This is, of course, especially true where an ATP-funded technology has significant cost or performance advantages over existing/defender technologies.

\section{Business Goals}

In the Baseline Reports, companies are asked to categorize, define, and quantify their business goals for their parts of the ATP-funded R\&D projects. As shown in Figure 7, performance improvements appear to be a somewhat more commonly expected and significant goal than cost reduction. For 29 percent of applications, a performance improvement in the range of 100-500 percent or more is anticipated. For 28 percent of applications, a cost reduction of 25 percent or more is expected. Improvements of these magnitudes, particularly when combined with the emphasis on "new" products or lines of business, are consistent with definitions of "discontinuous" or "breakthrough" innovations used in the joint Rensselaer Radical Innovation Research - Industrial Research Institute Project funded by the Sloan Foundation (Leifer, 1997). (Of course, for some projects, even a small cost reduction or performance improvement can represent a significant achievement and important competitive advantage when measured across a large production volume.) Other data show that one-third of applications are expected to involve some combination of cost reduction and performance improvement over existing technologies.

Figure 7. Quantitative Business Goals

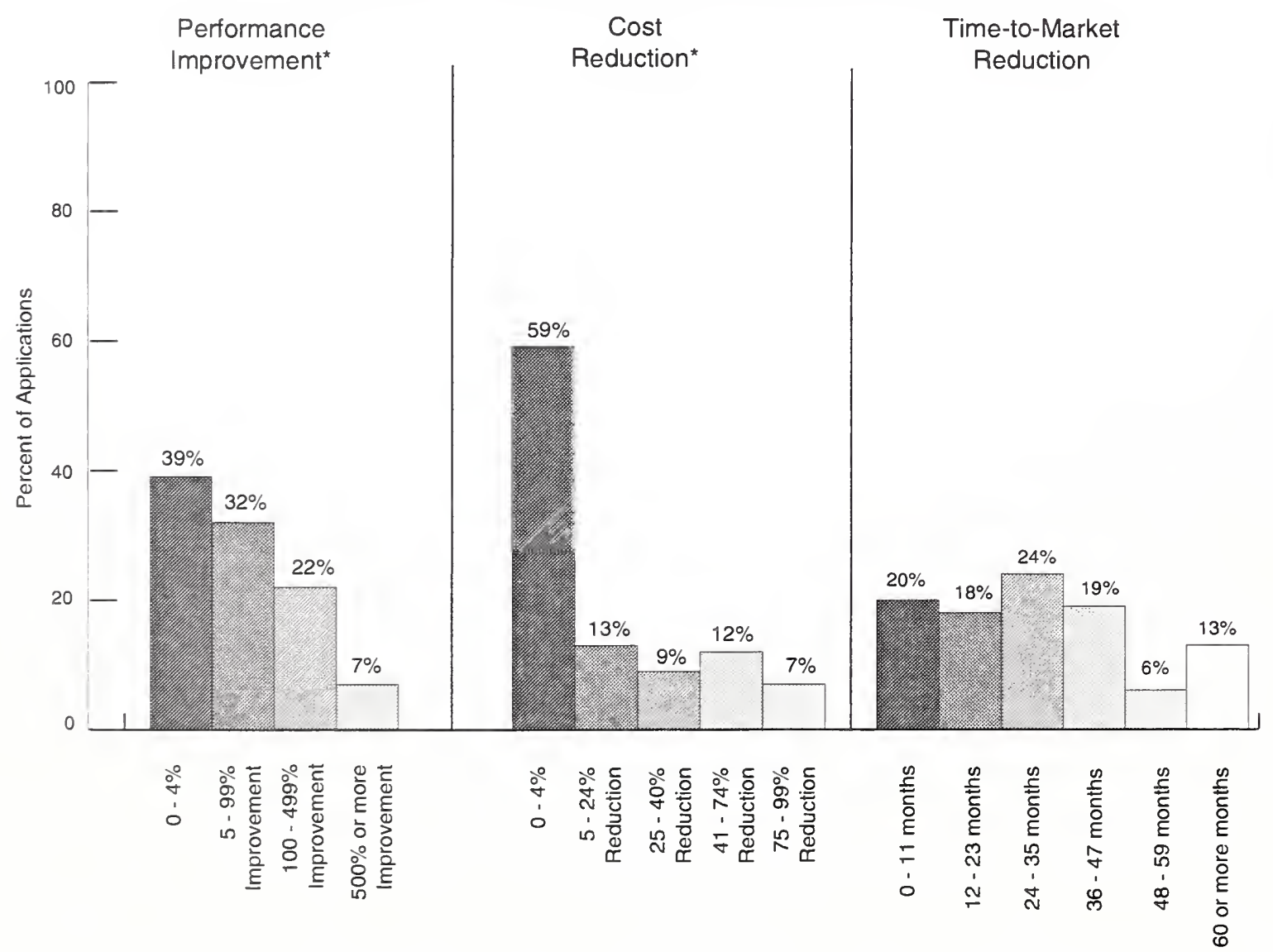

Note: "In a response to a different question, project participants indicate that one-third of applications involve some combination of cost reduction and performance improvement over existing products, processes, and services.

Source: Business Progress Reports for 778 applications being pursued by 375 companies in 207 ATP projects funded 1993-1995. 
Table 2. Examples of Effect of ATP Funding on Company Goals for the Technology

\begin{tabular}{|c|c|c|}
\hline Baseline & Goal with ATP Funding & Goal Without ATP Funding \\
\hline $1 \mathrm{kw} / \mathrm{\$} 10,000$ & $10 \mathrm{kw} / \$ 10,000$ & $3 \mathrm{kw} / \$ 10,000$ \\
\hline 60 microseconds process speed & 10 microseconds process speed & 60 microseconds process speed \\
\hline$\$ 100$ cost & $\$ 25$ cost & $\$ 100$ cost \\
\hline 3,300 hours lifetime & 10,000 hours lifetime & 5,000 hours lifetime \\
\hline $2,500 \mathrm{cars} /$ day & $2,875 \mathrm{cars} / \mathrm{day}$ & $2,500 \mathrm{cars} /$ day \\
\hline 34 trains/day & 51 trains/day & 34 trains/day \\
\hline $1,000 \mathrm{CPU}$ time & $10 \mathrm{CPU}$ time & $100 \mathrm{CPU}$ time \\
\hline 60 degrees $C$ & 100 degrees $C$ & 60 degrees $C$ \\
\hline $800 \mathrm{~nm}$ & $200 \mathrm{~nm}$ & $800 \mathrm{~nm}$ \\
\hline$\$ 60,000$ per unit & $\$ 1,000$ per unit & $\$ 10,000$ per unit \\
\hline 1 test/day & 5 tests/day & 1 test/day \\
\hline 40 bases/minute & 2,000 bases/minute & 533 bases/minute \\
\hline$\$ 500 /$ medical test & $\$ 50 /$ medical test & $\$ 500 /$ medical test \\
\hline 1 gene/day sequencing & 100 genes/day sequencing & 5 genes/day sequencing \\
\hline 3.9 gigabytes data storage & 60 gigabytes data storage & 4.7 gigabytes data storage \\
\hline \$62/gigabyte & $\$ 1 /$ gigabyte & \$25/gigabyte \\
\hline
\end{tabular}

Source: Business Progress Reports for 778 applications being pursued by 375 companies in 207 ATP projects funded 1993-1995.

Table 2 provides an illustrative list of quantitative examples of how ATP funding is expected to affect the technological capabilities of companies as measured by expected changes in value for the attribute identified as most critical to commercialization for a specific application. Quantification of cost and performance advantages of the ATP-funded technology, such as provided by this business goals analysis, is useful in tracking project progress as well as assessing business opportunities and estimating the potential magnitude of economic spillovers. Both "with" and "without ATP" goals are needed to assess the potential for ATP funding to make a difference relative to what would have occurred without government funding. An ex ante comparison of baseline values with project goals for key technology parameters/attributes helps to identify the anticipated degree of technological advancement and to assess the expected impact of the project. An ex post comparison of progress made against cost/performance targets will make it possible to assess the level of actual technical accomplishments within a business and economic context.

Acceleration of R\&D is another commonly cited business goal of ATP projects. As shown in Figure 7 (above), nearly all the companies expect some reduction in the time it will take to complete the R\&D phase and bring their products to market/or implement new production processes as a result of ATP funding. A reduction of at least two years is anticipated for 62 percent of applications; with a reduction of four or more years expected for 19 percent of applications and a reduction of two to nearly four years expected for 43 percent of applications. 
The importance of the acceleration aspect of ATP funding is reflected in Figure 8. For 98 percent of applications, speed-to-market is considered "important" or "critical;" it is considered "critical" for more than half. Further emphasizing the importance of acceleration, the window of opportunity for 75 percent of the applications to enter the marketplace is considered to be within two years after ATP funding ends; i.e., it appears that companies believe they would miss the opportunity, or a significant part of it, without the acceleration enabled by ATP funding.

Figure 8. Importance of Market Timing

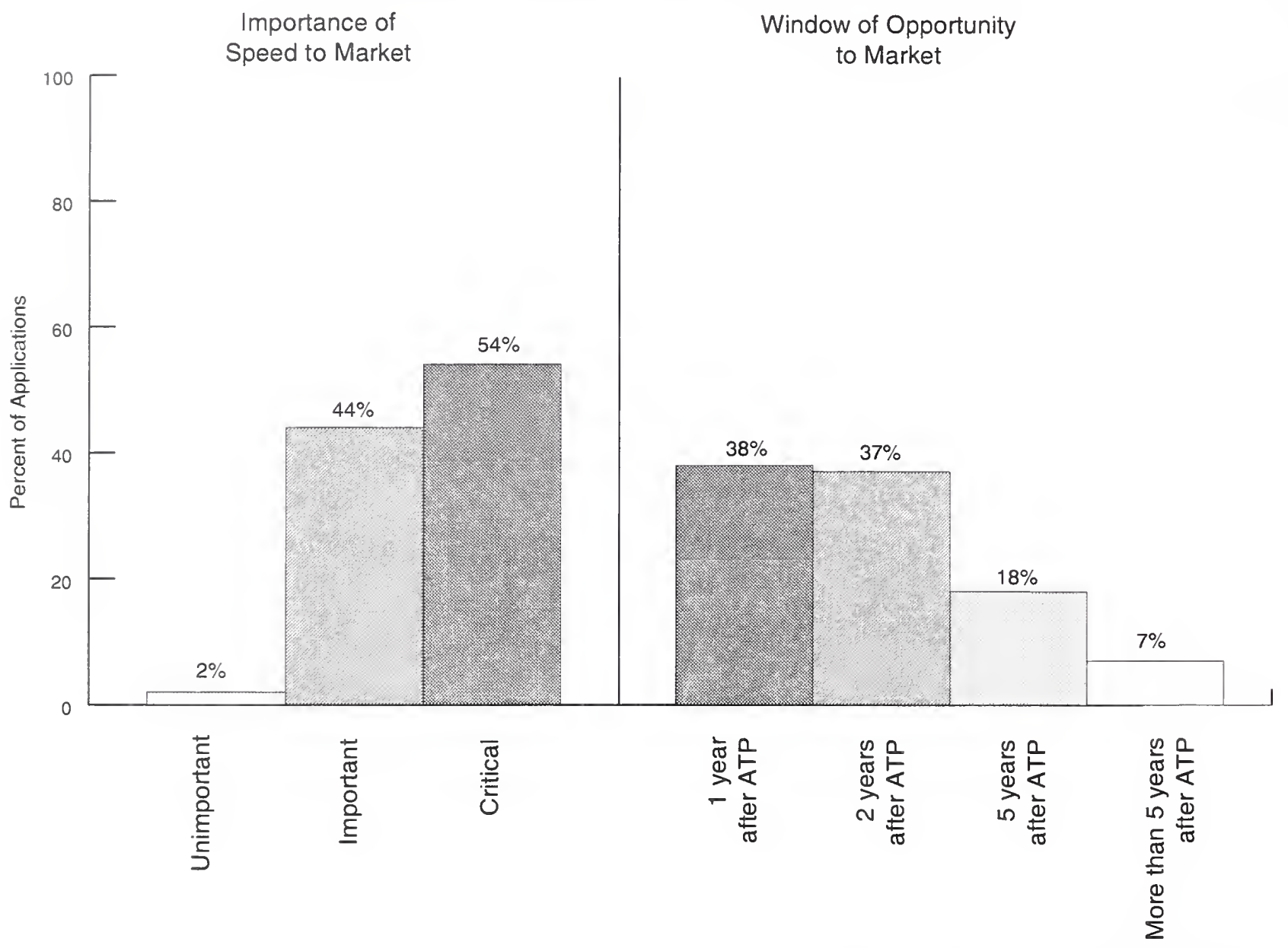

Source: Business Progress Reports for 778 applications being pursued by 375 companies in 207 ATP projects funded 1993-1995.

The following are some additional business goals cited in company business reports:

"Achieve broad adoption..."

"Be \#l supplier of ... technology"

"Expand applications into ... industry"

"Obtain a licensee by end of ATP"

"Become global expert in ... technology"

"Diffuse technology to cover 5 technology niches"

"Increase market share by ..."

"Be recognized as leading vendor of ..." 


\section{Identification of Commercialization Strategies}

As their primary means of commercialization, most ATP-funded companies plan to achieve commercialization for at least one application through production of a product or service in-house, in their own existing or planned facilities. As shown in Figure 9, in-house production is the focus for 65 percent of applications. For 24 percent of applications, licensing to others is the primary strategy; for 43 percent of applications, licensing is the primary or secondary means of commercialization. For 79 percent of applications, including some of those where in-house production is the primary means, licensing to others is a possible supplementary means, if not the primary focus. Thus companies recognize the opportunity to increase their revenues beyond what their internal production facilities can support, while at the same time increasing opportunities for diffusion of the technology to other firms and potentially other applications and industries. Jaffe confirms that potential for licensing the technology to others is a factor that makes economic spillovers relatively more likely (Jaffe, 1996).

Figure 9. Strategies for Commercializing ATP-funded Technologies

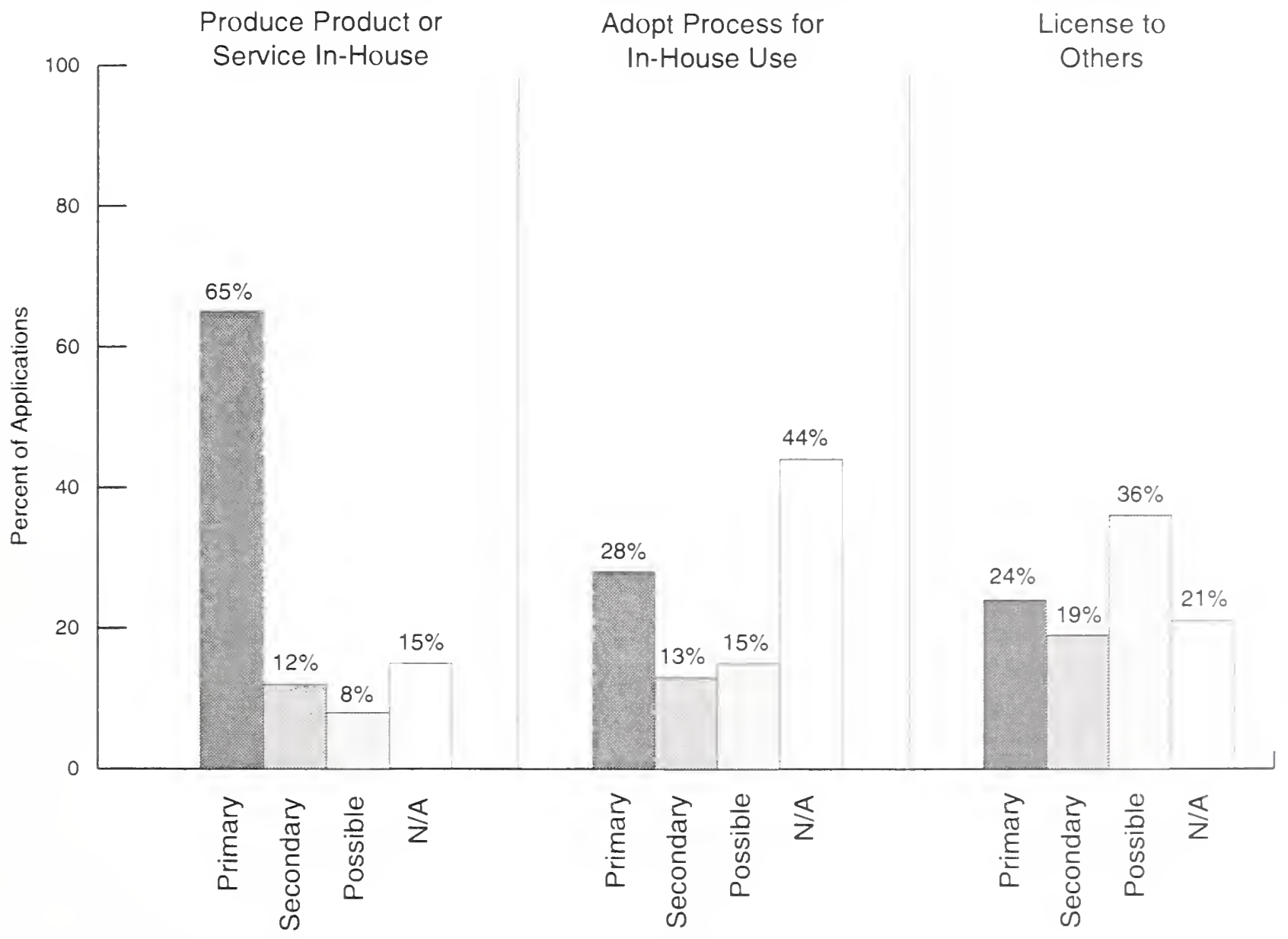

Note: Some companies reported more than one strategy as "Primary."

Source: Business Progress Reports for 778 applications being pursued by 375 companies in 207 ATP projects funded in 1993-1995.

Close supplier-customer linkages are important to successful technological innovation. Among the work that addresses this issue, von Hippel suggests that such linkages can increase the productivity of the innovation through more efficient communication of technological and market information (von 
Hippel, 1994). Given the large number of small companies involved in the projects, and the rather early stages of production they address, one would expect a large number to pursue strategic alliances for commercialization. But Figure 10 shows that only for a relatively small percentage of applications (one-fourth or less), do the commercialization plans indicate heavy reliance on strategic alliances with customers, suppliers, partners in joint production, or distributors.

Figure 10. Strategic Alliances Planned

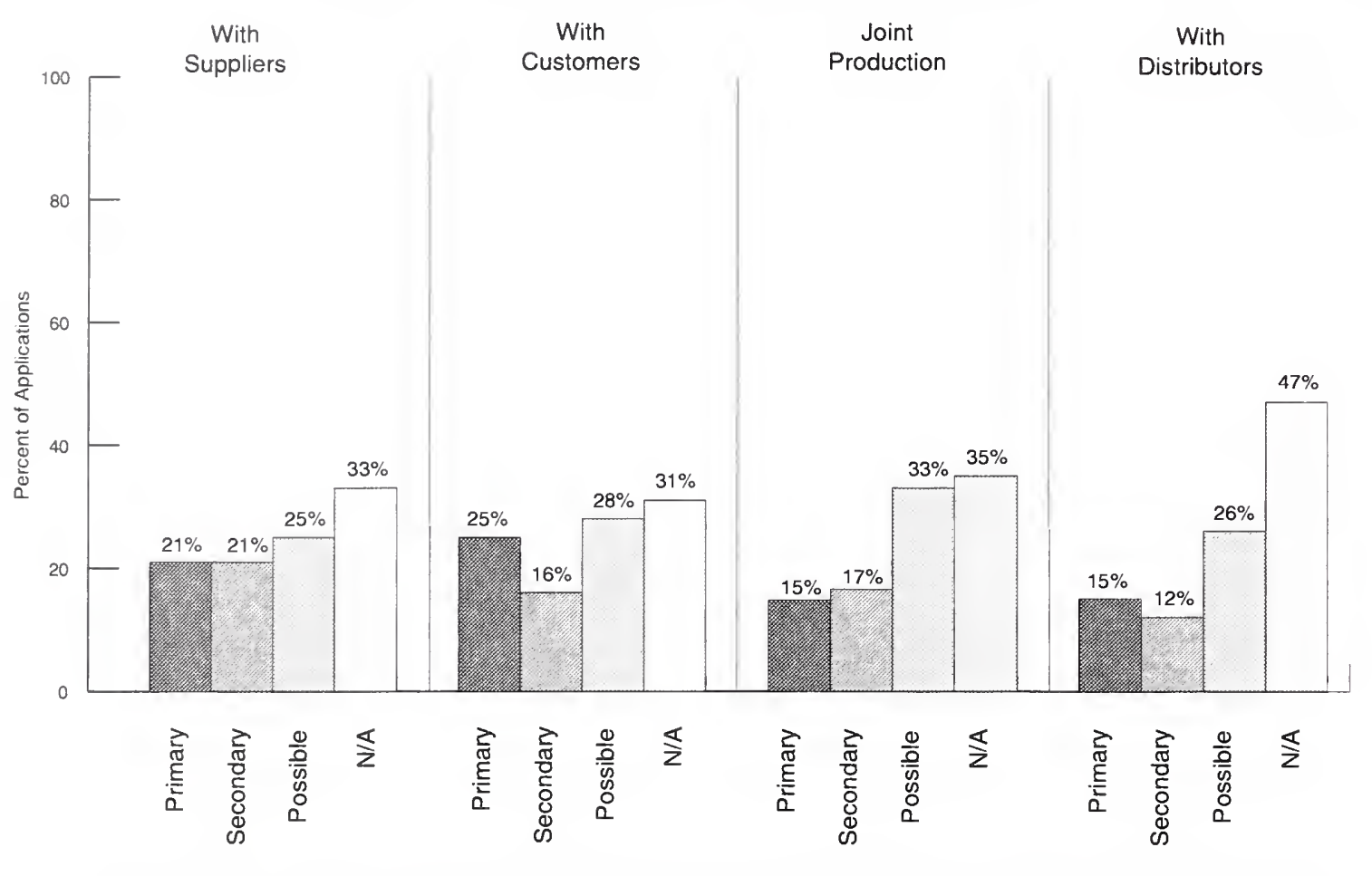

Source: Business Progress Reports for 778 applications being pursued by 375 companies in 207 ATP projects funded $1993-1995$.

Further analysis at the company level, however, reveals that (a) 91 percent of companies plan at least one of these types of alliances and (b) at least one of these types of alliances is planned in pursuing 88 percent of applications (graph not presented).

The subset of reports from small businesses reveals that strategic alliances to pursue commercialization are more important for small businesses than for larger ones, as one would anticipate. Small businesses plan alliances with customers as a primary strategy for 31 percent of applications and as a primary or secondary strategy for 54 percent of applications (compared with 25 and 41 percent respectively for all respondents); small businesses plan alliances for joint production as a primary strategy for 21 percent of applications and as a primary or secondary strategy for 47 percent of applications (compared with 17 and 32 percent respectively for all respondents); small businesses plan alliances with distributors as a primary strategy for 22 percent of applications and as a primary or secondary strategy for 38 percent of applications (compared with 15 percent and 27 percent respectively for all respondents). 


\section{R\&D STATUS REPORT}

\section{Level of Progress in Completing R\&D Phase}

Data available for this report reflect commercialization planning and progress during early phases of $\mathrm{R} \& \mathrm{D}$ for most of the projects covered. Of the 210 projects reporting, 31 were in their first year of ATP funding and/or had submitted only their baseline commercialization plan; 179 had completed one-to-two years of ATP funding and submitted one or two anniversary reports of actual commercialization progress and other effects of ATP funding. ATP funding had been completed for only three projects. Projects funded in FY 1995 represent about half the projects covered, none of which had completed more than one year of ATP funding by the end of the period covered by this study. (See Chapter 1, Table 1.) The study looks at the overall progress of the entire group of projects in the BRS as a whole, at their varying levels of $R \& D$ completion.

Figure 11. R\&D Status

\section{Current level of progress:}

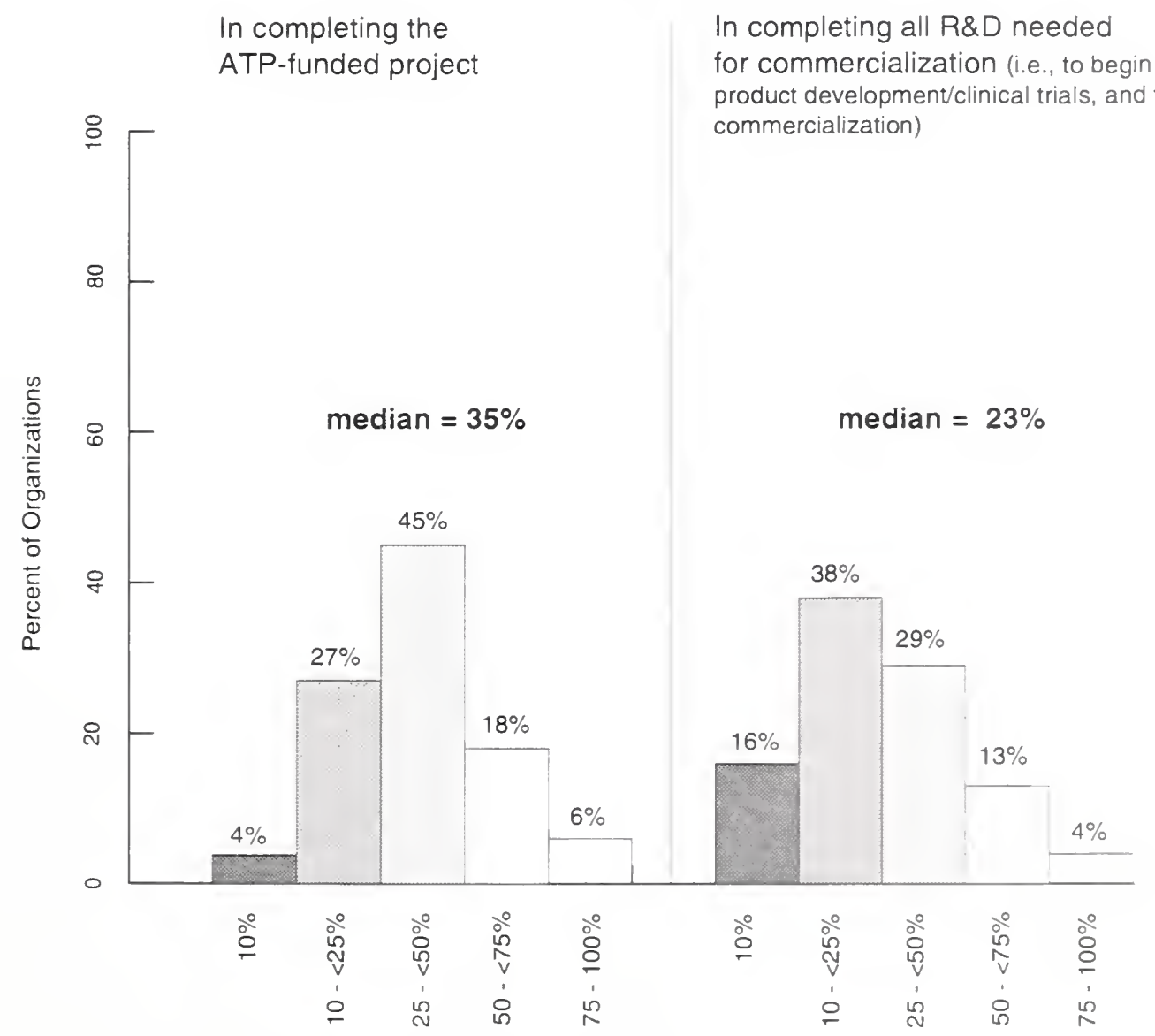

Source: Business Progress Reports from 285 organizations in 179 ATP projects funded 1993-1995-after one or two years of ATP funding.

Reports for the projects which had completed at least one year of funding by December 31, 1996 , indicate in Figure 11 that 31 percent were less than 25 percent complete; only six percent were 75 100 percent complete with their R\&D, which corresponds with the small number of organizations that had completed their projects. The median level of completion of the ATP project is estimated for the 
group in the database to be 35 percent. Considering the total R\&D (including that beyond the ATP project) needed for significant commercialization to occur, the median level of R\&D completion is estimated to be 23 percent. These two median values mean that 50 percent of the organizations have completed at least 35 percent of their ATP-funded projects but only 23 percent of the total R\&D needed for full-scale commercialization. The fact that considerable additional R\&D will be required for many organizations after the ATP funding period ends is not surprising given that ATP is funding relatively early stage applied R\&D with considerable technical risk.

\section{Effect of ATP Funding on R\&D Progress}

After just one-to-two years of ATP funding, project participants indicate that they are already significantly ahead in their R\&D cycle as a result of ATP funding as compared with where they would be without their ATP award. As shown in Figure 12, 86 percent indicate that ATP funding has helped accelerate R\&D efforts in the ATP-funded area. Of these, 39 percent believe they would not have pursued the R\&D at all without the ATP award; 53 percent believe they are one to three years ahead as a result of ATP funding. Only one percent indicated they were behind. Those reporting they were behind are all members of joint ventures and may catch up as their projects progress and overcome initial organizational start-up delays. Overall, measurable progress appears to have been made towards meeting critical windows of opportunity for the ATP-funded technologies.

Figure 12. Acceleration of R\&D

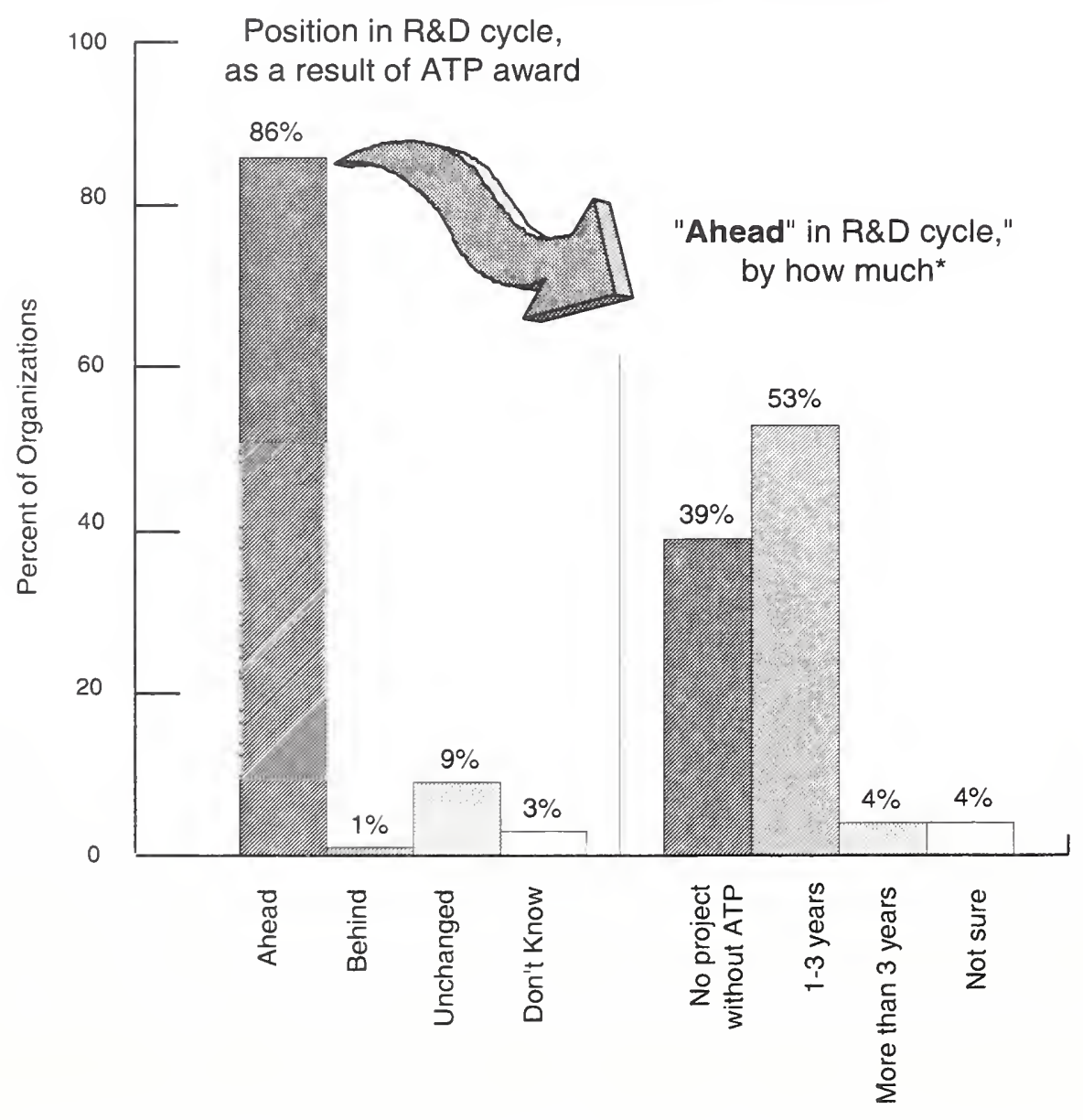

Note: "Includes responses from organizations indicating "Ahead" to prior question.

Source: Business Progress Reports from 285 organizations in 179 ATP projects funded 1993-1995--after one or two vears. 


\section{When Can Revenue Be Expected?}

Although the ATP funds R\&D that involves considerable technical uncertainties and difficulties, technical progress tends to come in stages. Early-to-intermediate stage accomplishments may have commercial value worth capturing by incorporating newly gained knowledge in a near-term generation of products and processes even though attainment of the ultimate goals required for the full spectrum of applications remains distant.

A significant amount of commercialization planning activity is expected over the course of the ATP project, and some projects are expected to experience the beginnings of revenue generation from spinoff activities. Across the projects, companies, and applications encompassed by this report, approximately one-third of the projects and one-third of the companies pursuing commercialization expect to see some revenues from at least one early application of the ATP-funded technology by the end of the ATP funding period. (See Figure 13.) For more than 50 percent of the applications, revenue isn't expected until a year or more after the end of ATP funding; for nine percent of applications and projects, revenues are not expected until four or more years after the end of ATP funding. Only two percent of organizations indicated they do not expect to earn revenues at any time. All these were universities, non-profits, or other joint venture members without a significant future commercialization role, although they might be performing testing and other services important to future commercialization by companies in their joint ventures.

Figure 13. When Can We Expect To See Revenues from ATP-funded Technologies?

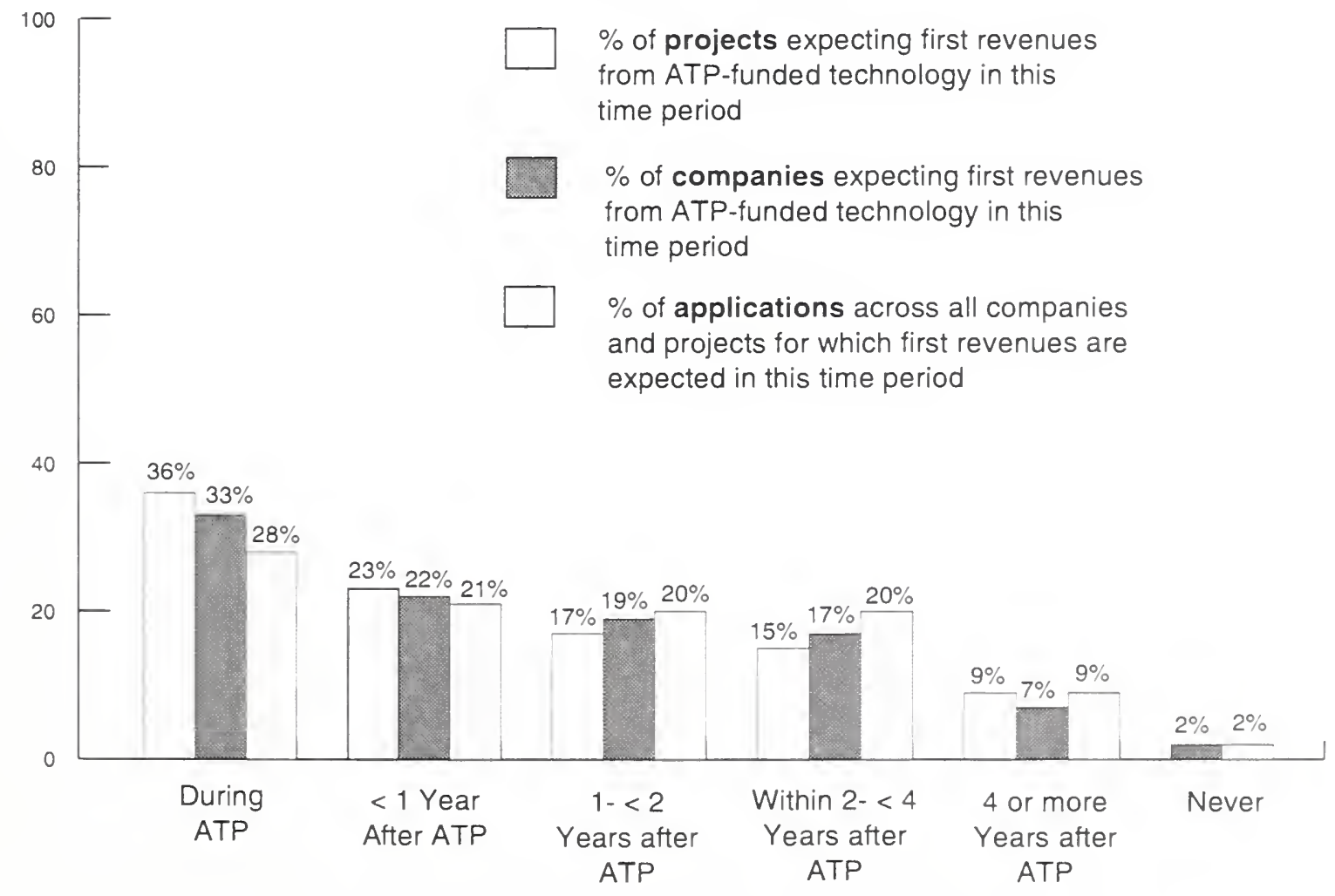

Source: Business Progress Reports for 777 applications being pursued by 374 companies in 206 ATP projects funded $1993-1995$

Small, young companies, such as the large number of start-ups the ATP has funded, typically strive for early spin-off products to generate cash flow needed for financial survival. Taking advantage of early product opportunities may help them attract the private capital needed to pursue the breadth of 
technological development required to compete in cost-sensitive markets, and for a broad range of potential applications. From observation of ATP-funded companies involved in manufacturing of advanced products and from analysis of individual company reports, it appears that at any given time many of the companies are engaged in a mix of R\&D and related commercialization activities involving a single core technology. These activities may feed into the development of several different generations of products, including some entirely new product lines, which will enter the marketplace at different times over the next five or more years. In the case of bio-technologies for human therapeutics, for example, early applications may involve research tools and test kits. Significant commercialization of the targeted human medical therapeutics may not be possible for five or more years after ATP funding ends because of the lengthy regulatory processes required.

The remainder of this report describes the effects of ATP funding, actual commercialization progress, and the beginnings of technology diffusion, within the context of the relatively early R\&D stage of most of these projects. Substantial technical uncertainties remain, and full business and economic potential are very difficult to predict in the face of both technical and economic uncertainties still remaining at this time. These caveats notwithstanding, early effects of ATP funding can be identified and conditions necessary for significant future commercial success and national economic impact can be monitored. With the further passage of time, and additional data collection and analysis, we will learn much more about the evolution of these projects. At this time, the evidence points to the conclusion: "So far, so good." 


\section{STIMULATION OF COLLABORATION AND RELATED EFFECTS}

\section{Stimulation of R\&D Collaboration}

Stimulation of collaborative R\&D relationships among companies, universities, and other research organizations is part of ATP's legislated mission. The objectives are to increase research efficiency and effectiveness, expand capabilities, reduce R\&D cycle time, and accelerate commercialization and competitiveness. The level of collaborative activity has indeed been considerable from the beginning of the program. In the first competition, ATP funded five joint venture projects among the first 11 awards. From 1990 through 1997, the ATP has funded 119 joint ventures, involving about 600 participants. Many of these joint ventures involve companies which had never worked together before and were formed explicitly to apply for ATP funding (Silber, 1996, p. 23). Of the approximately 285 organizations in 179 FY 1993-1995 projects for which data are available after one-to-two years of ATP funding, 164 are members of 58 joint ventures. (See Chapter 2, Figure 2.) In addition to the formal joint ventures, the ATP has found that most of the "single company projects" it funds are, in fact, also rich in collaborative relationships. These are implemented through subcontracting arrangements and informal alliances.

As shown in Figure 14, 78 percent of respondents, including a mix of 77 single company awardees (64 percent of the entire single company award group) and 144 joint venture participants ( 87 percent of the entire joint venture participant group), reported that collaboration has helped them achieve the

Figure 14. Stimulation of Collaborations

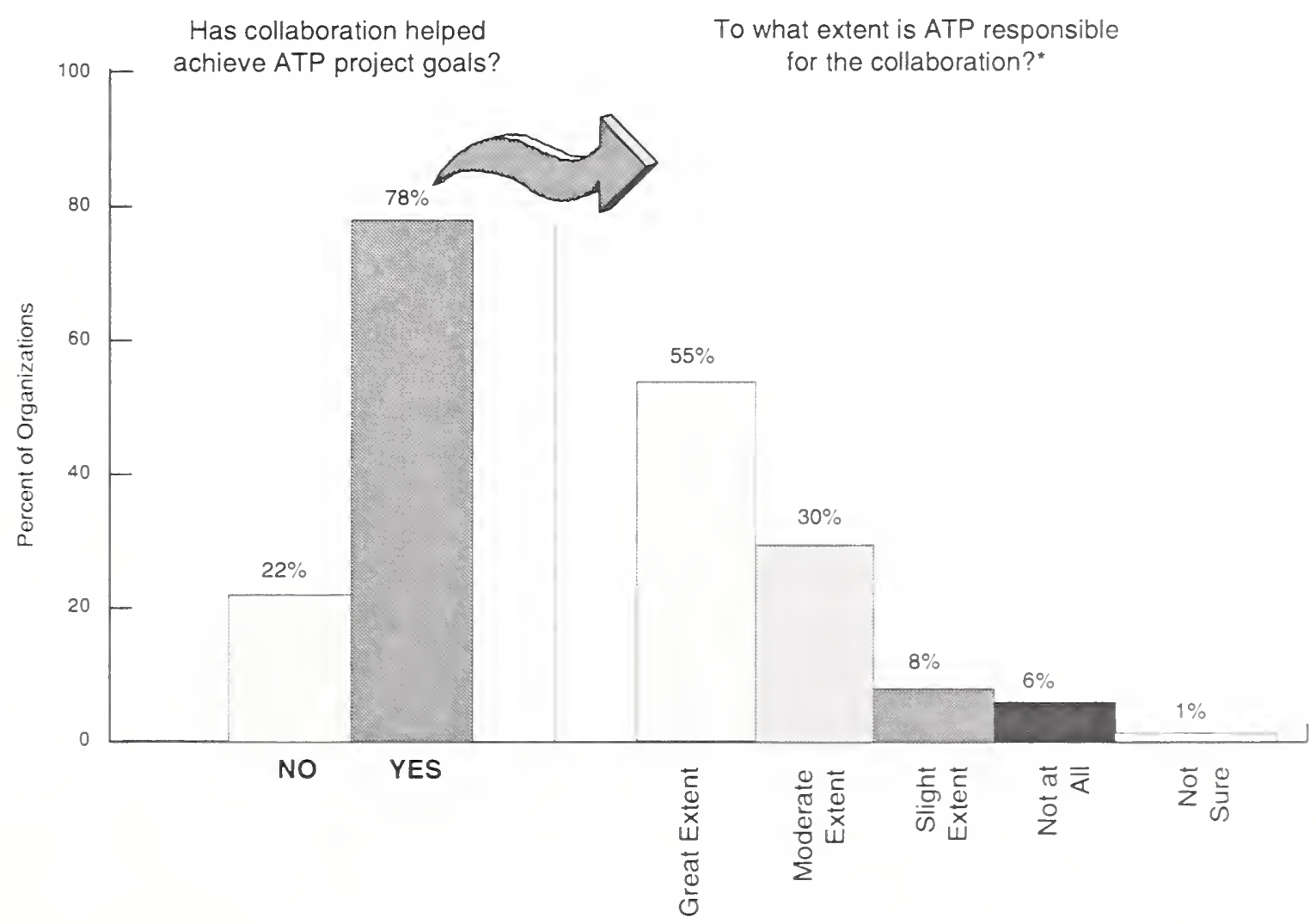

Note: "Includes responses from organizations indicating "YES" to prior question.

Source: Business Progress Reports from 286 organizations in 179 ATP projects funded 1993-1995 .. after one or two years of ATP funding 
goals of their ATP project. Of the group indicating this positive effect of collaboration, 55 percent indicated that the ATP was responsible for the collaboration to a great extent. Eighty-five percent indicated ATP was responsible to a moderate or great extent.

As indicated above, many ATP collaborations reach beyond the official, defined joint venture relationship. Both single company award recipients and joint venture members form collaborative relationships through subcontractor arrangements and informal alliances. A total of 436 subcontractor arrangements, for example, have been reported by single company awardees and joint venture awardees filing BRS reports. Nearly one-half of the subcontractors are small companies; the remaining half consists of universities and medium-to-large companies, in near equal numbers; eight others are government or non-profit laboratories.

\section{Collaboration Effects}

Figure 15 shows effects most significantly enabled by ATP collaborations of these multiple types. More than 70 percent of respondents indicated that collaboration enabled these effects significantly or moderately. Nearly everyone (99 percent) indicated that collaborations had "stimulated creative thinking;" over 80 percent indicated that collaborations had enabled the company to accelerate entry to the marketplace and to save time in general (corroborating acceleration effects cited in Chapter 3); about 75 percent reported that collaboration had enabled the company to obtain R\&D expertise, and to identify customer needs; and 79 percent indicated that their experiences with ATP collaborations had encouraged them to consider future collaborations.

\section{Figure 15. Effects Most Enabled by Collaboration}

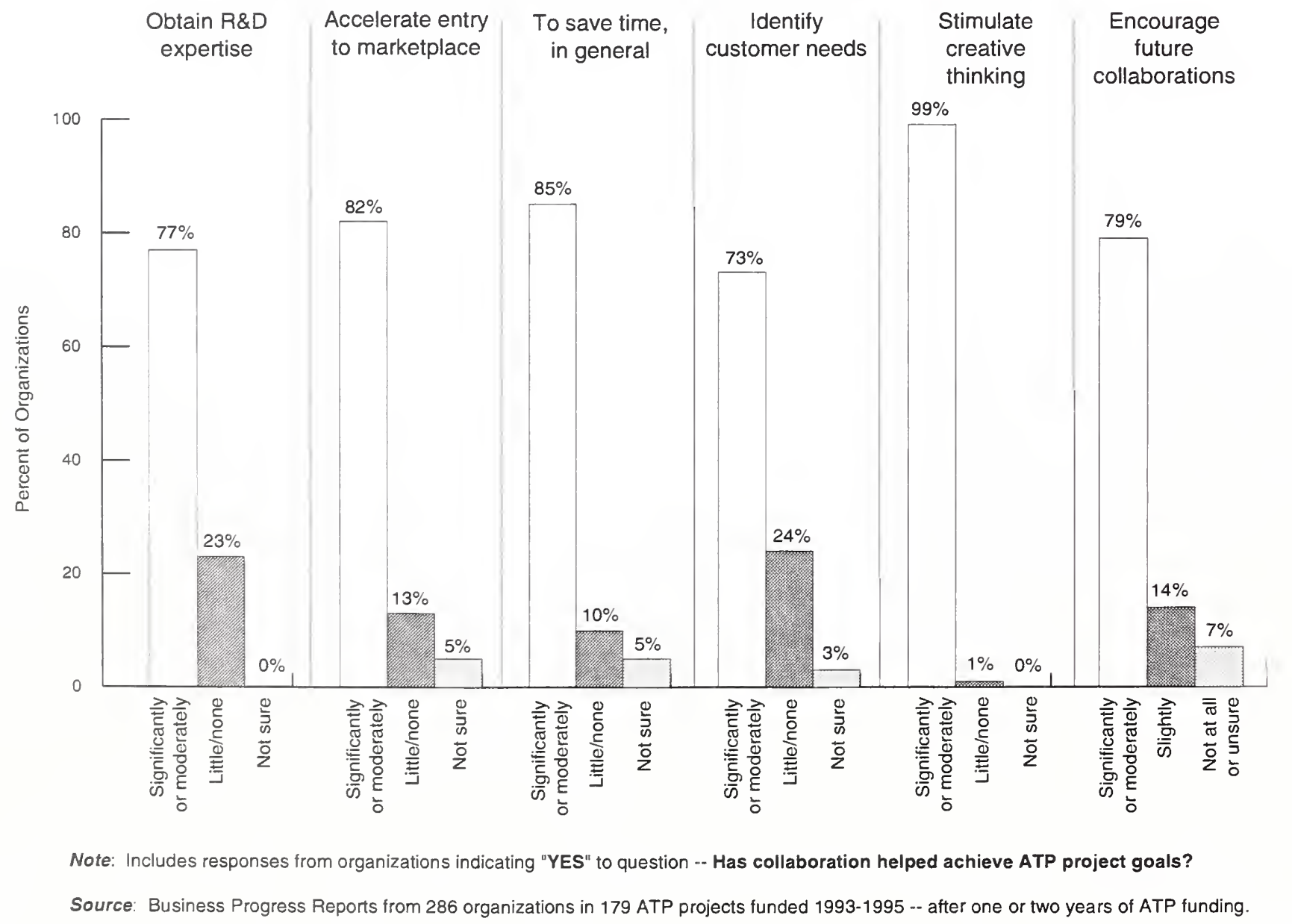


Figure 16. Other Effects Enabled by Collaboration

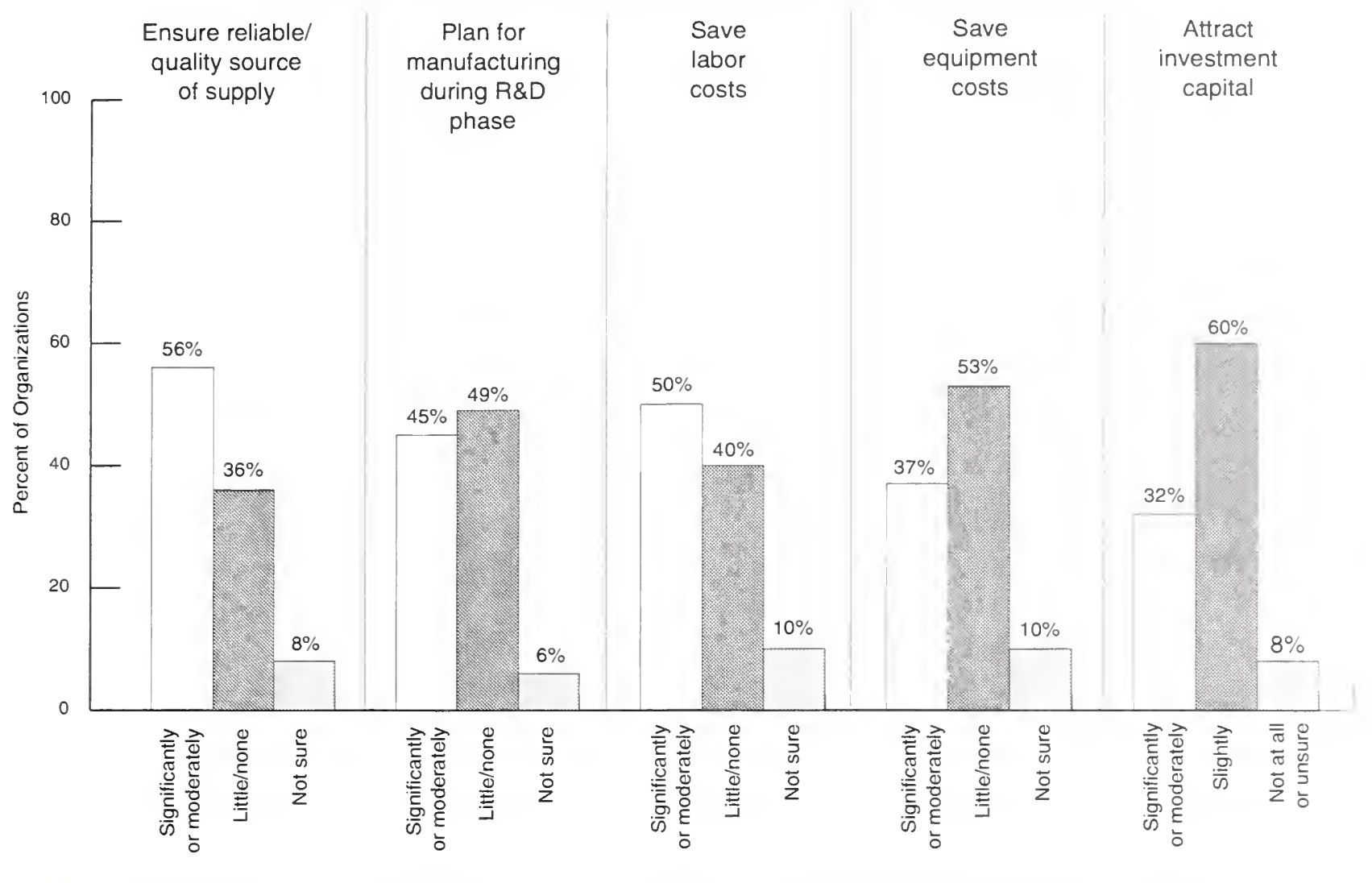

Note: Includes responses from organizations indicating "YES" to question -- Has collaboration helped achieve ATP project goals?

Source: Business Proaress Reports from 286 organizations in 179 ATP proiects funded 1993-1995 -- after one or two years of ATP fundina

Figure 16 shows other effects of ATP collaborations. Among the other effects analyzed, "ensuring a reliable/quality source of supply" was cited as significantly or moderately enabled by 56 percent; "labor cost savings" were cited by 50 percent; "attraction of investment capital," "planning for manufacturing," and "saving equipment costs" were cited as significantly or moderately enabled by 32 percent, 45 percent, and 37 percent, respectively. These effects may be indicative of the relatively early project stage of most of the organizations reporting and may become more important as the companies move closer to commercial deployment.

There is no doubt that R\&D joint ventures/consortia involve some project start-up time and costs, and possibly continuing costs not experienced by single-company awardees. As shown in Figure 17, of the organizations which indicated that collaboration had helped them achieve their project goals, half confirmed that project coordination and management costs had increased significantly or moderately as a result of collaboration. More detailed analysis of this group (not shown) reveals that nearly all reported only a "moderate" cost increase. Only 20 percent indicated that associated delays in starting projects had resulted significantly or moderately as a result of collaboration, and only six percent anticipate a delay of product entry into the marketplace as a result.

\section{Anecdotal Comments}

Anecdotal information from the BRS provides additional insight into effects of collaboration experienced by ATP-funded organizations and amplifies the statistical analysis. Some comments elaborate on the positive and negative impacts of ATP collaboration; others address issues not covered in specific reporting questions. 
Figure 17. Costs Attributed to Collaboration

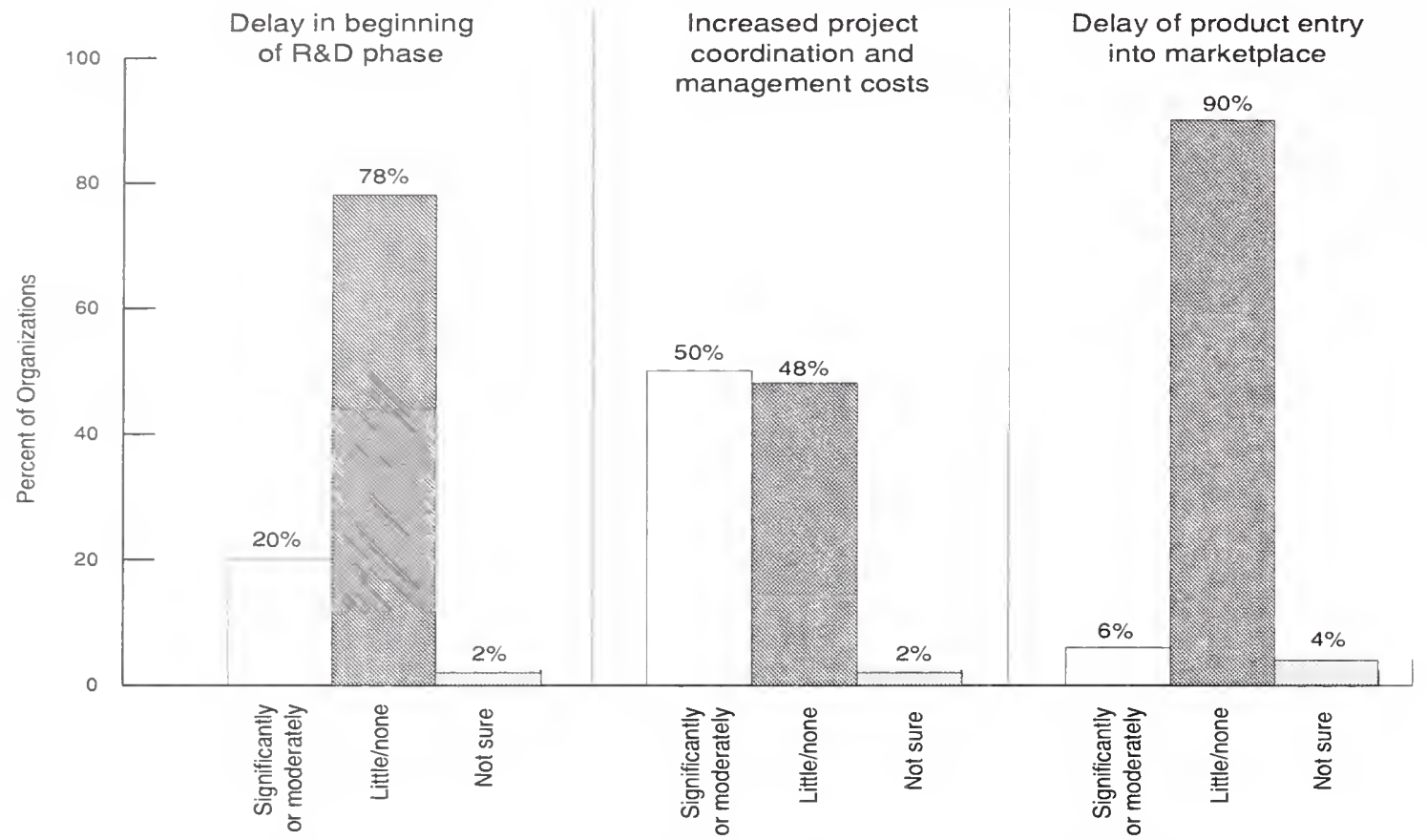

Note: Includes responses from organizations indicating "YES" to question -- Has collaboration helped achieve ATP project goals?

Source: Business Progress Reports from 286 organizations in 179 ATP projects funded 1993-1995 -- after one or two years of ATP funding.

\section{Obtaining expertise not otherwise available}

"The work with our subcontractors [has] enabled us to utilize their expertise in fields [where we] are not staffed. The interactions with our joint venture partners provide us access to work they are doing in fields [where] we are not active." [Joint venture member]

"Critiques of work conducted independently [have] provided invaluable outside perspective to stimulate creative thinking and exposed several oversights early in the development process." [Single applicant]

"The breadth of experience brought in on these projects is extensive." [Joint venture member]

"Excellent collaborative environment and complementary technical capabilities have improved the quality of technical output and effectiveness of the team. There has been tremendous synergy between the companies that are collaborating on this project. Each company brings a particular expertise that the others don't have and which would be difficult to develop. Each party is an enabler for the others." [Joint venture member]

"Collaboration has provided [us] with access to compounding, conversion, and fabrication resources, complementary ... materials and technical expertise that would not otherwise have been available." [Single applicant]

"In general, [subcontractor] has a wealth of experience and knowledge on ... processing and control. Their insight has been a primary driver on overcoming several technical problems and developing process simplifications." [Single applicant] 
"Our collaboration with other partners has helped us to access first hand data for medical vocabularies, and understand size and complexity of that data." [Joint venture member]

"Exposed to new ideas, technologies that would otherwise not have been exposed to. Enabled us to leap forward with newer approaches into our architectural design. " [Joint venture member]

"Access to software has been very beneficial in defraying costs which may have been prohibitively high and blocked any attempt to accomplish this work." [Joint venture member]

"Medical expertise and related product requirement insight would not have been possible from within our own organization." [Single applicant]

"Through collaboration we have been able to bring experts in this field to our test facility and work with live systems." [Single applicant]

"Able to evaluate other alternative processes for research and development... that would not have been possible from both cost and time considerations... Both [companies] have benefitted by mutual exchange of core competencies... No negative impact." [Joint venture member]

\section{Obtaining assistance from universities}

"University students are exposed to industry as summer students so they become acquainted with the needs of industry and the workings of an $R \& D$ industrial lab. The resulting collaborations result in joint publications and patents. [Single applicant]

"[Our] collaboration with ... University (as subcontractor) has [led] to the acquisition of some fundamental optimization technology that has been useful." [Single applicant]

"Our collaboration involves working with two universities and an equipment vendor. The universities have done early work to explore ... possibilities. We have then followed up with more results-oriented experiments. This saves us time in helping to identify things that work and provides us with an estimate of the process regime in which decent results can be obtained." [Single applicant]

"1. Significant input on optimized structural shape design from Dr...at [university]. 2. Structural testing facilities and equipment at [university] utilized for testing ATP prototype shape. Could not perform test with in-house laboratory facilities." [Single applicant]

"We have just begun the first phase of a collaboration with the ... center at [university], which involves the use of their clean room facilities. Duplicating those facilities at [our company] would have been completely impossible. In addition, we are being trained in various ... techniques, which speeds up the research phase considerably. The only negative impact has been the time required for setting up the legal structure of this collaboration. " [Single applicant]

"There have been a number of positive collaboration effects, particularly with our work with the [university]. He has a group of excellent students, that have helped us to produce ... software, better ... layout technology, and also increase our research standing in the community of international researchers. Our company always had strong people working for it, but we have been able to attract, and keep several very talented people because of the NIST funding and are 
grateful for this. So I would say that the research collaboration with this university, sponsored through NIST has been very positive." [Single applicant]

"Our ability to use subcontractors from academic medical centers has greatly improved our ability to achieve the goals of our project. These collaborators have given us both a lab for testing and a reality check on what works." [Single applicant]

Learning more about potential markets and customer needs and accelerating entry into the marketplace

"The most significant collaboration has come from securing a contract ... to install a pilot demonstration.... This has facilitated a number of discussions which has identified the real customer needs and therefore accurate functional and performance requirements of the products. In this process the team at ... working on the project have been introduced to domain knowledge that would have otherwise been difficult to obtain." [Single applicant]

"The manpower-multiplying and synergistic creative effects of using subcontractors has accelerated the $R \& D$ process to make it possible to plan and begin to initiate business alliances for the technology that capitalize on a fast-approaching market opportunity." [Single applicant]

"Main advantage is to fully understand all criteria for success upfront thereby avoiding the cost and project delays associated with unnecessary re-development." [Single applicant]

"Maximize resource dollars. Expedite new composite applications." [Joint venture member]

"The partnership which was established for this ATP project is a true vertical partnership of suppliers and a manufacturer. Unlike other $R \& D$ alliances in which [these companies] have participated, which were horizontal partnerships of manufacturing companies, this project had no inherent conflicts of interest. There is a single motivation in this project: to advance the state-of-the-art of the ... technology ... to allow for broad substitution of composites for traditional materials. And to date the NIST/ATP project has been central to achieving this goal." [Joint venture member]

"The collaboration has allowed us to understand healthcare needs for the technology to which we have been able to focus our $R \& D$. This has greatly increased commercialization chances and technology impact. Collaborator has already started to use our technology and has hired our students as interns and employees, which represents an important form of technology transfer. More collaboration has occurred than originally planned." [University joint venture member]

"In general, the collaboration has allowed us to contact new potential collaborators and markets. Some of these markets are for new equipment using our technology in ways we had not considered. Due to the success of the JV, the various members are investigating projects outside the ATP." [Joint venture member]

"Without the joint venture and collaborations from the other members it would have been almost impossible to assess the market needs and define the customers and requirements." [Joint venture member]

"The vertical structure of our joint venture (2nd tier vendor, 1st tier vendor, OEM) assures that our project direction is kept focused on real customer needs and addresses real customer 
concerns." "Better coordination of program brainstorming to advanced technology has enhanced the commercial focus. Has accelerated the commercialization effort." [Two members of a joint venture]

"Huge time savings; by vertically integrating the consortium, we can effectively design at all levels of the system simultaneously, rather than the serial design process normally used." [Joint venture member]

"It has created a greater awareness of the complete HDTV product environment. It has allowed [us] to pursue alliances outside of our narrowly defined ... product environment and work towards a greater understanding of new product and services offerings." "Complex system architecture issues are better studied in industry teams. This is made possible by the ATP grant." [Two members of a joint venture]

"There have been no negative impacts. Positively, the collaboration has increased our awareness of our partners' need for advanced materials and the partners' efforts in identifying opportunities in emerging markets which might match our long-term $R \& D$ material development work." "Assisted greatly in development of understanding of manufacturing costs and customer requirements, eventually leading to the abandoninent of the plastic LCD substrate effort." [Two members of a joint venture]

"The collaboration would have happened, eventually, but ATP has been the catalyst. The program has moved along much faster than anticipated and has been able to obtain managerial support and external assistance which would not have happened without ATP affiliation." " Intercorporate collaboration has fostered business relationships which are likely to continue beyond the ATP into product development and commercialization. This should greatly accelerate the application of the ATP-developed technology." [Two members of a joint venture]

\section{Formation of stronger supplier-customer relationships}

"The other joint venture partners are also customers for [company]. General understanding of business practices and other developmental needs have had a positive impact on all parties." [Joint venture member]

"Our collaboration with the equipment vendor has led to a promising new area of development. We hope to build a better original throughput goals." [Single applicant]

"[Collaboration has given us] a broader base of creative ideas for problem solving. Identify. potential problerns in future manufacturing. " [Joint venture member]

"Our subcontractor has a good deal of credibility in the marketplace. We have gone farther with prospects and vendor alliance discussions because of the choice of the subcontractor." [Single applicant]

"Collaboration has helped to align ideas of users and suppliers greatly." [Joint venture member]

"As an end user of the core technology being developed for this program, we would not have early access to the technology without the collaboration. Collaboration at this phase allows us 
to influence the design to meet our end product needs during the development. We have no intention to manufacture the [component], but to use it in our product; therefore collaboration is essential." [Joint venture member]

"There has been an awakening to the advantages of networking with our suppliers on an informal basis. This has resulted in leveraging research within [our] supply chains." "The collaboration with [lead company] has given us much insight and understanding as to the interests, needs, values, and talents of one of our largest international customers." "Without collaboration on this project with a major customer, this project probably would not exist. Collaboration provides us an unusual opportunity to work together." [Three members of a joint venture]

Strengthening credibility within the organization and with other organizations

"The joint venture with [partner] has focussed our $R \& D$ effort to a specific application and our price performance objective.... We anticipate the most significant impact will come in the near future when [partner] can assist us in gaining the capital investment for the transition to manufacturing and in the well-established market share [partner] currently enjoys." [Joint venture member]

"There is heightened credibility obtained from the concurrence of our competitors that we are doing the right things; i.e., if we tried to get this project approved in house alone, it might be perceived to not be as big a problem." [Joint venture member]

"Provided visibility into automotive market segment which we wouldn't normally have had access to." [Joint venture member]

"The fact [our company] has an ATP award has added credibility to our commercialization effort and in fact it has attracted some of our early collaborators and has been a major source of interest for our partners." [Single applicant]

"The mere fact of having won an ATP project has opened many doors to potential beta test partners, OEMs, and/or Resellers. " [Single applicant]

"Expanded awareness within the Products Group for need for more resources devoted to product $R \& D . "$ [Single applicant]

\section{Elaboration of the "benefits and costs" of collaboration}

"The main positive of collaboration is the sharing of expertise, and the stimulation of new approaches to the problem. The main negative has been that one of the companies was not really committed to provide sufficient resources to execute tasks on schedule and this slowed down all tasks in the critical path. Another negative (not major) has been the added approvals to change program directions, and the slow down in schedule due to co-ordination of tasks (technical and administrative)." [Joint venture member]

"This vertical teaming has enabled a free flow of ideas between the two companies and has made this collaboration a positive experience to date. The only negative of the collaboration, which is a result of the "large company syndrome," is that while large companies such as ... offer 
tremendous manufacturing resources, scheduling these resources can be difficult at times. "[Joint venture member]

"Positive: Reduction of "not invented here syndrome"; reduction of capital cost on equipment available from JV partner; positive factor in negotiating other contract research with outside company that involves complementary technologies of both JV partners. Negative: Difficulties experienced in initial collaboration with JV partner revolving around issue of trust (viewing the other company as a potential competitor)." [Joint venture member]

"Some negative impact results when a participant does not contribute to the extent expected and others have to fill the void." [Joint venture member]

"Positive Impacts: Elevated awareness of Healthcare marketplace. Understanding the healthcare information technology requirements. Negative Impacts: Very difficult to settle the intellectual property rights between multiple collaborators. " [Joint venture member]

"On the positive side, there was a great exposure to other technologies and transfer of technical knowledge between large multinational companies and research institutions. On the negative side, the research has been delayed because of the effort required to establish collaborative agreements and work through conflict resolutions." [Single applicant]

"On the positive side, the collaboration has allowed a group of companies to come together that otherwise wouldn't have and work jointly through a leveraged investment of $R \& D$ efforts. On the negative side, not all of the business models of the participating companies were compatible which resulted in some serious business negotiation problems relative to intellectual property." [Joint venture member]

\section{Formation of Strategic Alliances Outside the ATP Project for Commercialization of ATP-funded Technologies}

The numerous ATP joint ventures represent concrete evidence of ATP's ability to stimulate strategic alliances. Some are largely horizontal R\&D collaborations attacking problems of mutual interest across an entire industry. Most involve complex R\&D and commercialization collaboration across the supply chain. For example, in the area of data storage, one project is using a "virtual corporation" approach to develop and integrate multiple technologies--spanning laser optoelectronics, media materials chemistry, lens optics, motors and mechanisms, and software algorithms--needed for affordable mass data storage using optical tape. The joint venture participants (Terabank Systems, Polaroid, Science Applications International, Energy Conversion Devices, Xerox, and Motorola, with technical assistance from University of Arizona and Carnegie-Mellon University) are developing the individual component technologies. Several of the companies plan to form a new company (outside the ATP project) to commercialize the resulting low-cost tape library storage product capable of holding many hundreds of gigabytes of data. At the same time, the ATP-funded joint venture members are making plans to take advantage of the new technical capabilities in their existing, distinctly different product areas.

Many other strategic alliances have been formed outside the ATP research project to commercialize ATP-funded technologies. Following announcement of the ATP award and capitalizing on technical accomplishments that occurred early in their projects, a number of ATP-funded small companies have formed one or more commercialization partnerships. Although information concerning negotiations 
with potential commercialization partners, and the resulting alliances, is provided to ATP on a confidential basis, articles published by the industry and trade press sometimes provide public substantiation. Public sources confirm that partnering between ATP-funded small businesses developing DNA diagnostics technologies and pharmaceutical and medical instrumentation companies has been particularly active. Among the publicized alliances, GeneTrace (a 2-person start-up when it received an ATP award in the 1994 Tools for DNA Diagnostics Focused Program competition) has negotiated a licensing agreement with Incyte Pharmaceuticals which will generate cash payments in exchange for gene sequencing services utilizing the unprecedented speed of GeneTrace's time-of-flight (TOF) mass spectrometry technology. A key to this and future GeneTrace alliances is the coupling and synergy between their TOF mass spectrometry and proprietary DNA sequencing and sizing reactions controlled by pharmaceutical companies (Sedlak, 1996, p. 23). Affymetrix, also a 1994 award recipient in the Tools for DNA Diagnostics Focused Program competition, has recently entered into agreements with OncorMed to collaborate in development of clinical validation of genetic testing services utilizing their GeneChip ${ }^{\mathrm{TM}}$ for analysis of genes associated with cancer. Under a separate distribution and instrumentation alliance between Affymetrix and Hewlett-Packard, Hewlett-Packard is developing and supplying a next-generation scanner to read the GeneChip ${ }^{\text {TM }}$ (Regalado, 1996, p. 22). Affymetrix has other collaborations with Genetics Institute, Roche Molecular Systems, Incyte Pharmaceuticals, and Glaxo Wellcome (Regalado, 1996, p. 18). All of these partnerships are outside the ATP projects, but they occurred relatively early in the R\&D phase as a means of accelerating commercialization of the ATP-funded technology and raising capital for continuing R\&D.

Table 3 summarizes strategic alliance activity focused on commercialization of technologies funded by the ATP during 1993 to 1995. The data reveal that a substantial amount of negotiation and discussion activity is underway. Seventy-six alliances had been formed by December 31, 1996: 27 with suppliers; 24 with customers; 17 for joint production; and 8 with distributors. Fifteen license agreements had been signed by that time.

\section{Table 3. Strategic Alliances and Licensing Agreements for Commercialization}

\begin{tabular}{|l|c|c|c|}
\cline { 2 - 4 } \multicolumn{1}{c|}{} & $\begin{array}{c}\text { Number of } \\
\text { Projects }\end{array}$ & $\begin{array}{c}\text { Number of } \\
\text { Companies }\end{array}$ & $\begin{array}{c}\text { Number of } \\
\text { Applications }\end{array}$ \\
\hline $\begin{array}{l}\text { Negotiations/discussions held with } \\
\text { potential strategic partners }\end{array}$ & 69 & 77 & 114 \\
\hline Alliances formed with suppliers & 24 & 27 & 34 \\
Alliances formed with customers & 24 & 24 & 30 \\
Alliances formed for joint production & 16 & 17 & 21 \\
Alliances formed with distributors & 8 & 8 & 9 \\
\hline \hline \multicolumn{1}{c|}{ Total alliances formed } & 72 & $76^{*}$ & 94 \\
\hline \hline Negotiations/discussions held with & 32 & 32 & 47 \\
potential licensing partners & 15 & 15 & 19 \\
\hline License agreements signed & & & \\
\hline
\end{tabular}

Note: "Companies reporting more than one type of alliance are included twice.

Source: Business Progress Reports for 778 applications being pursued by 375 companies in 207 ATP projects funded 1993-1995 


\section{IMPACT ON INDUSTRY R\&D}

\section{Stimulation of Private Sector Investment and Leveraging of Other Investment}

More than one-third of the organizations reporting believe there would have been no project at all without ATP; i.e., their combined cost-share commitment of $\$ 100$ million reflects an investment that they say would not have occurred at all without the ATP award. An additional 38 percent report they increased their investment in the ATP-funded technology area as a result of ATP funding, beyond what it otherwise would have been, by more than $\$ 100$ million in the aggregate. (See Figure 18.)

According to the responses from the two groups of organizations combined, ATP has stimulated industry to invest more than $\$ 200$ million in internal company funds beyond what industry would have invested without the ATP awards. The increased industry investment represents an estimated 59 percent increase over what industry would have invested without ATP funding. The increased level of funding from industry and ATP sources has helped to accelerate the R\&D for ATP-funded projects and thereby helped the companies enter the market within the critical windows of opportunity. (See Chapter 2.)

\section{Figure 18. Stimulation of Industry R\&D Investment}

As a result of the ATP award, industry R\&D investment in the ATP-funded technology area has:

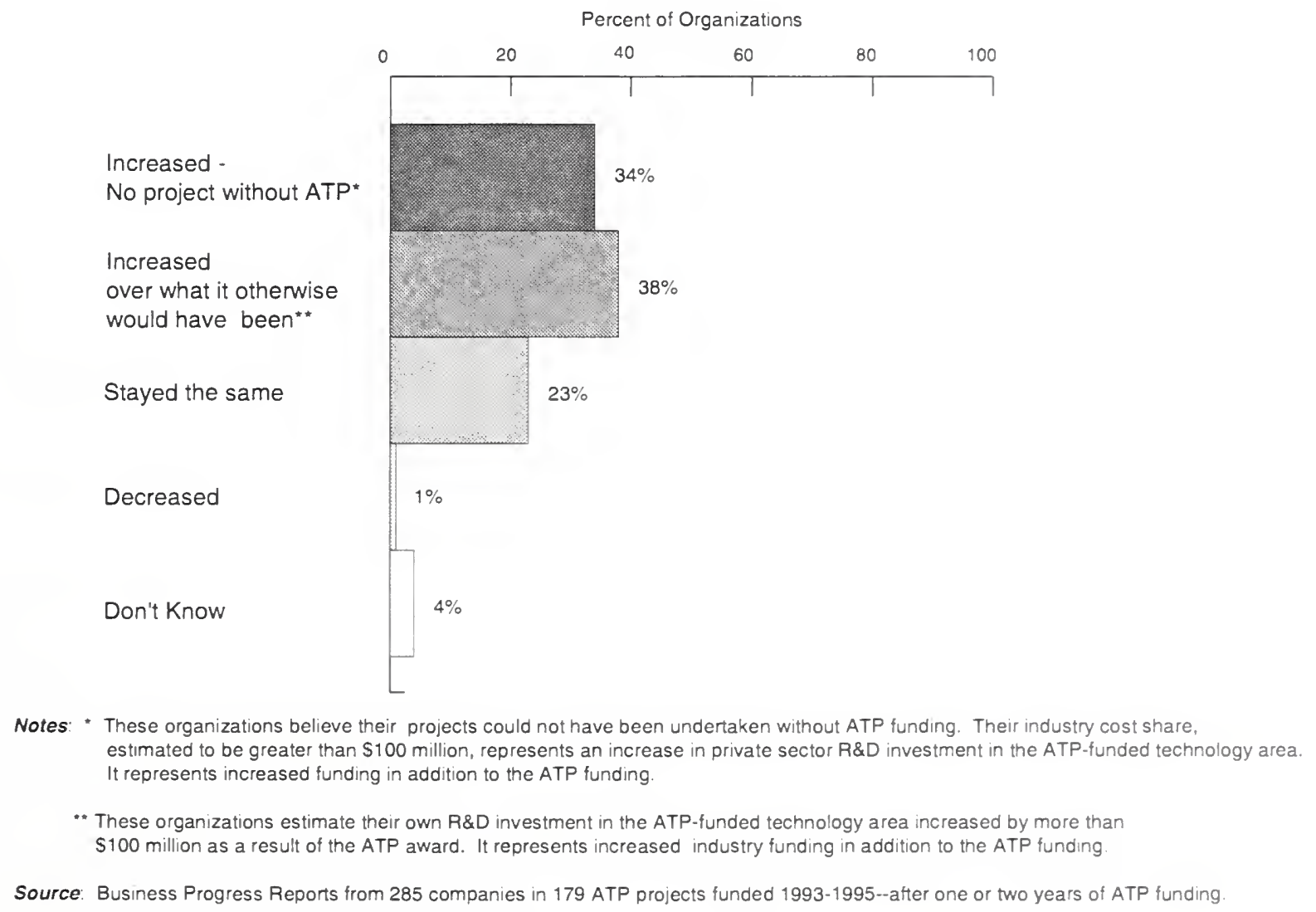


As shown in Figure 19, 70 percent of the organizations indicated that they had increased the R\&D scope, and 70 percent that they were more willing to accept technical risk as a result of ATP funding. Scope expansion and technical risk are usually highly correlated, as scope expansion gives rise to increased challenge. Fifty-seven percent reported that ATP funding had increased their interest in long-term research. From the combination of these two sets of data, it appears that ATP funding has stimulated pursuit of higher risk, longer-term, more ambitious R\&D projects than would have been undertaken without ATP funding.

Figure 19. Change in the Nature of Industry R\&D

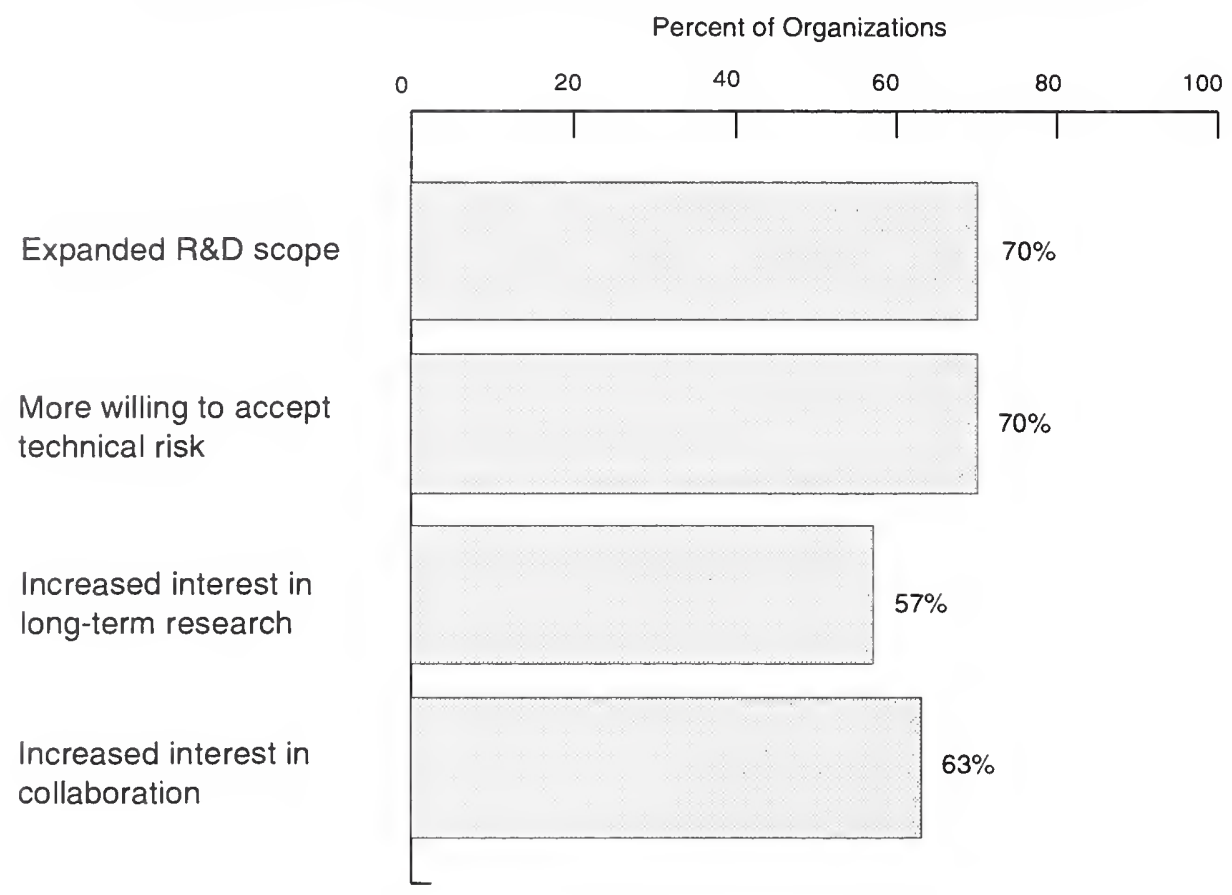

Source: Business Progress Reports from 285 organizations in 179 ATP projects after one or two years of ATP funding.

\section{Increased Credibility}

Ninety-two percent of organizations that have completed one-to-two years of funding cite increased credibility as a result of the ATP award, documenting that the ATP award has a "halo effect" on organizations and technologies receiving awards, apart from the award's monetary value. The most frequently cited "halo effect" was by researchers with "upper" management in their own organizations. As shown in Figure 20, respondents from 83 percent of all the organizations reported increased credibility with management; 73 percent indicated improved credibility with customers; 58 percent with suppliers; and 43 percent believed the ATP award had a "halo effect" with investors.

The "halo effect" may be expected to be of particular benefit to ATP-funded small businesses, particularly start-ups, which have little if any market presence and very limited financial resources at the time of the ATP award. A comparison of results for the small business group of companies alone with the entire group shows that the "halo effect" with outside firms and investors was indeed stronger for small businesses than for the group as a whole. As shown in Figure 21, 82 percent of small businesses experienced increased credibility with customers (compared with 73 percent for the group as a whole); sixty-eight percent with suppliers (compared with 58 percent for 
Figure 20. Increased Credibility

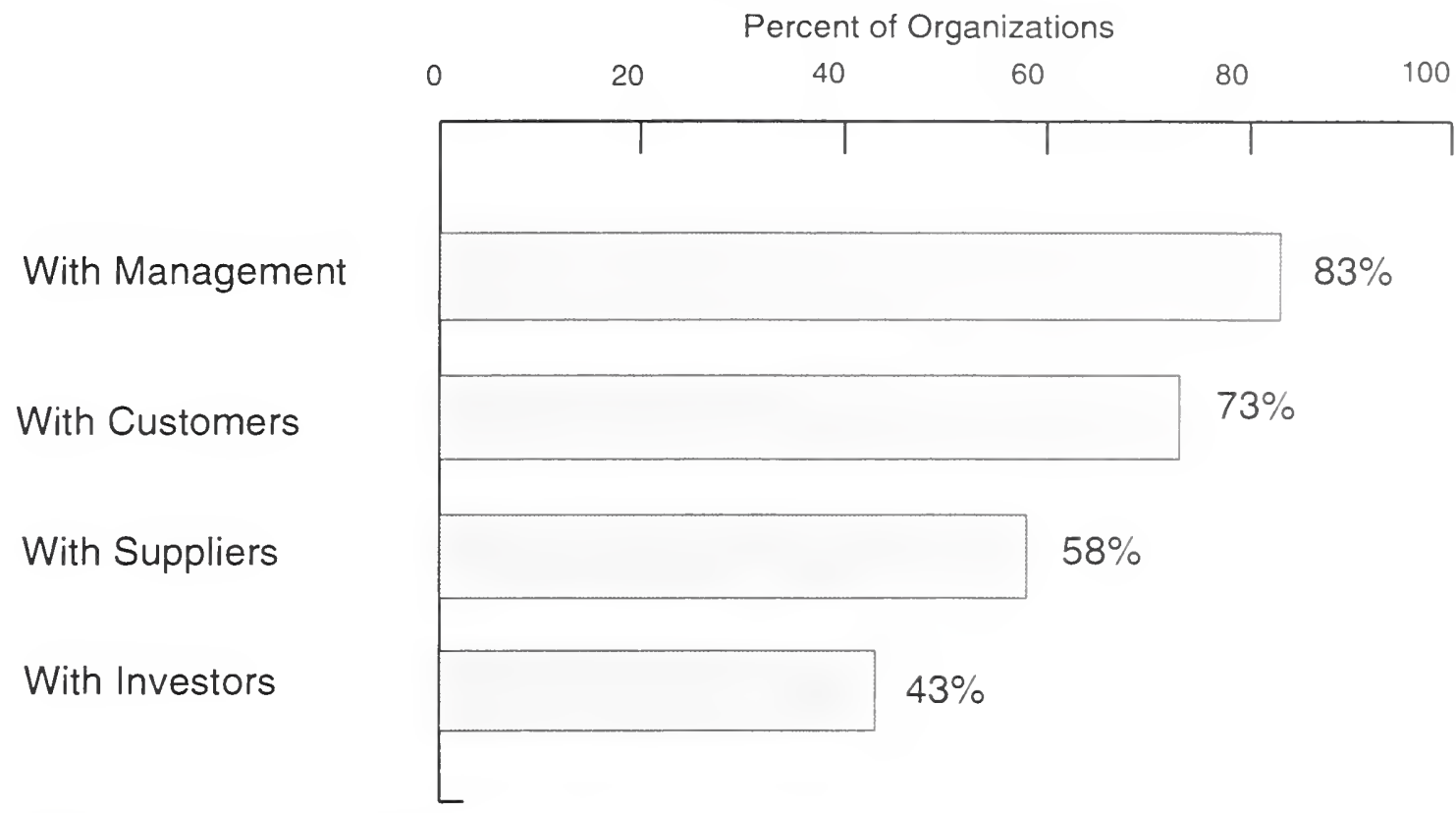

Note: Ninety-two percent of organizations reported increased credibility with at least one of these parties.

Source: Business Progress Reports from 285 organizations in 179 ATP projects funded 1993-1995 -after one or two years of ATP funding.

the group as a whole); and 75 percent with investors (compared with 43 percent for the group as a whole). Some anecdotal examples of "halo effects" related to joint venture and other ATP-stimulated collaborations are included in Chapter 4.

Figure 21. Increased Credibility -- Small Businesses

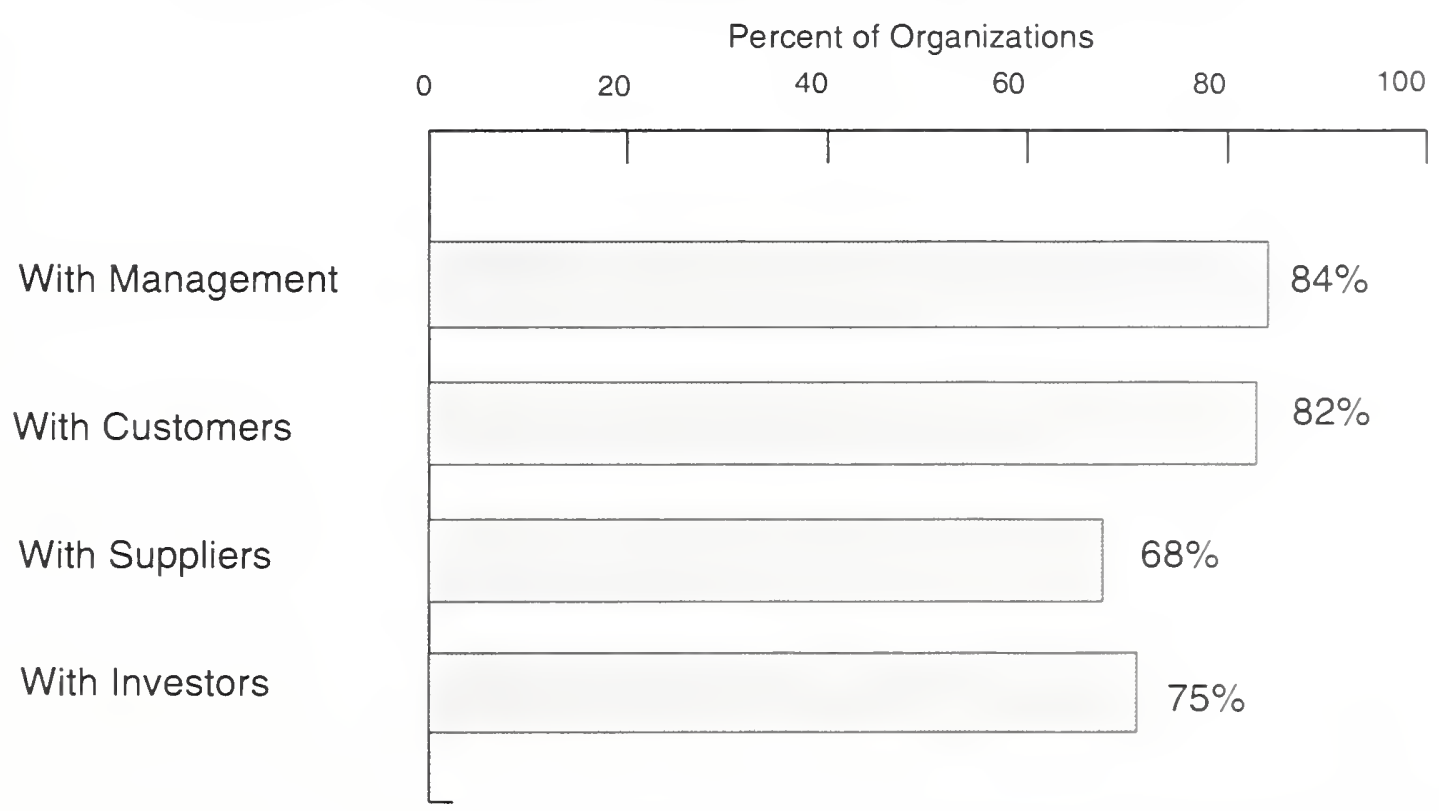

Note: Ninety-five percent of small businesses reported increased credibility with at least one of these parties.

Source: Business Progress Reports from 112 organizations in 95 ATP projects funded 1993-1995 -after one or two years of ATP funding. 
A significant number of organizations have attracted new sources of capital following announcement of their ATP award. The new funding has gone to support the ATP-funded research area or related commercialization efforts. Of the 285 organizations reporting after one-to-two years of ATP funding, 65 (23 percent) had received new funding from external sources, amounting to more than $\$ 150$ million, to pursue their technology development and commercialization activities.

As shown in Figure 22, more than 60 percent of the additional capital attracted was from owner/angel/friends capital contributions or from other/corporate partners. Although by far the preponderance of funding came from private sources, a significant number of organizations reported receiving additional federal (non-ATP) or state/local funding.

In general, the new federal funding appears to support R\&D in technology areas related to the ATPfunded technology but outside the scope of the ATP project; state funding appears directly to support ATP-funded research by companies, thereby leveraging ATP and private cost-share funds.

Figure 22. Attraction of Capital

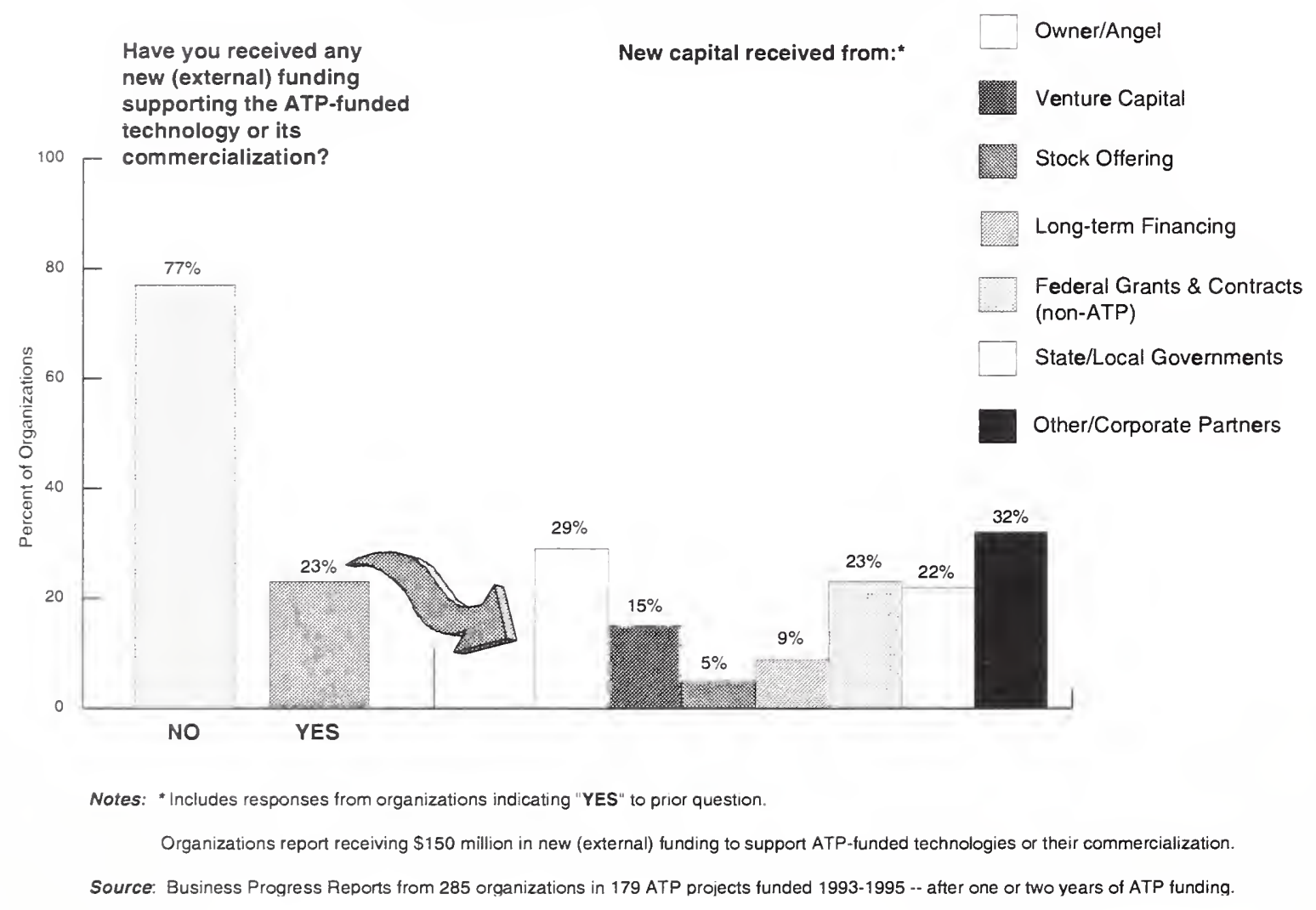




\section{EARLY COMMERCIALIZATION ACTIVITIES}

Even for applications where commercial production is several years off, successful, timely entry into the marketplace is likely to entail a significant level of effort in market analysis, capital planning and acquisition, and negotiation with potential partners over the entire R\&D phase. The trend to shorter product life cycles in many industries dictates that companies engage in market analysis and planning for manufacturing and scale-up from the earliest stages of R\&D in order to have a new product or process ready in time to compete successfully in international markets (See Laidlaw, Chapter 1, 1997). ATP monitors this activity as part of its project management and evaluation process both to assess the likelihood that successful commercialization will result and to measure the level and significance of progress. This chapter provides a statistical snapshot of commercialization progress, along with some specific examples from individual companies and projects.

\section{Commercialization Planning Activities}

As shown in Figure 23, companies in 77 percent of the projects have completed product/process definition for at least one application; companies in 56 percent of the projects have completed concept testing for at least one application; and concept testing has been conducted for one-third of all applications being pursued.

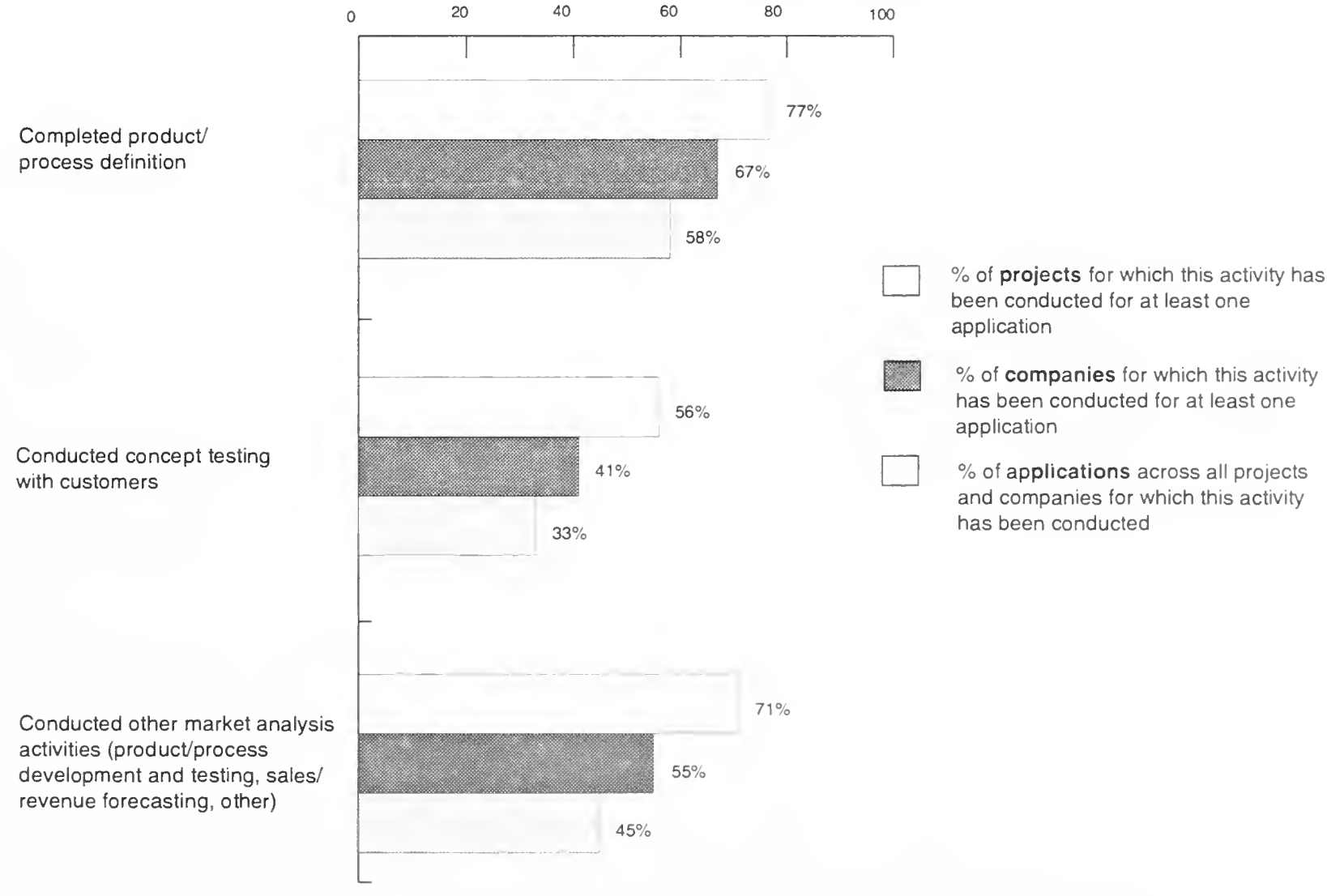

Figure 23. Market Analysis Progress

Source: Business Progress Report for 778 applications being pursued by 375 companies in 207 ATP projects funded 1993-1995.

As shown in Figure 24, 47 percent of the companies report they have increased their investment in facilities for R\&D; 19 percent have increased their investment in facilities for production; 25 percent have moved to expand production related to the ATP-funded technology. Acquisition of new 
facilities and equipment is significant to economic activity in two ways: (1) as an indication of intention to intensify commercialization activities to bring new goods and services to market and (2) as generating commercial activities in the construction and equipment sectors.

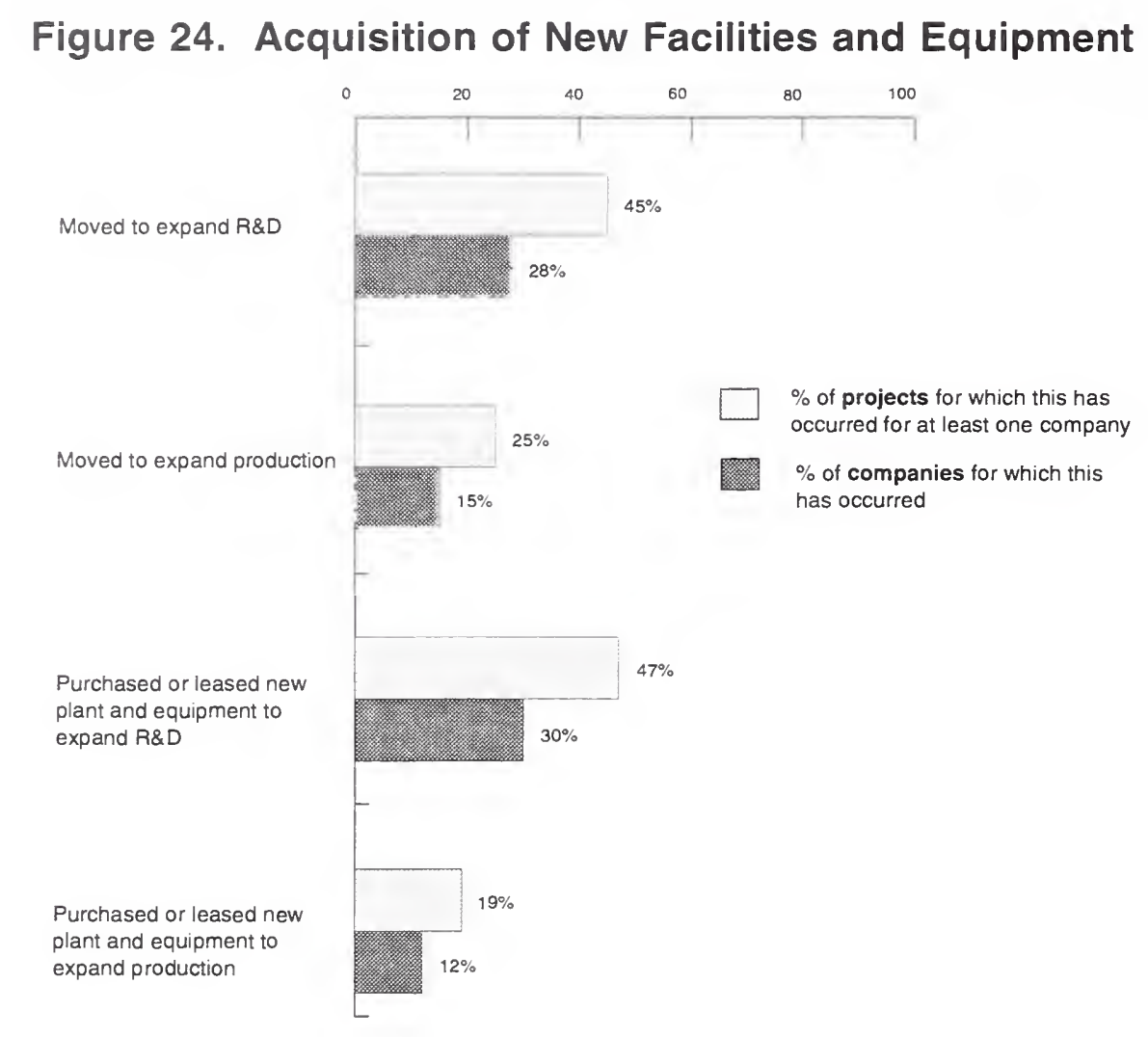

Source: Business Progress Report for 778 applications being pursued by 375 companies in 207 ATP projects funded 1993-1995.

Companies are engaged in the long-term process of planning for scale-up from preparation of smallsample prototypes to commercial production. As shown in Figure 25, 29 percent of companies, participating in 41 percent of projects, indicate they have completed a production prototype, and 35 percent of projects have completed pilot production or a commercial demonstration for at least one application of the ATP-funded technology. A small percentage of the companies (eight percent of companies from 12 percent of the projects) indicate they have actually begun production for at least one application. Production has begun for four percent of applications.

\section{Early Economic Impacts}

Although revenues are relatively small, a number of new products have been announced. The following are some examples from company press releases and product announcements.

Fragment Length Polymorphism for DNA Diagnostics. In mid 1996, Third Wave "launched its initial product from its lead product platform, Cleavase ${ }^{\mathrm{R}}$ Fragment Length Polymorphism (CFLP ${ }^{\mathrm{R}}$ ) developed as part of its ATP project, into the life science research market using two distributors," and had over $\$ 300,000$ in sales by the end of the year. This product is part of the "tool box" of faster, cheaper, and more user-friendly technologies for detecting and manipulating DNA that Third Wave is developing for molecular human diagnostics applications such as assessing tissues for transplantation suitability, forensic and paternity tests, diagnosing hereditary and infectious diseases, assessing susceptibility to specific diseases, and monitoring the response of disease pathogens to specific medical treatments. 


\section{Figure 25. Progress Towards Commercial Production}

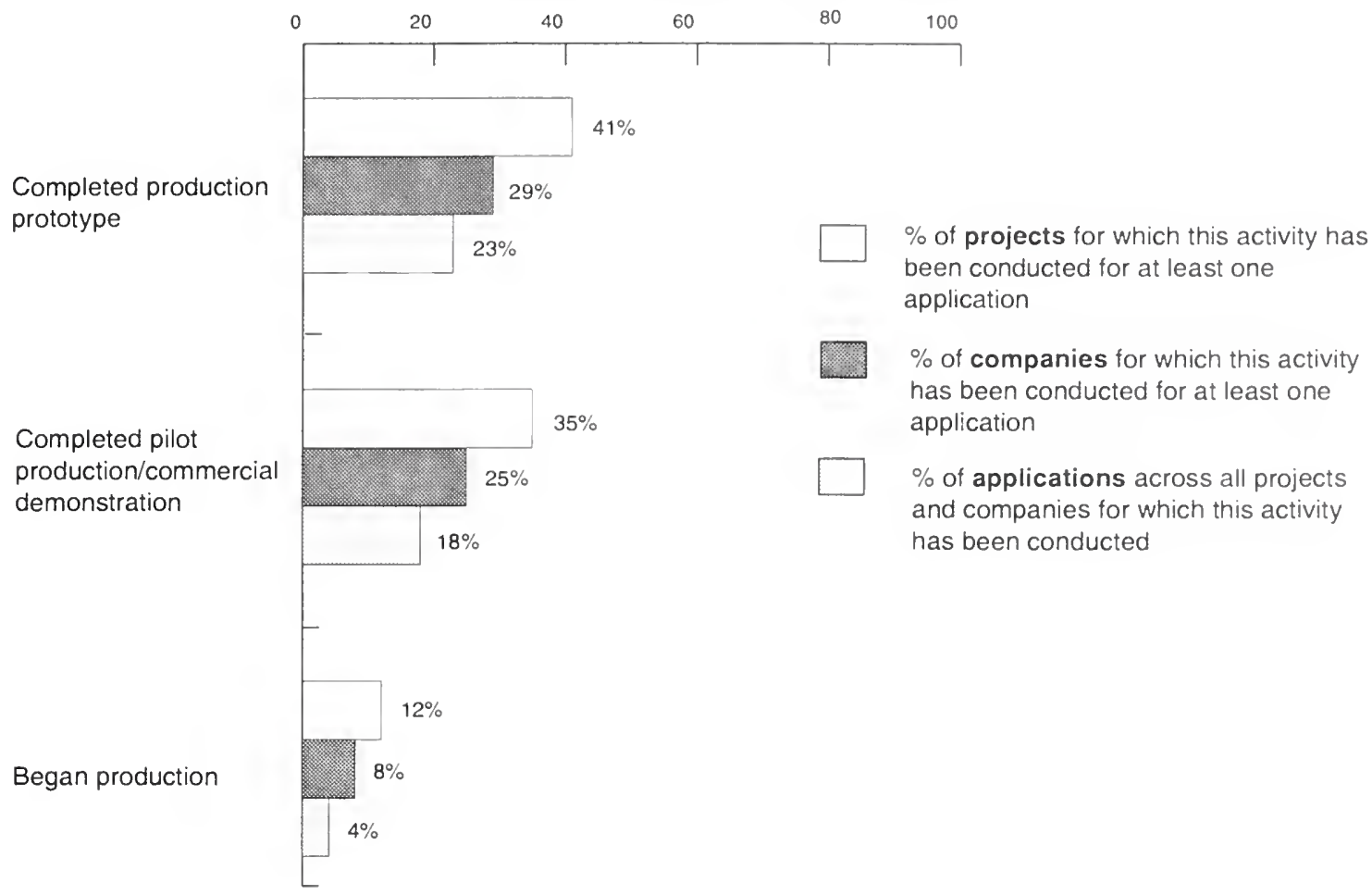

Source: Business Progress Reports for 778 applications being pursued by 375 companies in 207 ATP projects funded $1993-1995$

Process Advisor for Advanced Process Modeling and Optimization. AI Ware has launched a next generation software product called Process Advisor for advanced process modeling and optimization. "Process Advisor's modeling and optimization benefits have been proven in [these] industries: plastics, rubber, paper, paint \& coatings, electrical utilities, adhesives, sealants, petrochemicals, biotechnology, glass, alloys, specialty chemicals, food products, building materials, castings, [and] pharmaceuticals." This new tool incorporates self-teaching neural networks and genetic algorithm optimization techniques which build dynamic time series process models from information buried in current process data in order to discover and control the complex, non-linear forces driving the process. It is different from conventional diagnostics, SPC and SQC, in that "you get more insight and more accuracy when you base your analysis and decisions on accurate process models rather than just trends of individual parameters. Process models help you understand relationships and trade-offs in all their complexity, and anticipate changes."

CyberDisplay Miniature Display Device. Kopin Corporation recently introduced "the world's smallest high-performance, high resolution, full-function information display. The low cost CyberDisplay ${ }^{\mathrm{TM}}$ is light-weight, power efficient, rugged, solid state, and only 0.24 -inch diagonal in size. It enables portable communications devices and personal information products to display text, e-mail, graphics, and video from Internet, intranet and other data or video sources."

T-Vox Volume Visualization Software. HT Medical, recently named one of the fastest growing companies in Maryland, has officially released $\mathrm{T}-\mathrm{Vox}^{\mathrm{TM}}$, volume visualization software that allows researchers to interactively explore internal and external human anatomy through real-time volume rendering, in gray-scale or color.

Low-cost Manufacturing of Composite Structural Shapes. "Ebert Composites has developed an advanced process for machining pultruded composites to make complex high strength structural 
shapes. The new process substantially reduces the cost of manufacturing and enables the company to produce large load-bearing structures made of fiberglass-reinforced composites for construction and infrastructure applications. Structures like transmission poles and towers for electric power lines can be made using light-weight corrosion-resistant composites as a cost-effective replacement for steel, wood, and concrete."

Precision Gear Inspection System. "M\&M Precision Systems, with its new ability to provide the highest accuracy ever achieved on the open market, is securing orders for inspection systems for U.S. manufacturers of large precision gears formerly produced overseas."

Figure 26 provides a statistical summary of early commercial progress reported by the FY 1993-1995 projects after one-to-two years of ATP funding. Forty percent of companies, participating in 52 percent of the projects, believe they are now able to make a new or better product as a result of their ATP project; 28 percent of companies, participating in 39 percent of projects, have adopted process improvements embodying ATP-funded technology; 10 percent of companies, participating in 15 percent of projects, report revenues from sales of prototypes and early spin-off products that amounted to more than \$20 million from eight percent of applications by December 31, 1996 and licensing royalties that amounted to $\$ 445$ thousand by that date.

\section{Figure 26. Progress Towards Early Products and Processes}
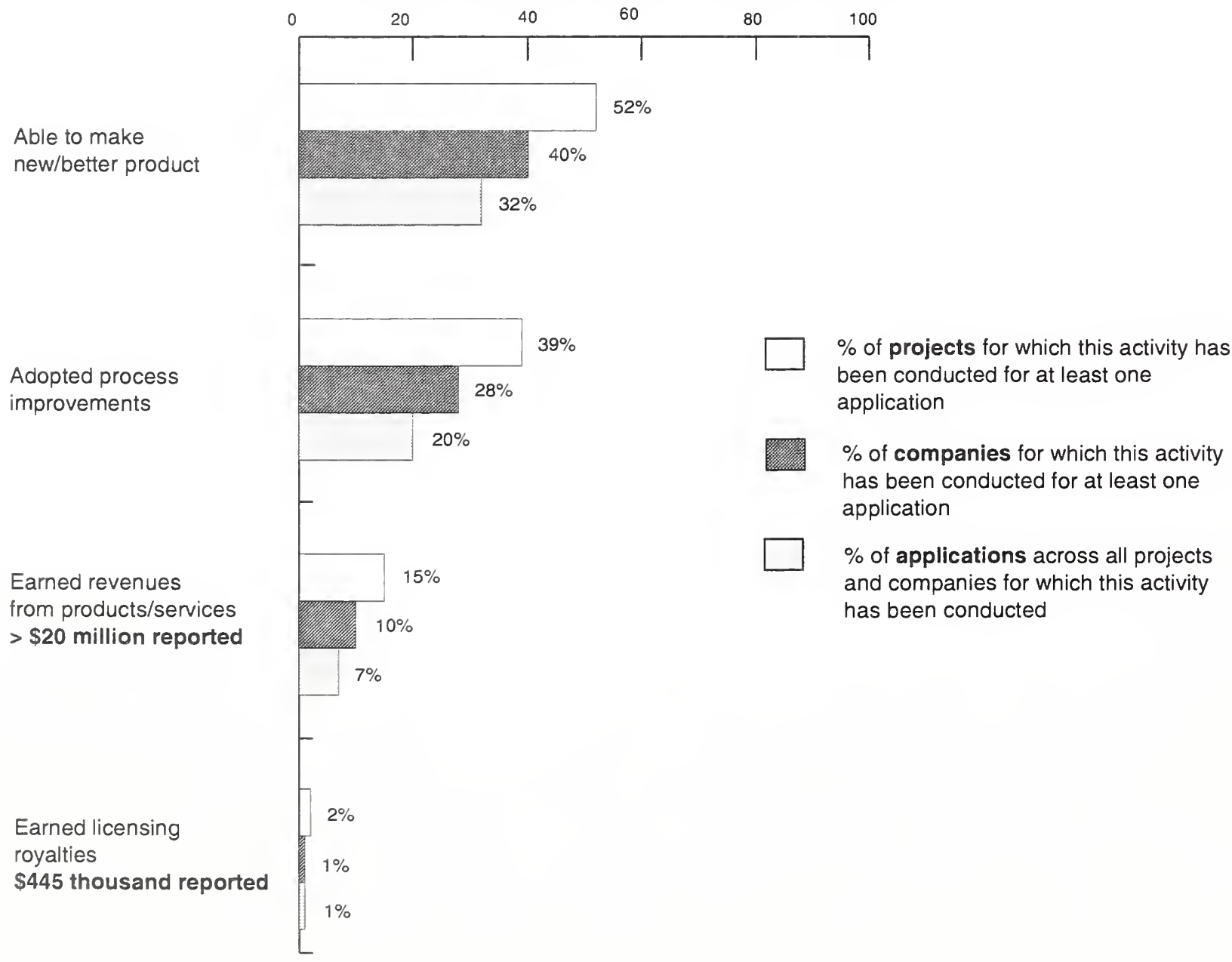

Source: Business Progress Reports for 588 applications being pursued by 268 companies in 176 ATP projects funded 1993-1995-after one or two vears of ATP funding. 


\section{Anecdotal Comments}

Anecdotal comments provided in the business reports help establish a clearer perspective for the commercialization progress reported above at relatively early stages of the R\&D.

\section{Ability to make new and/or better products}

Many of the 40 percent who report an ability to make new and/or better products are not yet ready to start commercial production. Market launch may be some years off; however, key technical barriers to commercialization have been overcome.

"We are able to make ....drills with life expectancy 10-20X."

"We can now make good quality, repeatable automotive lighting fixture parts. The performance is good, and samples have gone past the prototyping stage, and are now in the designed-in stage of development."

"Five-inch diagonal proof of concept display built."

"Developed new, improved, lower cost product."

"We have taken an observation made just prior to ...ATP proposal... and transformed it into a revolutionary product line ... that we manufacture and that are distributed by '2' of the world's largest and most respected life science companies."

"We are able to make a better metrology product for the fuel injector industry. Based on test results and direction from our strategic partner..., we have reduced the amount of residual instrument error.... Work continues ... to improve its thermal stability. Further, we have achieved better accuracy while implementing phase diffractive optics."

"Higher density of the part was achieved. Extended the range of usable materials. Enhanced magnetic properties."

"Higher power, higher reliability red devices are now possible."

\section{Prototyping and customer testing}

"We are currently conducting field molding trials at five different potential customers. A wide variety of specialty electrical parts are being prototyped with significant positive response."

"Our first prototype fabrication allows us to make a manufacturing cost estimate based on experience and known processes. It predicts [our product] will be at least $2 X$ less expensive than other optical technologies and competitive with comparably performing copper interconnections."

"We have gone from concept to a dernonstrable prototype and will soon have scalability and performance data to match." 
"An early prototypical implementation has been built and demonstrated, with additional work planned for the second and final year of performance leading to a 'beta' release, appropriate for technology transfer to the product development side of the company."

Implementation of new or improved production processes

The 28 percent of companies reporting implementation of new or improved production processes embodying some part of ATP-funded technology (Figure 26), in experimental or actual production lines, further described early effects on production efficiency, costs, and/or product quality.

"Implemented continuous cable assembly fabrication technique, which should result in lower cost cable assemblies."

"Laser lithography brought fully on line as viable in-house process."

"... We have made great strides in improving the quality and repeatability of our manufacturing processes."

"These improvements include: 1) Getting our cleanroom cleaner, and identifying the sources of contaminants, early in the 'master' preparation process. 2) switching to a new method of making ...masters, from which replicas are later made....3) [installing] a new UV curing system, which allows much more control over the amount and timing of UV exposure... an important breakthrough, because it gives us much more control over dispersion angles, performance, and has reduced rejects."

"Improved raw materials screening, improved process control and improved measures to assure product consistency."

"We have reduced necessary on-site time by approximately one third and developed much better reporting systems."

"1) Improved glue seal dispensing method; 2) new production method reduces labor component, reduces cost, and increases total capacity."

"We established a new way of casting ... with the proper coefficient of expansion as well as other parameters such as 1) size, 2) thickness. This achievement is unique as only one in the industry has been able to achieve same."

"ATP has enabled [us] to begin building an interoperability lab for testing interoperability between different video and network devices from multiple vendors. This interoperability lab will enable us to build better products and solve interoperability issues before products reach the field."

"We have developed engineering scale automated cleaning-in-place and testing systems for membrane separations and are developing new applications." 


\section{Installation of demonstration units}

A number of companies have reported installation of prototype demonstration units with potential customers and users:

Integrated Surgical Systems (ISS) has installed their new software for controlling revision hip replacement surgery at two hospitals in Germany (where the regulatory approval process is shorter than in the U.S.). According to the company, the software "is fully functional and requires no explicit ISS intervention or supervision although it does require experienced, well-trained users."

Wizdom, a member of the Health Informatics Initiative, reports it has launched two healthcare pilot sites for testing and demonstrating project tools which will add validity and credibility to future commercialization efforts. The work will be done remotely using ATP-funded tools. Through a strategic alliance with other consortium members, Wizdom anticipates a joint-product demonstration soon.

Lumina Decision Systems announced the "first interactive, medical decision support application" available over the World Wide Web. The company "completed a test of its Decision Engine Object Library. The test included a Web based, interactive application to help expectant parents consider the risks and benefits of amniocentesis." 


\section{INTELLECTUAL PROPERTY PROTECTION AND DIFFUSION OF TECHNOLOGY}

\section{Protection and Disclosure of Intellectual Property}

Protection of intellectual property through formal patent and copyright mechanisms provides legal protection against use of an invention without permission or compensation. The patent or copyright thus converts the intellectual property into a potential income-earning asset and, for many applications and industries, is critical to the ability of the innovator to commercialize a new technology. In return for patent protection, however, the innovator must agree to public disclosure of the patented invention and (to a lesser extent) copyrighted material. Disclosure provides a means of attracting commercial partners interested in licensing or joint production opportunities, and thus reinforces the private commercial purposes of the intellectual property protection; however, it also is a mechanism for unintended knowledge spillovers--to competitors or others who may be in a position to exploit the knowledge without paying for it. (See Jaffe, 1996.)

Both aspects of patent and copyright protection are important to achieving maximum commercialization, diffusion, and social benefit of the ATP-funded technologies: Patent and copyright protection afford ATP-funded firms the necessary incentives; i.e., protection of title to their innovations, to undertake costs of product development and marketing needed to launch a commercial product, and may help open new licensing and other partnering opportunities. The wider the commercial use of the technology and the greater the spread of information concerning resulting products and processes, the greater the opportunity for market spillovers to users and customers and for knowledge spillovers to others in a position to make use of the knowledge for their purposes.

Most companies report plans to protect intellectual property created in their ATP project, whether they plan to produce in-house or to license the technology to others. As shown in Figure 27, patent protection, copyright protection, and maintenance of trade secrets are listed respectively as primary strategies by 61 percent, 27 percent, and 51 percent of companies. A more detailed analysis (not shown) indicates that ten percent of the companies listed all three strategies as primary; 15 percent listed both patents and copyrights as primary; and 25 percent listed both patents and trade secrets as primary strategies. Thus some combination of legal protection and secrecy/first mover advantages appears to be a common strategy. Of course, to the extent that companies patent their technology they cannot expect to maintain the same knowledge secret; but companies may identify some aspects of their technology best protected by patent and other aspects best protected by secret, and thus combine the two strategies.

Organizations receiving ATP awards in the FY 1993-1995 competitions report that the ATP-funded technologies build on, and intellectual property rights are protected by, nearly 2,000 pre-existing patents. Companies seeking title to new intellectual property created with ATP funding have reported to NIST 105 new patents filed and 7 copyrights filed; and 11 patents have been issued. Often initial patents predate the ATP project, and the ATP project focuses on bringing the technology beyond a rough concept. 
Figure 27. Intellectual Property Strategies Planned

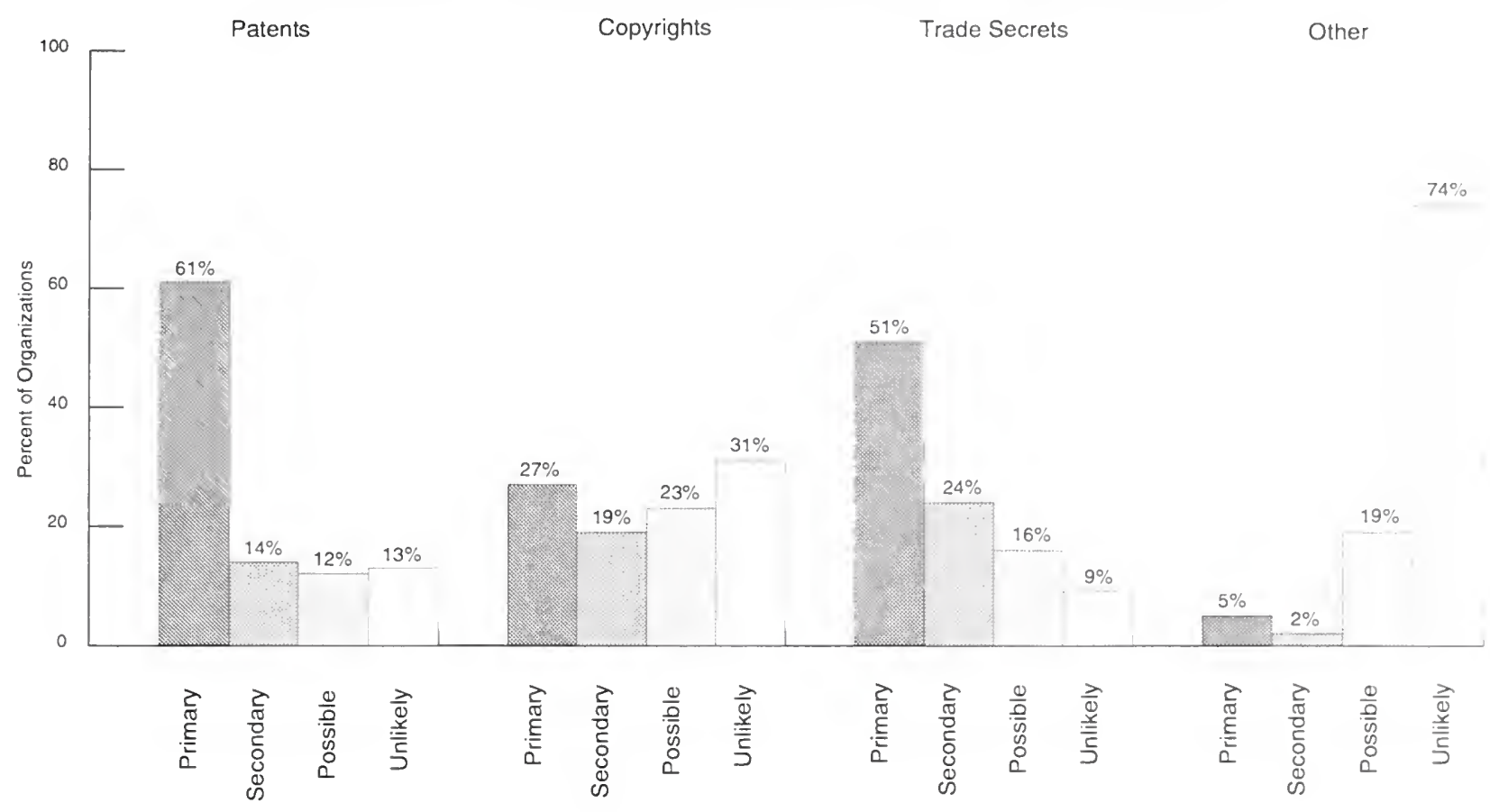

Source: Business Progress Reports from 480 organizations funded 1993-1995.

\section{Dissemination of Non-Proprietary Information}

Published papers, conference participation, news articles, press releases, and internet sites provide additional dissemination of information about ATP-funded technologies. Although some companies are more active than others in dissemination, many are very active in publishing papers, issuing press releases, and making public presentations concerning their R\&D activities. Universities and other research organizations, with permission from the for-profit companies holding title to ATP-funded intellectual property, have also been active in disseminating non-proprietary information about their ATP-funded technology development. Table 4 provides a summary of the activity through December 1996 in published professional journal articles and conference papers alone.

Table 4. Dissemination of Non-proprietary Information from ATP-funded Projects

\begin{tabular}{|l|c|c|}
\cline { 2 - 3 } \multicolumn{1}{c|}{} & Papers in Professional Journals & $\begin{array}{c}\text { Papers Presented at } \\
\text { Conferences }\end{array}$ \\
\hline Total Number of Papers & 131 & 372 \\
$\begin{array}{l}\text { Number of Organizations } \\
\text { Reporting Papers }\end{array}$ & 54 & 154 \\
$\begin{array}{l}\text { Number of Projects Reporting } \\
\text { Papers }\end{array}$ & 47 & 110 \\
\hline
\end{tabular}

Note: Across the 208 projects reporting, an average of 0.6 professional journal articles were published and 1.8 conferences papers presented per project. Thirty-six percent of the projects produced at least one professional journal article; fifty-three percent of the projects produced at least one conference paper.

Source: Business Progress Reports from 210 ATP projects funded 1993-1995. 
According to the BRS data, more than half the projects covered in this study have produced published conference papers, and approximately one-fourth have produced published articles in professional journals. On average, about 1.8 conference papers have been presented and 0.6 professional journal articles published per project. 


\section{RELATIONSHIP TO PRIOR WORK AND CONCLUSIONS}

Although nearly all the ATP projects funded 1993-1995 were still in the R\&D phase as of December 31,1996 , an analysis of the business reports from 179 projects after one-to-two years of funding suggests that the necessary conditions for achieving national economic benefits are evolving, although not necessarily at the same rate or to the same extent for all projects.

\section{Relationship to Prior Work}

Findings from the BRS data are largely consistent with the findings of two third-party surveys of projects not in the BRS. Silber \& Associates surveyed projects funded from 1990 through 1992 after approximately two-to-three years of funding (Silber \& Associates, 1996). Solomon Associates surveyed ATP's first competition awardees after just one year of funding (Solomon, 1993). The BRS captures much greater detail than the third-party telephone surveys, explicitly covering the evolution of a myriad of applications. And, of course, the BRS captures the voices of awardees directly without a third party intervening. Although specific summary statistics differ somewhat, analyses of BRS data generally confirm earlier survey results that ATP awards are "enabling [industry] to afford and engage in high risk research," "stimulating collaboration and formation of strategic alliances," "shortening the R\&D cycle," "helping attract additional funding," and "creating new business opportunities," among the many other effects reported by those earlier studies. Results of the current study are also consistent with and confirmatory of preliminary results given in a recently published conference paper which analyzed data for ATP projects funded in 1993-1995, but with only the 1993 projects (41 companies reporting) having completed at least one year of ATP funding (Powell, 1997).

\section{Summary of Findings}

Opportunities for economic spillovers from the portfolio of projects in the BRS appear strong, and for the most part consistent with the original peer-review proposal assessments. Project participants have identified more than 1,000 applications of the technologies under development and provided commercialization plans for nearly 800 applications spanning the spectrum of SIC industries. Most applications involve new products with significant performance improvements over existing/defender technologies, offering dramatic possibilities for productivity improvements. Many are "new-to-theworld-products" aimed at brand new markets. Most companies seek to address stages of production relatively early in the production chain, for example, materials processing or component manufacture, creating maximum opportunity for intermediate producers/customers at multiple later stages, and even in multiple application areas, to experience market spillovers.

Opportunities for additional economic spillovers through technology diffusion are being enhanced by patent and licensing activity and dissemination of non-proprietary information. ATP projects build on more than 2,000 existing patents, and more than 60 percent of companies plan to patent or copyright their ATP-funded technologies as a major intellectual property strategy. More than one hundred patents have been filed, and the first patents have been issued. Licensing to others is a primary or secondary strategy for commercializing 43 percent of the planned applications. Conference activity and publication of papers has been very vigorous, with an average of nearly two conference papers presented and 0.6 professional journal articles published per project.

Consistent with ATP's mission to accelerate the creation and commercialization of advanced technologies, acceleration of the $R \& D$ process and time-to-market reduction appear to be important 
project goals, with acceleration of at least two years anticipated for 62 percent of applications. In many cases the time saved may be critical to meeting the narrow window of opportunity in fastpaced, highly competitive technology and product areas. Eighty-six percent of organizations indicate they are already ahead in their R\&D cycle as a result of ATP funding; of these, 39 percent believe they would not have started the project without ATP funding; 53 percent are one to three years ahead after just one-to-two years of ATP funding.

ATP funding appears to have stimulated increases in private sector investment in high risk R\&D. Some projects would not have been undertaken at all with ATP funding, and others received a higher level of private investment as a result of ATP funding. An estimated $\$ 200$ million of company internal funds have been invested in or committed to ATP projects beyond what industry alone would have invested in the absence of the ATP awards, an estimated 59 percent increase in industry's investment in the ATP-funded technology areas. This increased industry investment is in addition to the ATP funding and the funding industry would otherwise have invested. An additional $\$ 150$ million of new funding from other sources has been attracted to support the ATP-funded technology development and commercialization of current or future products. Most organizations further report that the ATP award has changed the nature of their R\&D program to encompass a broader scope, higher level of technical risk, and/or longer-term R\&D horizon.

The ATP appears to be meeting its legislated objectives of stimulating successful collaborations among companies and among industry, universities, and research laboratories. Seventy-eight percent of organizations, from a mix of joint venture and single-company projects, report that collaboration has helped achieve the ATP project goals. Of these: 85 percent indicated that the ATP was responsible to a moderate or great extent for the collaborations; 99 percent reported that stimulation of creative thinking was significantly or moderately enabled by collaboration; 80 percent reported that saving time and/or accelerating entry into the marketplace were significantly or moderately enabled by collaboration; and more than 75 percent reported that obtaining R\&D expertise, identifying customer needs, and/or encouraging future collaborations were significantly or moderately enabled by collaboration. Of the same group, about half indicated that project coordination and management costs were significantly or moderately affected by collaboration; however, only 20 percent reported significant delays in beginning the $\mathrm{R} \& \mathrm{D}$, and only 6 percent anticipated delays in product entry into the marketplace or other difficulties as a result of collaboration costs.

Companies report active engagement in the commercialization planning activities needed to enter the marketplace in a timely manner, once the technology is ready. Companies in 77 percent of the projects have completed product/process definition for at least one application; companies in 56 percent of the projects have completed concept testing for at least one application. Companies in 25 percent of the projects have moved to new space in order to expand production; companies in 19 percent of projects have purchased or leased new plant and equipment to expand production. Although production has begun for only four percent of applications being planned, 41 percent of projects have completed a production prototype for at least one application, and 35 percent of projects have completed pilot production or a commercial demonstration for at least one application. Alliances are being negotiated with strategic partners for commercialization, with small companies particularly focused on this activity.

Progress towards achieving revenue goals is also reported. Most expect revenue one-to-three years after the project ends, but for about one-fourth of applications, revenue is expected from spin-off activities before the end of ATP funding, and for nearly 10 percent of applications and projects revenue is not expected until four or more years after the ATP project ends. Forty percent of the 
companies, representing 52 percent of the projects, report they are now able to make a new or improved product, even though the product may not be ready for the marketplace for some time. Twenty-eight percent of companies, representing nearly 39 percent of projects, report they have adopted process improvements resulting from ATP funding. About 10 percent of companies, representing 15 percent of projects, indicate they had already earned some early revenues, amounting to more than $\$ 20$ million by December 1996, from sales of samples and prototypes and early "spinoff" products. The first licensing revenues have also been realized. The nature and timing of the first revenues appear consistent with the R\&D status of these projects and projected timeline for revenues (see Figure 13).

\section{Plans for Future Work}

The ATP plans to continue the BRS data collection for future projects and participants funded by the program. In addition to providing a large volume of data covering more projects for a longer time period, the BRS will continue to provide an evolving picture, with statistical summary metrics, of the status of ATP projects towards meeting ATP's legislated economic objectives. Besides routine data collection and maintenance, work is anticipated in a number of areas:

- Improved data quality--More analysis is needed to ensure high data quality for all responses. New strategies and procedures are being developed to test for misunderstanding of questions or inappropriate mode of response, and to obtain validation/correction in an efficient and unbiased manner.

- Additional, detailed studies using the BRS--The BRS supports detailed analysis of any project subgroup of interest, for example, a specific project type, industry sector, technology, or geographical location. The BRS database is part of the broader ATP relational database structure and can further be linked to external, establishment-level national data sources by 4-digit SIC code. Under appropriate restrictions to maintain confidentiality, the data will be used by economic researchers in studies of ATP project and program progress and impact. The BRS data can also be used in conjunction with information from diverse sources to support a variety of evaluation studies, including detailed case studies. (An overview of other ATP evaluation studies recently completed or nearing completion is provided by Ruegg, "ATP's Evaluation Plan and Progress," 1997. Guidelines for developing and selecting evaluation studies are described by Ruegg in "Guidelines for Economic Evaluation of the Advanced Technology Program," 1996).

- Extension of the BRS--Extension of this database is focusing on development of questions for post-project reports required every two years for six years following the end of the ATP award. These questions will update commercialization activity and probe in more detail for evidence of intra-industry and inter-industry diffusion of ATP-funded technologies and of benefits to users, for example, health and safety impacts, as well as longer-term economic impacts on the companies funded. This information will be invaluable in studies of economic spillovers. 


\section{REFERENCES}

Jaffe, A.B. (1996). Economic Analysis of Research Spillovers: Implications for the Advanced Technology Program. Gaithersburg, MD: National Institute of Standards and Technology.

Leifer, R. (1997). Managing Discontinuous Innovation in Established Firms: Reducing Uncertainty and Resistance. (forthcoming)

Laidlaw, F. (1997). Acceleration of Technology Development by the Advanced Technology Program: The Experience of 28 Projects Funded in 1991. Gaithersburg, MD: National Institute of Standards and Technology.

Mansfield, E. (1996). Estimating Social and Private Returns from Innovations Based on the Advanced Technology Program: Problems and Opportunities. Gaithersburg, MD: National Institute of Standards and Technology.

Mansfield, E., Rapoport, J., Wagner, S. and Beardsley, G. (1977). "Social and Private Rates of Return from Industrial Innovations." Quarterly Journal of Economics.

Powell, J. (1997). "The ATP's Business Reporting System: A Tool for Economic Evaluation." The Evolution of Firms and Industries. Helsinki, Finland: Tilastokesus Statistikcentralen Statistics Finland. Also available as a National Institute of Standards and Technology Report, 1996.

Regalado, A. (1996). "The DNA-Chip in Diagnostics." Start-Up. September 1996.

Ruegg, R. (1997). "ATP's Evaluation Plan and Progress." Paper presented at the 7th International Forum on Technology Management, and published in Conference Proceedings November 1997.

Ruegg, R. (1996). Guidelines for Economic Evaluation of the Advanced Technology Program. Gaithersburg, MD: National Institute of Standards and Technology.

Sedlak, B. (1996). "GeneTrace Systems Bets its Future in Genomics on TOF Mass Spectroscopy." Genetic Engineering News. December 1996.

Silber \& Associates (1996). Survey of Advanced Technology Program 1990-1992 Awardees: Company Opinion About the ATP and Its Early Effects. Gaithersburg, MD: National Institute of Standards and Technology.

Solomon Associates (1993). The Advanced Technology Program - An Assessment of Short-Term Impacts: First Competition Participants. Gaithersburg, MD: National Institute of Standards and Technology.

von Hippel, E. (1994). "Sticky Information and the Locus of Problem Solving: Implications for Innovation," Management Science 40, no. 4 (April). 


\section{APPENDICES}

\section{Appendix A. Plans for Diverse Applications of ATP-funded Technologies-- Information/Computer Systems}

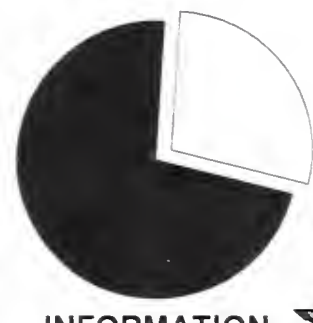

Example: ATP-funded INFORMATION/COMPUTER SYSTEMS

technologies support applications in numerous industry sectors

INFORMATION TECHNOLOGYI COMPUTER SYSTEMS $28 \%$

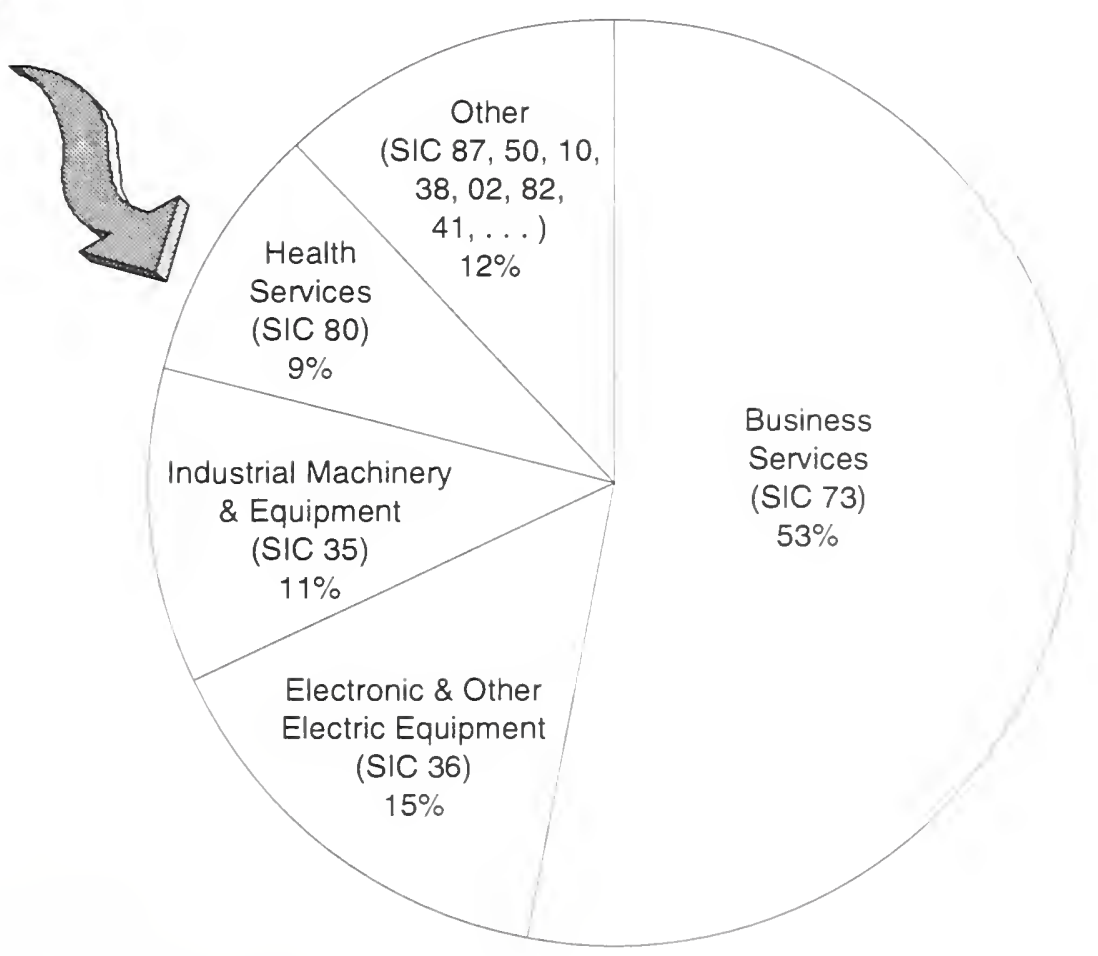

Note: "Other" SIC categories are defined in Appendix G.

Source: Business Progress Reports for 778 applications being pursued by 375 companies in 207 ATP projects funded $1993-1995$. 


\section{Appendix B. Plans for Diverse Applications of ATP-funded Technologies-- Manufacturing (Discrete)}

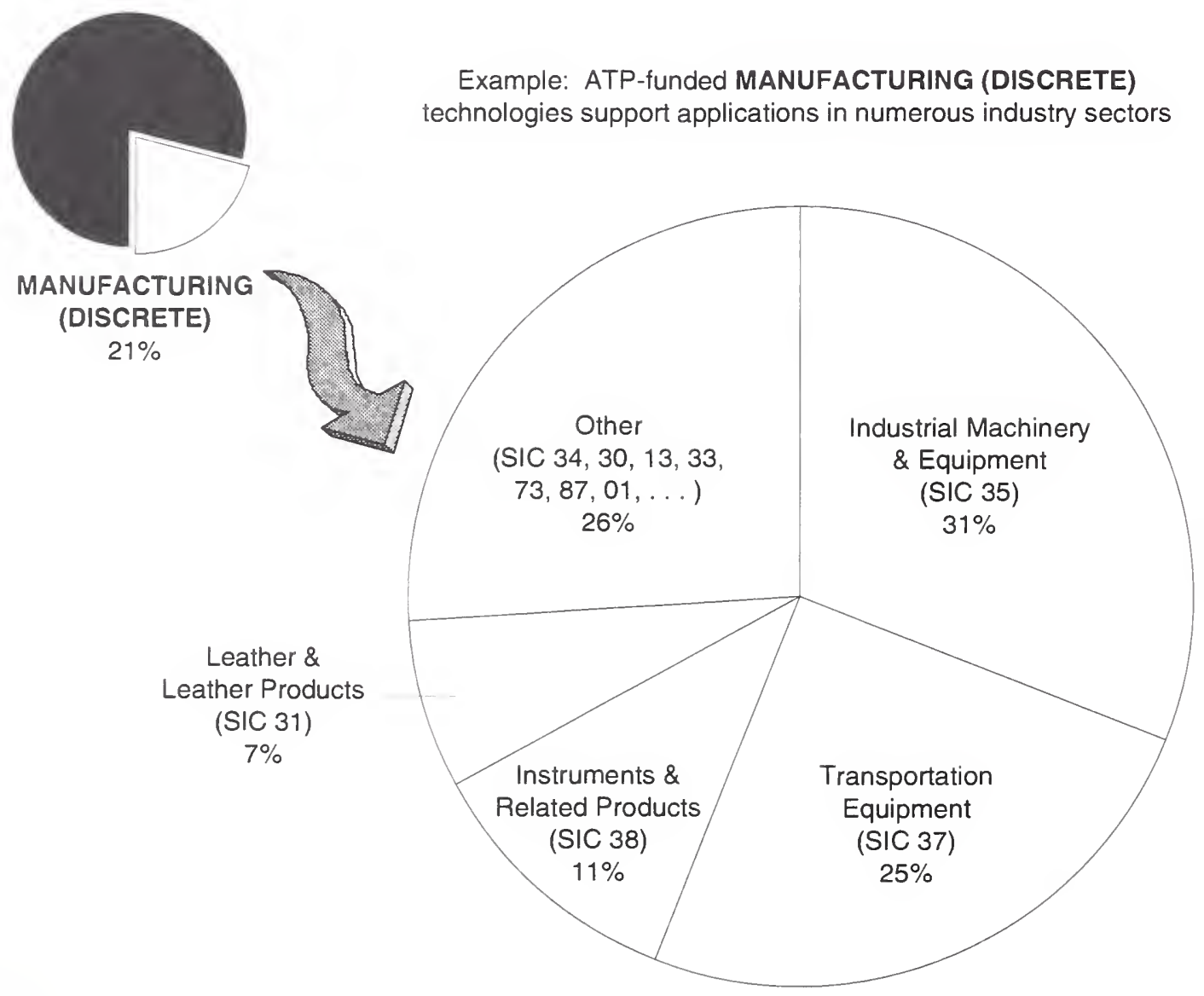

Note: "Other" SIC categories are defined in Appendix G.

Source: Business Progress Reports for 778 applications being pursued by 375 companies in 207 ATP projects funded $1993-1995$. 


\section{Appendix C. Plans for Diverse Applications of ATP-funded Technologies-- Biotechnology}

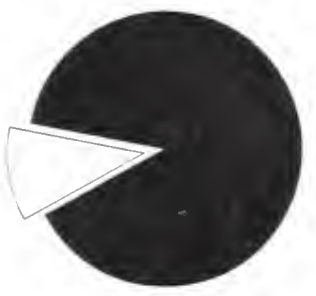

\section{Example: ATP-funded BIOTECHNOLOGY technologies support applications in numerous industry sectors}

\section{BIOTECHNOLOGY \\ $11 \%$}

\section{Engineering \&} Management Services

(SIC 87)

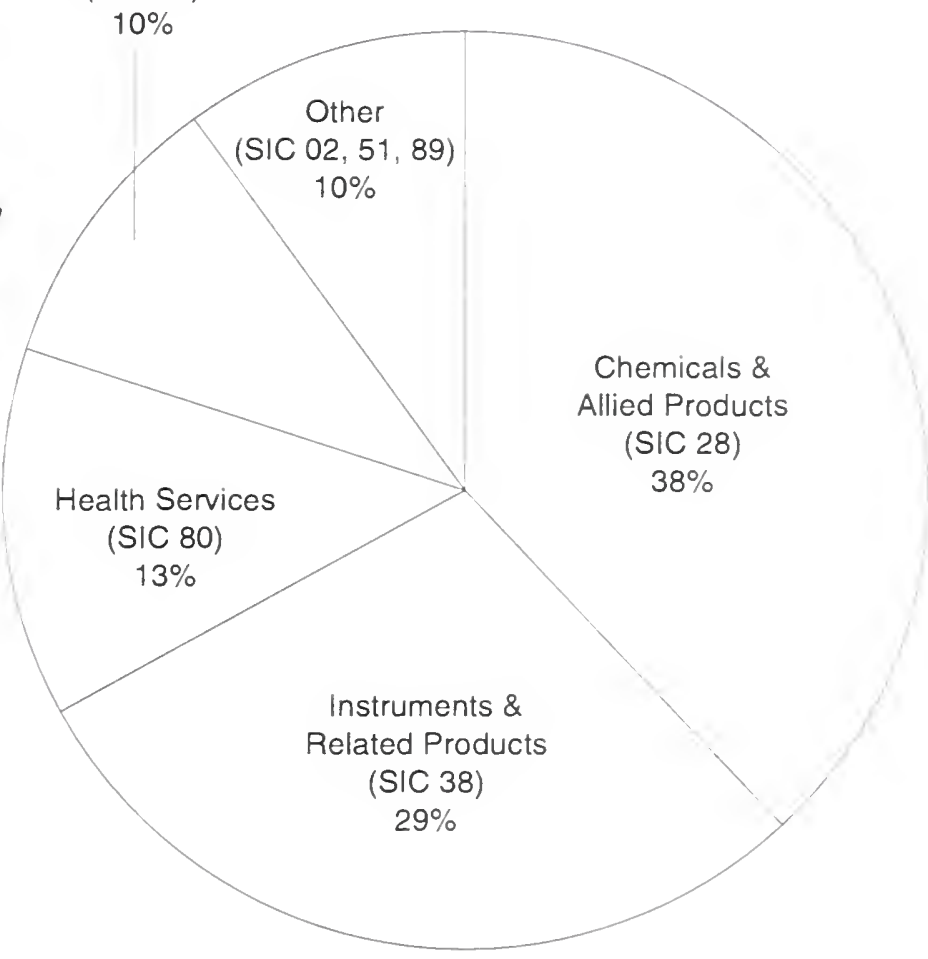

Note: "Other" SIC categories are defined in Appendix G.

Source: Business Progress Reports for 778 applications being pursued by 375 companies in 207 ATP projects funded $1993-1995$ 


\section{Appendix D. Plans for Diverse Applications of ATP-funded Technologies-- Electronics}

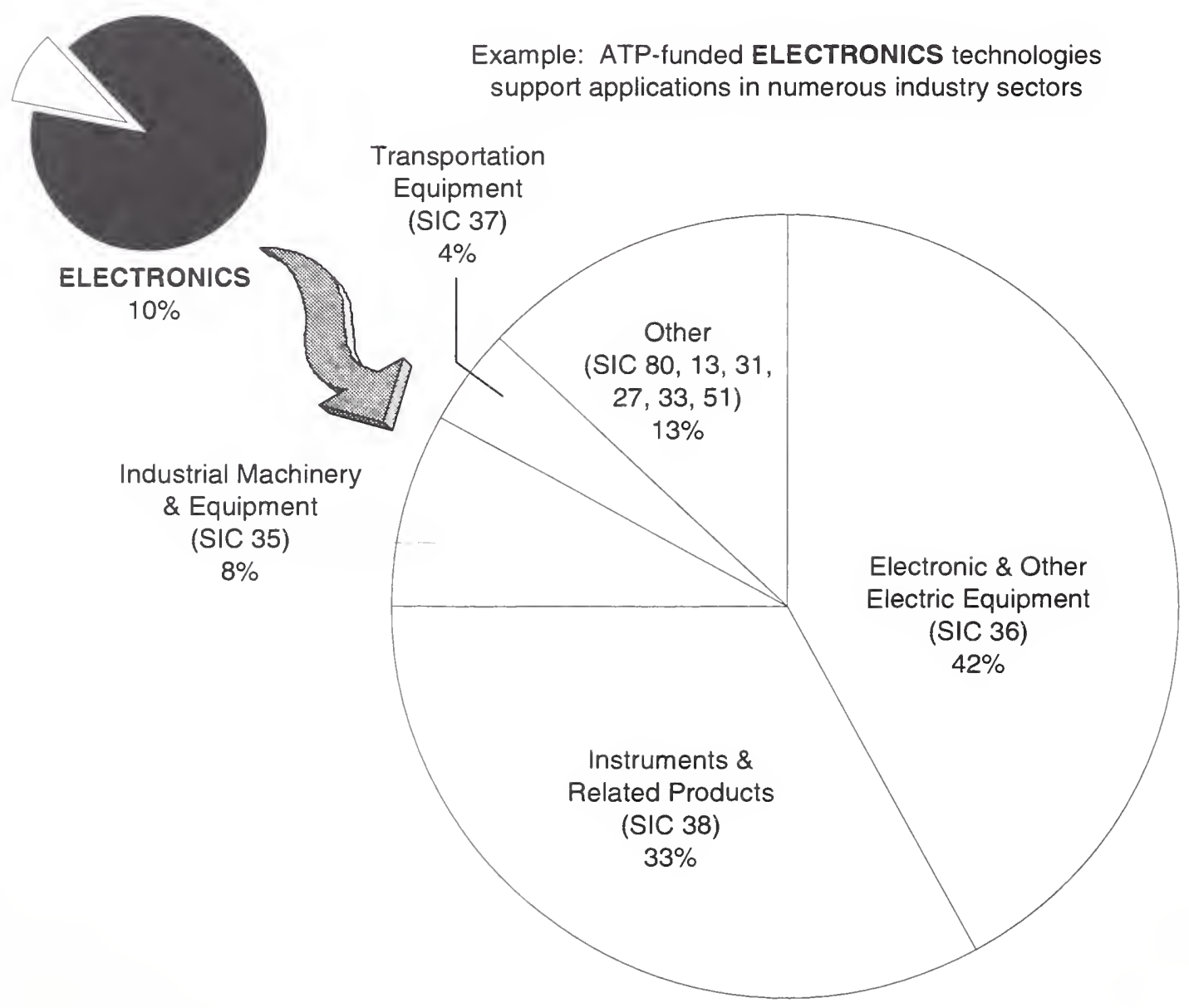

Note: "Other" SIC categories are defined in Appendix G.

Source: Business Progress Reports for 778 applications being pursued by 375 companies in 207 ATP projects funded $1993-1995$. 


\section{Appendix E. Plans for Diverse Applications of ATP-funded Technologies-- Chemicals \& Chemical Processing}

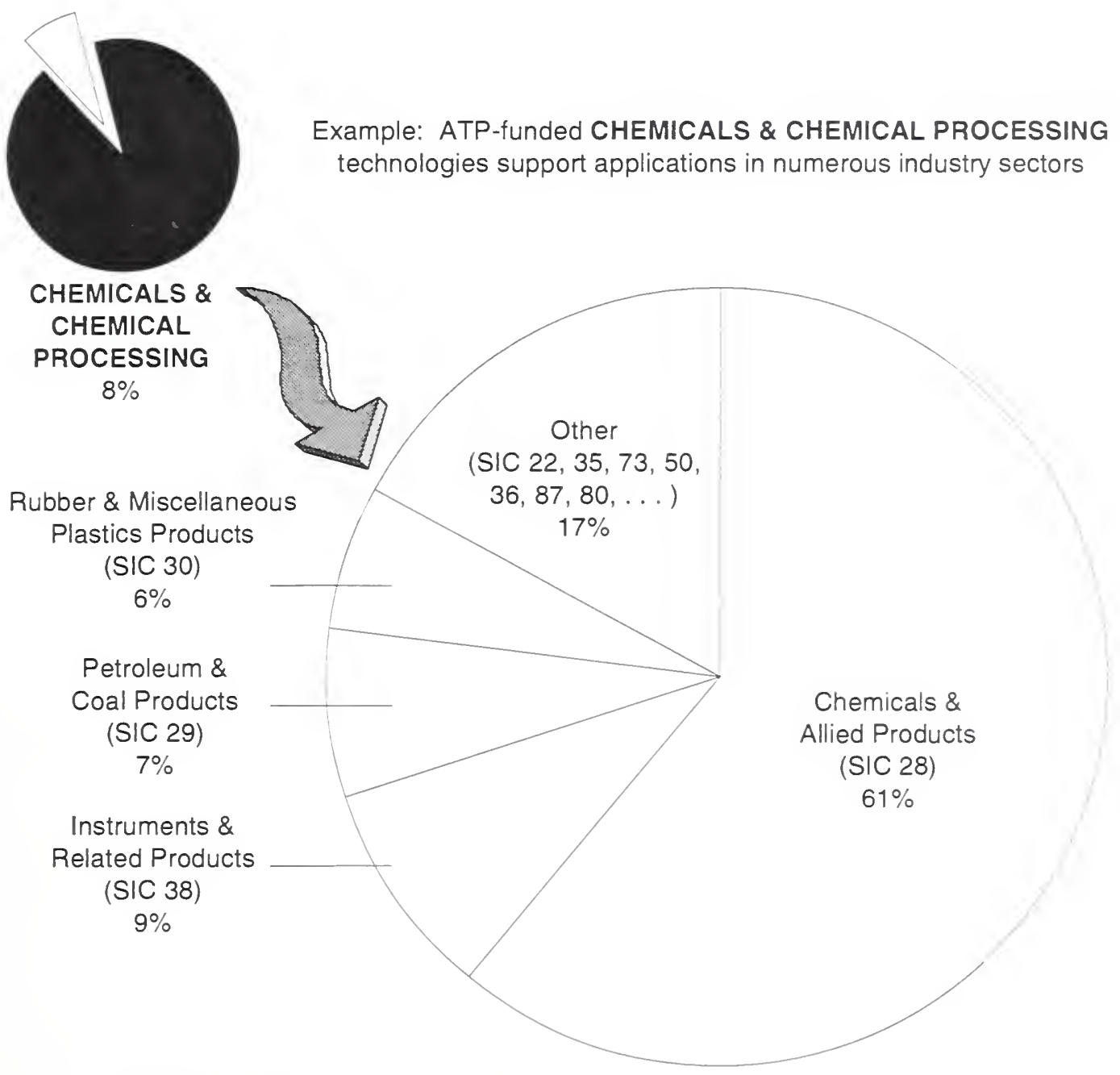

Note: "Other" SIC categonies are defined in Appendix G.

Source: Business Progress Reports for 778 applications being pursued by 375 companies in 207 ATP projects funded 1993-1995. 


\section{Appendix F. Plans for Diverse Applications of ATP-funded Technologies--Energy and Environment}

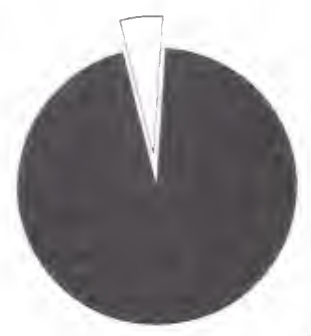

Example: ATP-funded ENERGY AND ENVIRONMENT

technologies support applications in numerous industry sectors

ENERGY AND
ENVIRONMENT

$5 \%$
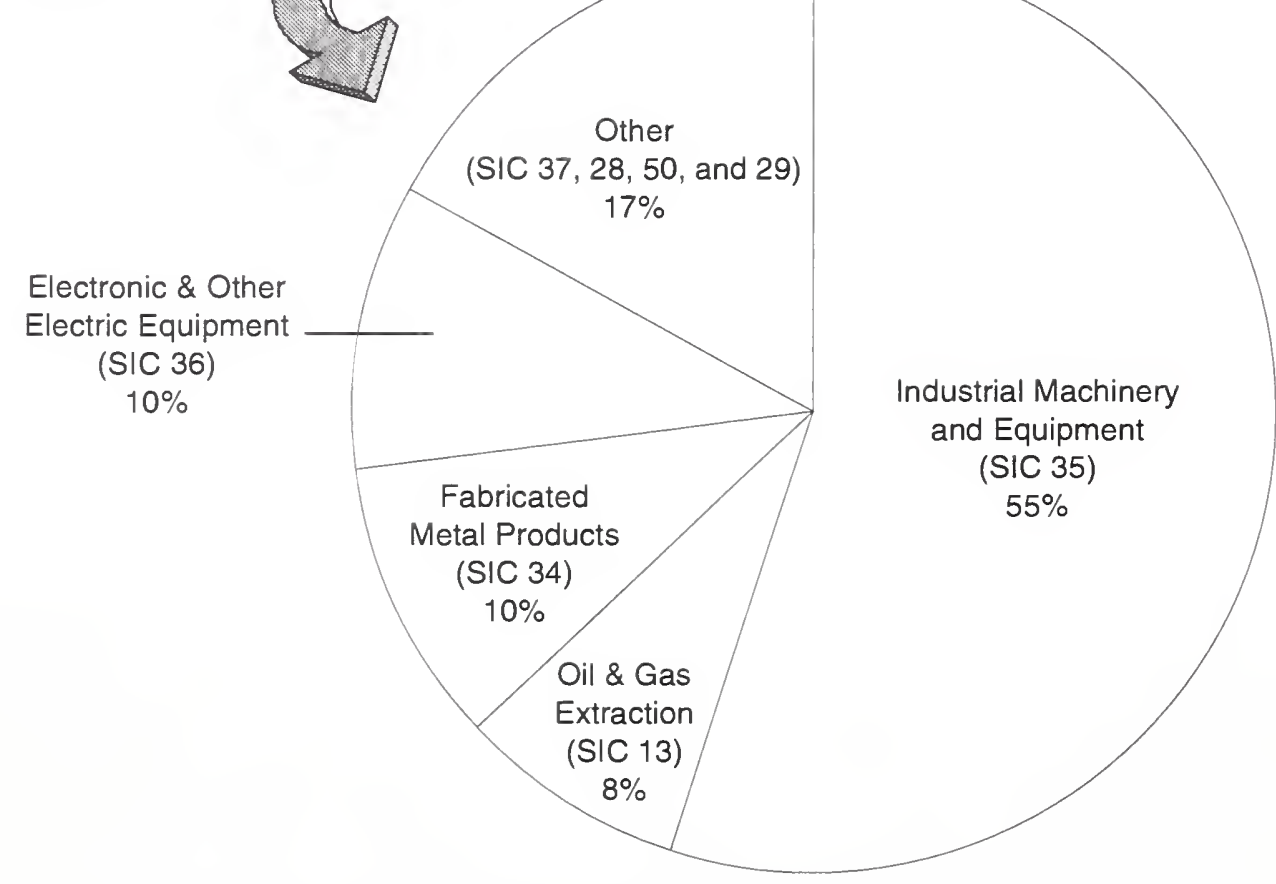

Note: "Other" SIC categories are defined in Appendix G.

Source: Business Progress Reports for 778 applications being pursued by 375 companies in 207 ATP projects funded $1993-1995$. 


\section{Appendix G: SIC Codes Included in "Other" Category}

\section{Applicable to Figure 4 and Appendices A through F}

01 Agricultural Production - Crops

02 Agricultural Production - Livestock

10 Metal Mining

13 Oil and Gas Extraction

16 Heavy Construction, Ex. Building

22 Textile and Mill Products

23 Apparel and Other Textile Products

27 Printing and Publishing

28 Chemicals and Allied Products

29 Petroleum and Coal Products

30 Rubber and Misc. Plastic Products

31 Leather and Leather Products

32 Stone, Clay, and Glass Products

33 Primary Metal Industries

34 Fabricated Metal Products

35 Industrial Machinery and Equipment

36 Electronic and Other Electric Equipment

37 Transportation Equipment

38 Instruments and Related Products

41 Local and Interurban Passenger Transit

42 Trucking and Warehousing

49 Electric, Gas, and Sanitary Services

50 Wholesale Trade - Durable Goods

51 Wholesale Trade - Nondurable Goods

73 Business Services

76 Miscellaneous Repair Services

78 Motion Pictures

80 Health Services

82 Educational Services

87 Engineering and Management Services

89 Services, Nec

92 Justice, Public Order, and Safety

94 Administration of Human Resources

95 Environmental Quality and Housing

97 National Security and International Affairs 


